\title{
Intimate Partner Violence and Failure to Thrive in Children Less than Two Years of Age
}

\author{
Pamela Kimeto, MSN, RN \\ Charlottesville, Virginia
}

B.S.N., University of Eastern Africa, Baraton-Kenya, 2001

M.S.N., University of Nairobi-Kenya, 2007

\author{
A Dissertation presented to Graduate Faculty \\ of the University of Virginia in Candidacy for the Degree of \\ Doctor of Philosophy \\ Department of Nursing
}

University of Virginia

May 2016 


\section{Financial acknowledgment}

I would like to acknowledge NIH Grant RO1: HD0045542: Nursing support:

Better infant outcomes in violent homes (BBK) and R01: NR05313: Nursing Smoking Cessation Intervention during pregnancy (Baby BEEP) NR05313. These grants funded BBK and Baby BEEP studies that provided the data for this secondary analysis. 


\section{Acknowledgment}

I would like to acknowledge the University of Missouri research team that worked on the Baby BEEP and BBK studies, including Dr. Linda Bullock. I would like to acknowledge the generous time, help and feedback offered by my dissertation committee: Kathryn Laughon, Linda Bullock, Guofen Yan and Christine Kennedy. I would also like to acknowledge my dissertation chair and doctoral student advisor, Kathryn Laughon, for her support, encouragement and guidance throughout my entire doctoral experience. 


\section{Table of Contents}

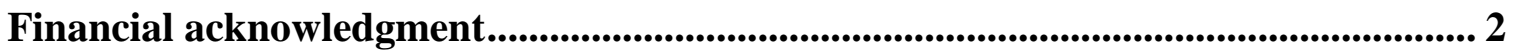

Acknowledgment .................................................................................................................. 3

CHAPTER ONE: INTRODUCTION .................................................................... 7

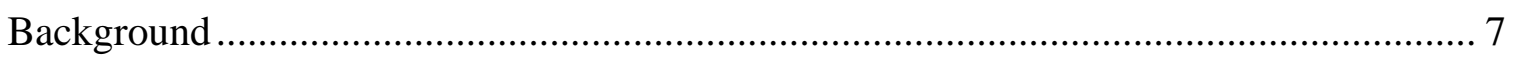

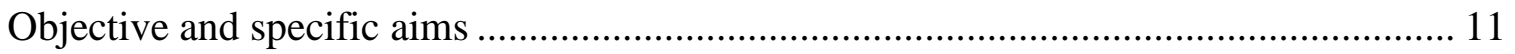

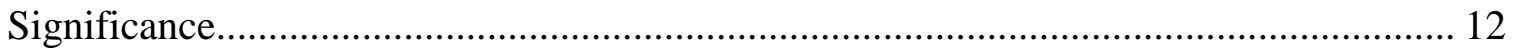

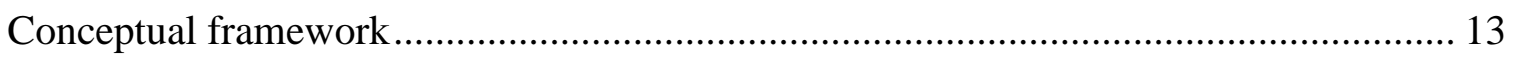

CHAPTER TWO: LITERATURE REVIEW (Manuscript One) ................................. 40

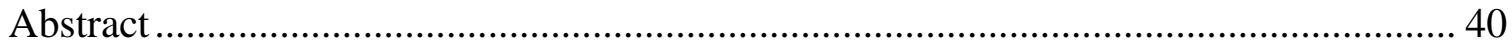

Introduction and Background ...................................................................... 41

Intimate partner violence and child physical health, cognitive and behavioral development ... 43

Intimate partner violence and failure to thrive ..................................................................... 45

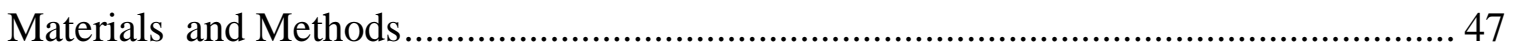

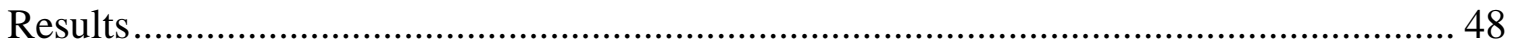

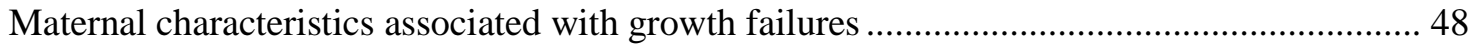

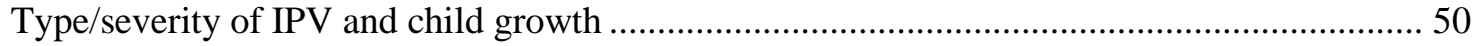

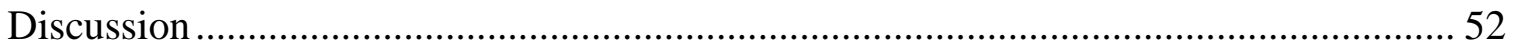

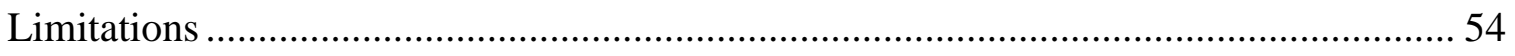

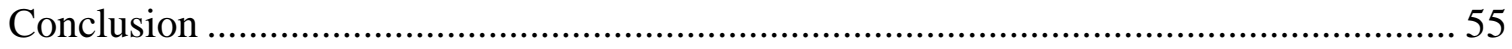

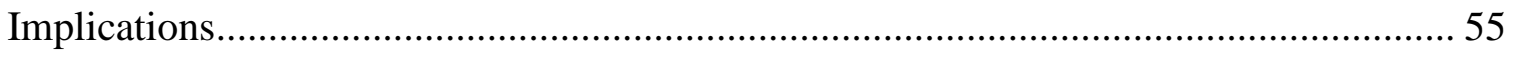

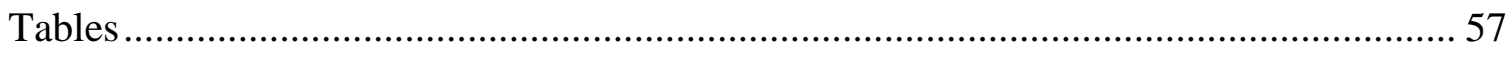

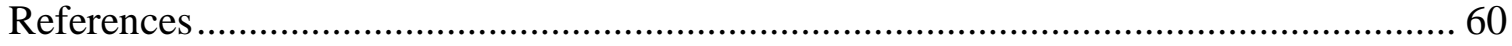

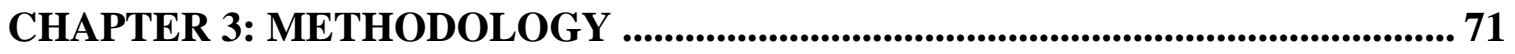

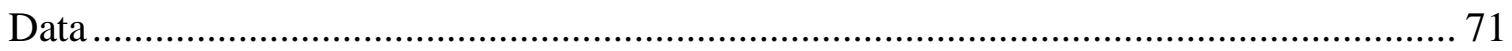

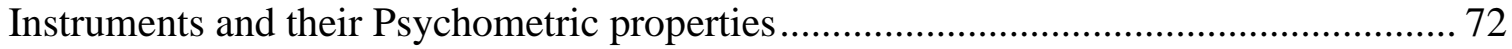

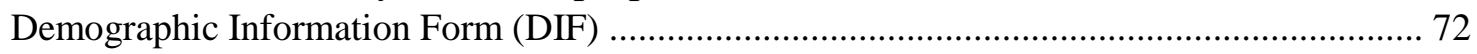

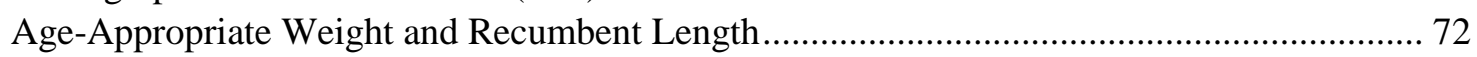

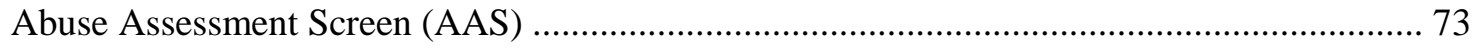

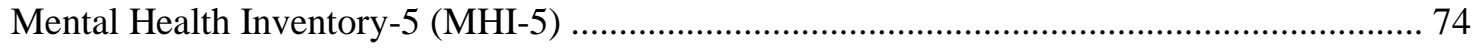

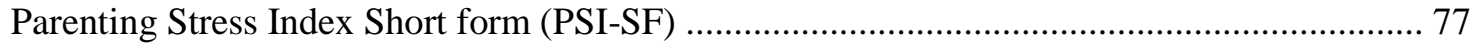

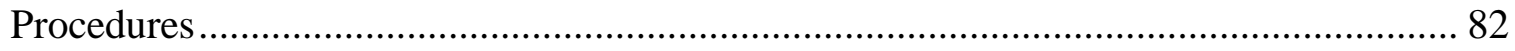

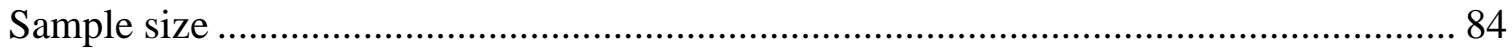

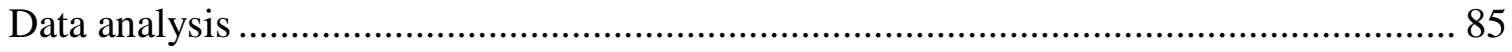




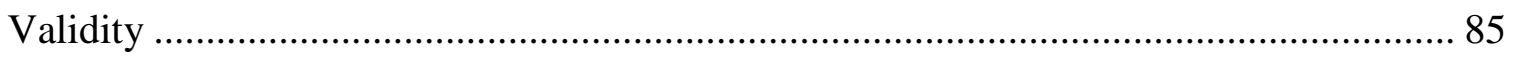

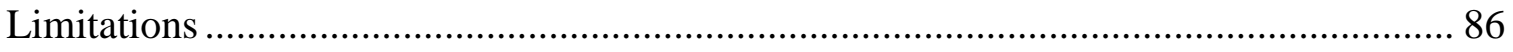

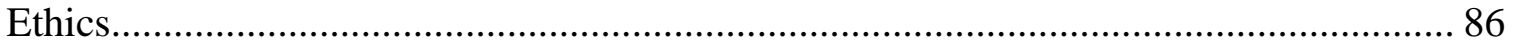

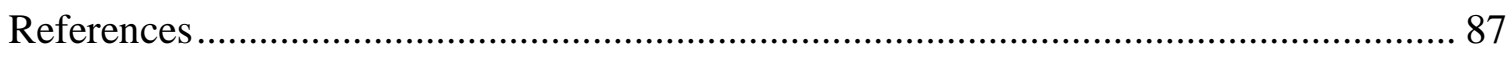

CHAPTER FOUR: FINDINGS (Manuscript 2) ..................................................... 90

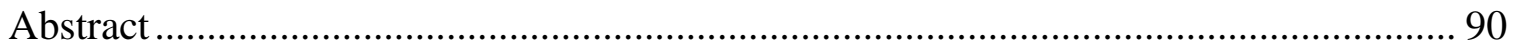

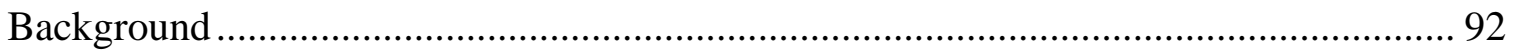

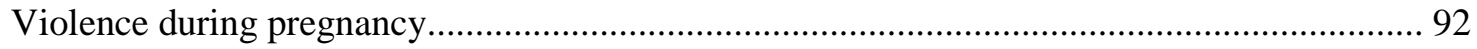

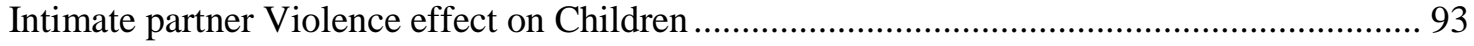

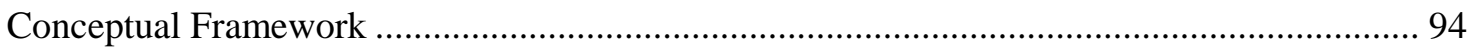

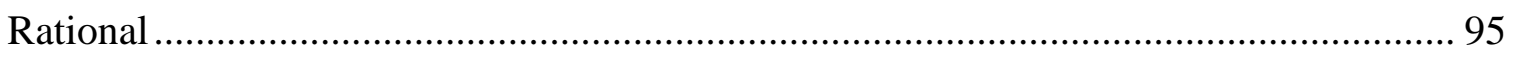

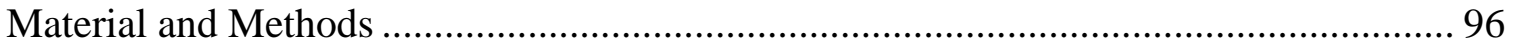

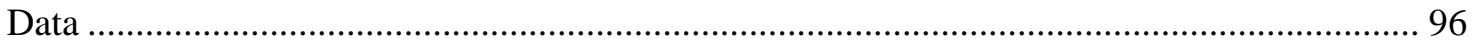

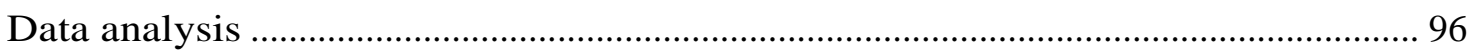

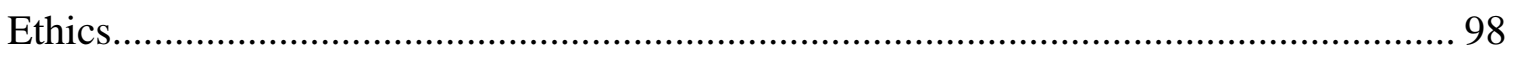

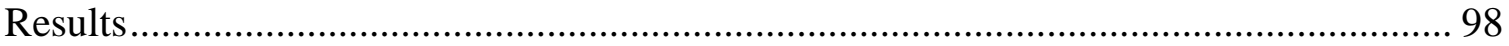

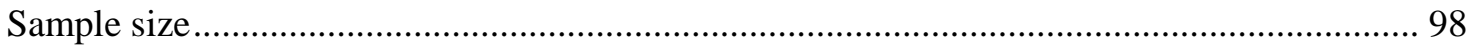

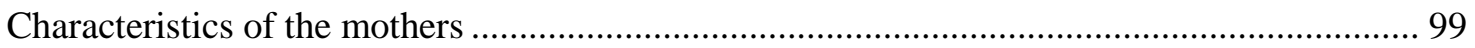

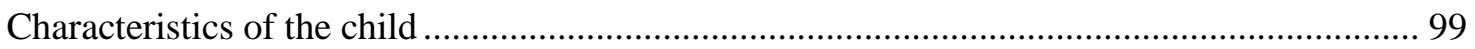

Association between baseline and follow up/postnatal predictors with weight-for height Z-

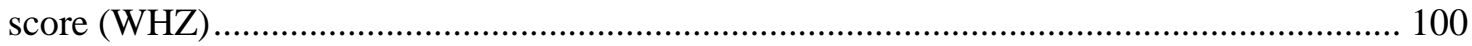

Association between baseline and follow up predictors with height-for-age $\mathrm{Z}$ score (HAZ) . 101

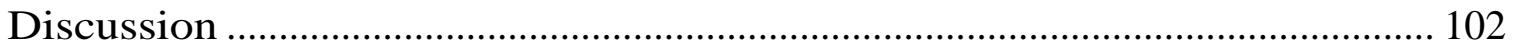

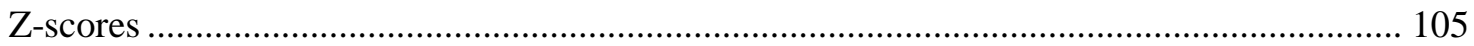

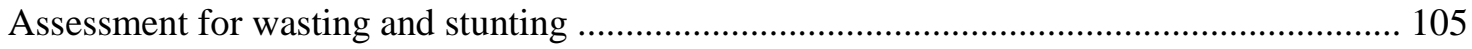

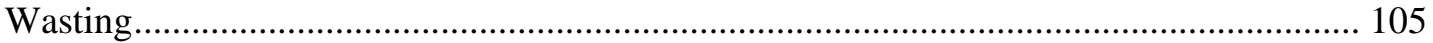

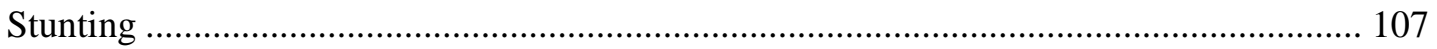

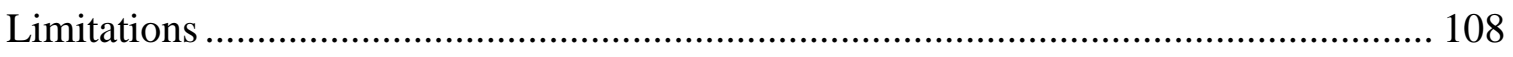

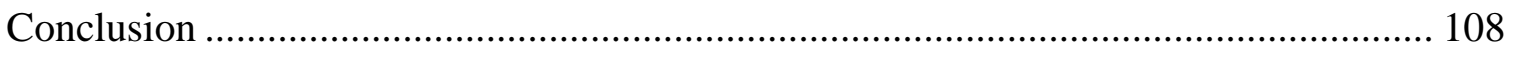

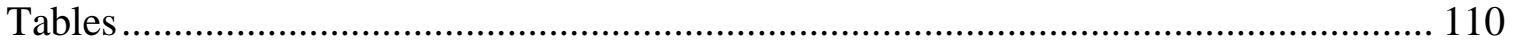

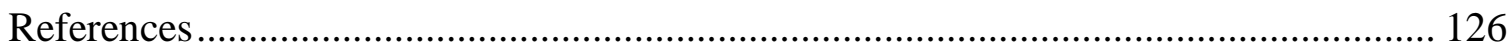

CHAPTER FIVE:FINDINGS (Manuscript 3) .............................................................. 132

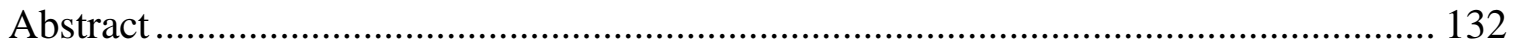

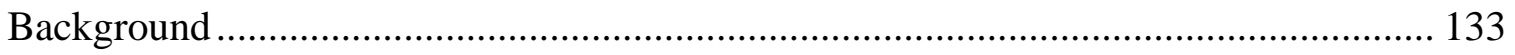

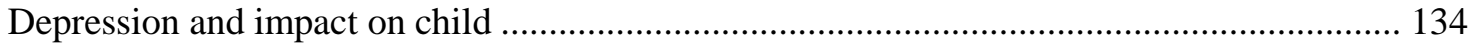

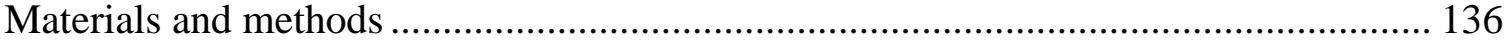

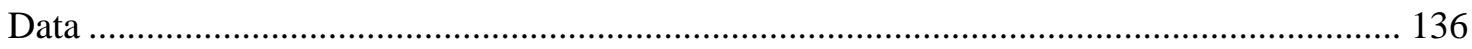




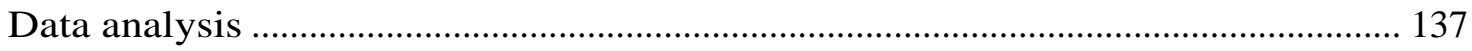

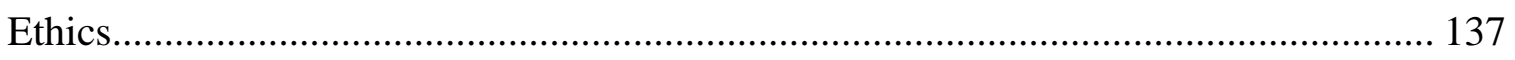

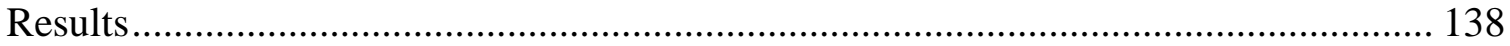

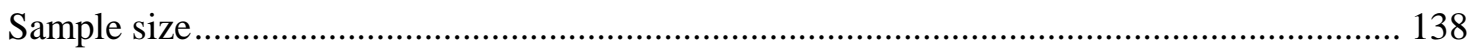

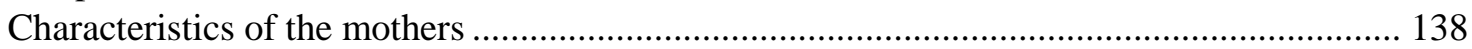

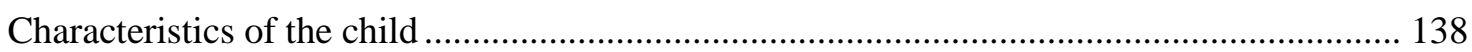

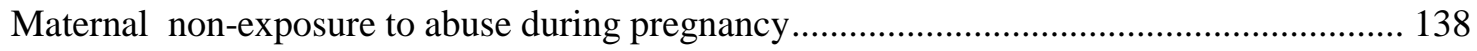

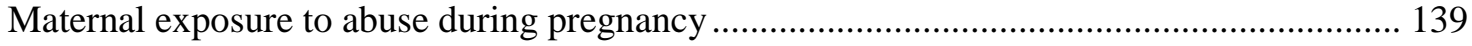

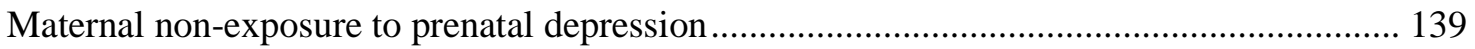

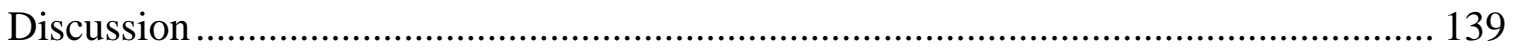

Effects of prenatal abuse and depression on the child ..................................................... 140

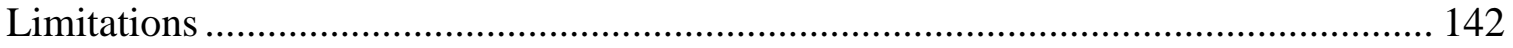

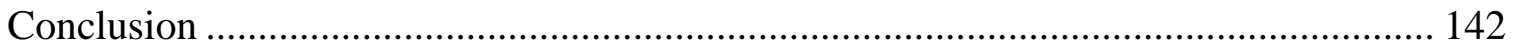

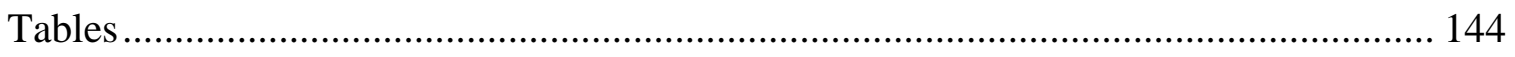

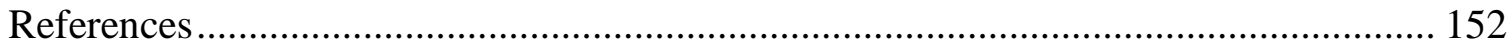

CHAPTER SIX: DISCUSSION AND CONCLUSION ................................................ 160

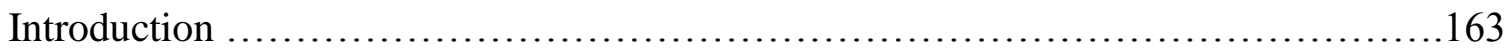

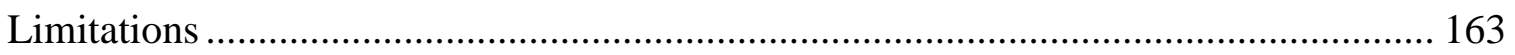

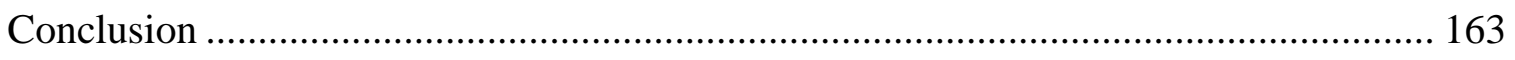

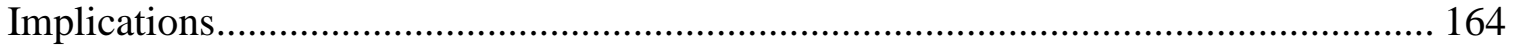

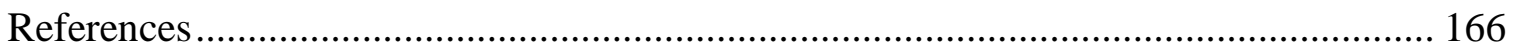




\section{CHAPTER ONE: INTRODUCTION}

\section{Background}

Intimate Partner Violence (IPV) is a common type of violence, and is a public health problem that exists in all societies and among people of higher and lower social strata (Krantz, Van Phuong, Larsson, Thi Bich Thuan, \& Ringsberg, 2005). IPV is physical, emotional or sexual abuse perpetrated against a current or former spouse, sexual partner, girl/boyfriend, or by parties with a child in common (Rhodes, Cerulli, Dichter, Kothari, \& Barg, 2010). In the recent past, a number of studies have highlighted the fact that IPV not only impacts the health of the mother but that of the baby as well (Alhusen, Lucea, Bullock, \& Sharps, 2013; Cerulli, Talbot, Tang, \& Chaudron, 2011; Garoma, Fantahun, \& Worku, 2012; Moraes, Sd de Oleveira, Reichenheim \& Lobato, 2011). Ten years ago the United Nations Children's Education Fund (UNICEF) estimated the number of children exposed to IPV worldwide to be 275 million. This is likely a conservative estimate based on the limitation of the available data; in actuality, millions more children may be exposed (UNICEF, 2006). At the same time in America, it was estimated that 10-15.5 million children were exposed to IPV annually (McDonald, Jouriles, \& Skopp, 2006); no current data are available on the frequency of exposure both in the United States and globally.

There is an increased interest in how abuse of mothers affects her children. Children living with IPV are at increased risk of developing cognitive (Busch \& Lieberman, 2010; Cummings, El-Sheikh, Kouros, \& Buckhalt, 2009; Gustafsson et al., 2013; Hungerford, Ogle, \& Clements, 2010) and behavioral problems (Lieberman, Van 
Horn, \& Ozer, 2005; Spilsbury et al., 2008). Negative physical health consequences have also been documented: development of asthma in children (Bair-Merritt, Johnson, Okelo, \& Page, 2012; Breiding \& Ziembroski, 2011; Subramanian, Ackerson, Subramanyam, \& Wright, 2007; Suglia, Enlow, Kullowatz, \& Wright, 2009; Suglia, Duarte, Sandel, \& Wright, 2010), early cessation of exclusive breastfeeding (Moraes et al., 2011), low immunization rates (Kuhlman, Howell, \& Graham-Bermann, 2012) and high risk for pneumonia (Arcos, Uarac, \& Molina, 2003). Studies have also shown a relationship between maternal IPV and the child's physical growth (Ackerson \& Subramanian, 2008; Asling-Monemi, Naved, \& Persson, 2009; Rico, Fenn, Abramsky, \& Watts, 2011).

Physical growth is the progressive development from early stage to maturity, including increases in size. Increase in size is measured in weight and height/length. Growth failure in children occurs when current weight or rate of weight gain is much lower than that of other children of similar age and gender.

Although the discussion of pediatric growth failure can be traced back over a century in the medical literature, the term failure to thrive (FTT) has only been used in the past several decades and no consensus exists regarding a specific definition (Cole \& Lanham, 2011). FTT has been used to cover a broad range of different anthropometric indicators, usually based on centile charts for weight or height (Olsen, 2006). Early works linked FTT to emotional deprivation by the mother and the child's own behavioral characteristics (Wolke, 1996) but a consensus in 1985 concluded that the diagnosis should be based solely on anthropometric parameters (Growth retardation indicators in 
children under 5 years old.1998; Olsen, 2006). Reviews further recognized that the unifying characteristic in FTT was relative under nutrition (Frank \& Zeisel, 1988; Olsen, 2006; Skuse, 1985).

Precise epidemiological data on FTT is lacking. Statistics from 12 years ago (current statistics not available), however, show that FTT accounts for 1-5 \% of all pediatric hospital admissions less than two years of age worldwide (Sullivan, 2004). The population prevalence of FTT was found to range between $1.3 \%$ and $20.9 \%$ globally (Sullivan, 2004). The imprecision of this data is a reflection of the difficulties in assessing the incidence of FTT in children. In addition to lack of consensus in the definition of FTT, noted above, some research has suffered from a preconception that FTT is always linked with poverty (Mackner, Black, \& Starr, 2003). As a consequence of this, most studies of FTT have focused on highly deprived groups and produced skewed and unhelpful results (Sullivan, 2004). Countering this misconception, Avon Longitudinal Study of Parents and Children (ALSPAC) failed to demonstrate a systematic effect of social variables on poor weight gain in infants (Blair, Drewett, Emmett, Ness, \& Edmond, 2004). In the United States, FTT is seen in $5-10 \%$ of children in primary care settings and accounts for $1-5 \%$ referrals to tertiary care centers of pediatric hospitals (Cole \& Lanham, 2011; Daniel, Kleis, \& Cemeroglu, 2008). Approximately $80 \%$ of children with FTT present before 18 months of age (Cole \& Lanham, 2011).

Although FTT has been defined in different ways (Hughes, 2007) and different objective standards have been defined (Olsen, 2006; Olsen et al., 2007) most practitioners 
diagnose FTT when a child's weight for age falls below the $5^{\text {th }}$ percentile of the growth standard chart or if it crosses two major percentile lines (Cole \& Lanham, 2011; Olsen, 2006). The growth standard charts are based on the growth of healthy children under optimal nutritional and environmental circumstances (Waterlow, 2007; Wright, 2005). WHO adopted this approach and in 2006 they published growth charts documenting how children should grow in all countries (WHO, 2006).

Anthropometric assessments are used to assess child's growth, nutritional status and well-being. Anthropometric measures involve the use of growth standards and /or growth reference (Wang et al, 2006; WHO 2006). A growth standard reflects optimal growth, suggesting that all children have the potential to achieve that level, while a growth reference is a distribution used for comparison (WHO MGRSG, 2006). The most commonly used anthropometric measures are $\mathrm{Z}$-scores, which have been used widely. These frequently used indicators of nutritional status in children are based on height and weight measurements: weight-for-high (WHZ), height-for-age (HAZ) and weight-for-age (WAZ) Z-scores. These three indicators provide estimates of both current and past under nutrition or of current status of obesity (WHO, 2006). Weight-for height Z-score reflects body mass in relation to body height or length and is sensitive to more recent and severe events and shock. Low WHZ is described as wasting. HAZ is a longterm measure of nutritional status and captures linear growth in utero and early childhood. A faltering linear growth is called stunting. Weight -for-age Z-scores provide a composite index and gives a general picture of overall nutritional status according to age (WHO, 2006). In addition to these Z-scores, body mass index (BMI) is a simple index of weight-for-height that is commonly used to determine underweight or 
overweight (WHO, 2006). The use of BMI in children is age and sex specific and is often referred to as BMI-for-age (WHO, 2006).

For this study, WHO WHZ and HAZ will be used to assess the nutritional status of the child. In September 2010, Centers for Disease and Prevention (CDC) recommended the WHO growth charts replace the previously recommended charts for children younger than 24 months. The CDC had published updated growth charts in 2000, based on growth variables of representative cross-sectional samples of US children that reflected a growth reference of the genetic and environmental conditions of the reference population at the time it was measured (Grummer-Strawn, Reinold, \& Krebs, 2010; Kuczmarski et al., 2000).

\section{Objective and specific aims}

The major objective for this study is to determine whether maternal exposure or nonexposure to IPV is associated with potential development of FTT in children and whether these associations are modified by maternal and child characteristics. Existing data from two large longitudinal studies will be used for this study [RO1 HD0045542: Nursing support: Better infant outcomes in violent homes (BBK) and R01 NR05313: Nursing Smoking Cessation Intervention during pregnancy (Baby BEEP) ]. The participants in Baby BEEP program were pregnant, low-income women recruited from Women, Infant, and Children Nutrition Supplement Program (WIC) clinics in 21 rural counties in Missouri. Mothers and infants in the BBK study were drawn from Baby BEEP study. Research nurses, who worked on both the Baby BEEP and BBK studies, interviewed all mothers to obtain demographic information, information about the children, obtained weight and height measurements of the child at months 5-11, 12-18 and 19-26 months. 


\section{The specific aims for this study are :}

1. To describe maternal parity, age, depression and the child's difficult scores, mean weight-for-length (WHZ), and height-for-age (HAZ) Z-scores (at 6, 15 and 24 months) in those exposed to IPV and those not exposed.

2. To describe the association between maternal characteristics, breastfeeding, child's gender, child's difficult scores, postnatal IPV and subsequent development of FTT in the child at 6,15 and 24 months.

3. To determine the relationship between IPV experienced by the mother and the likelihood of developing FTT in the child controlling for significant variables that are correlated to FTT in aim 2.

\section{Significance}

Growth assessment is the single most useful tool for defining health and nutritional status at both the individual and population level(Wang \& Chen, 2012). Growth monitoring strives to improve nutrition, reduce the risk of inadequate nutrition, educate caregivers, and produce early detection and referral for conditions manifested by growth impairment. Impaired growth is an important health determinant in children and has been associated with higher morbidity and mortality in children less than 5 years of age (Black et al., 2008). Few studies have been conducted using the proposed WHO anthropometric measures to assess the impact of IPV on child's growth especially those under two years of age (Ackerson \& Subramanian, 2008; Asling-Monemi et al., 2009; Hasselmann \& Reichenheim, 2006; Rico et al., 2011; Sobkoviak, Yount, \& Halim, 2012; Ziaei, Naved, \& Ekstrom, 2014) with no study from the United States. Findings from this study would contribute to the scientific knowledge about the impact of IPV on 
child's growth. It may also be of interest to scholars in global and public health; anthropometric findings from this study will help define health and the nutritional status in children exposed to violence for purposes of program planning, implementation and evaluation. Findings may also add to our knowledge about best screening practices for intimate partner violence in pediatric primary setting (Dubowitz, Prescott, Feigelman, Lane, \& Kim, 2008) as a means for early identification and management for both mother and child. Recognition of growth and development problems in infants and children is one of the major challenges of pediatric health care providers. Failure to thrive has been associated with adverse latter effects on growth and cognitive development(Krugman \& Dubowitz, 2003), thus findings from this study may inform practices regarding optimal monitoring of linear growth and weight in children using anthropometric measures.

\section{Conceptual framework}

The conceptual pathways linking children exposed to domestic violence (CEDV) to growth and nutrition in utero and early childhood conceptual framework (Fig 1) from Yount, DiGirolamo, and Ramakrishnan (2011) were used for this study. Yount and colleagues specified the biological and behavioral pathways by which domestic violence against mothers may impair the physical growth of children in utero through 36 months of life. Biologically, gestation and infancy are critical periods for the development of stress-responsive biological regulatory systems, which are central to maintain physical and mental health (Repetti, Taylor, \& Seeman, 2002). A child's observation of or involvement in domestic violence in these periods may permanently disrupt these regulatory systems. Dysregulation of these systems may cause deficits or delays in metabolic and immune activities; sexual maturation and reproductive function; mental 
and cognitive functioning; as well as physical growth (Mead, Beauchaine, \& Shannon, 2010). Chronic deficits or delays in these domains may impair intellectual functioning, behavior, health, and stature into adulthood (Repetti et al., 2002).

A mother's observation of domestic violence in her own childhood and/or her experiences of such violence in adulthood may impair her health and health behaviors in pregnancy. Such impairments may elevate her risk of a poor pregnancy outcome (Shah, Shah, \& Knowledge Synthesis Group on Determinants of Preterm/LBW Births, 2010) , which would strongly predict her child's early growth (Saigal \& Doyle, 2008). After delivery, poor maternal health and health risk behaviors that are predicted from observing and/or experiencing domestic violence may compromise the mother's care of her infant. Inadequate psychosocial, nutritional, and health-related care in infancy may also impair the child's early physical growth. On the other hand, the breast-feeding practices and parenting of mothers who experience domestic violence range from deficient to compensator (Yount et al., 2011).

The constructs that were used from the conceptual framework are as follow:

- Family social economic context: Women in this study were recruited from the WIC clinics, thus they all were of low social economic status.

- Domestic violence: Women were assessed for exposure to abuse during pregnancy using the Abuse Assessment scale (AAS) (McFarlane, Parker, Soeken, \& Bullock, 1992) and for follow up (after birth of the child) violence using severity of violence against women scale (SVAWS) (Marshall, 1992). 
- Maternal mental, physical and nutritional symptoms: Maternal age was obtained using demographic forms; maternal depression pre- natal and post-natal was assessed using the Five-Item Mental Health Screening Test (MHI-5) (Ware \& Gandek, 1994).

- Child attributes: This included child's gender, breastfeeding status and difficult child scores from Parenting Stress Index short form (PSI-SF) (Abidin, 1995) and early childhood growth and nutrition was assessed using WHZ and HAZ.

Figure1: Pathways linking children exposure to domestic violence (CEDV) to growth and nutrition in utero and early childhood conceptual framework

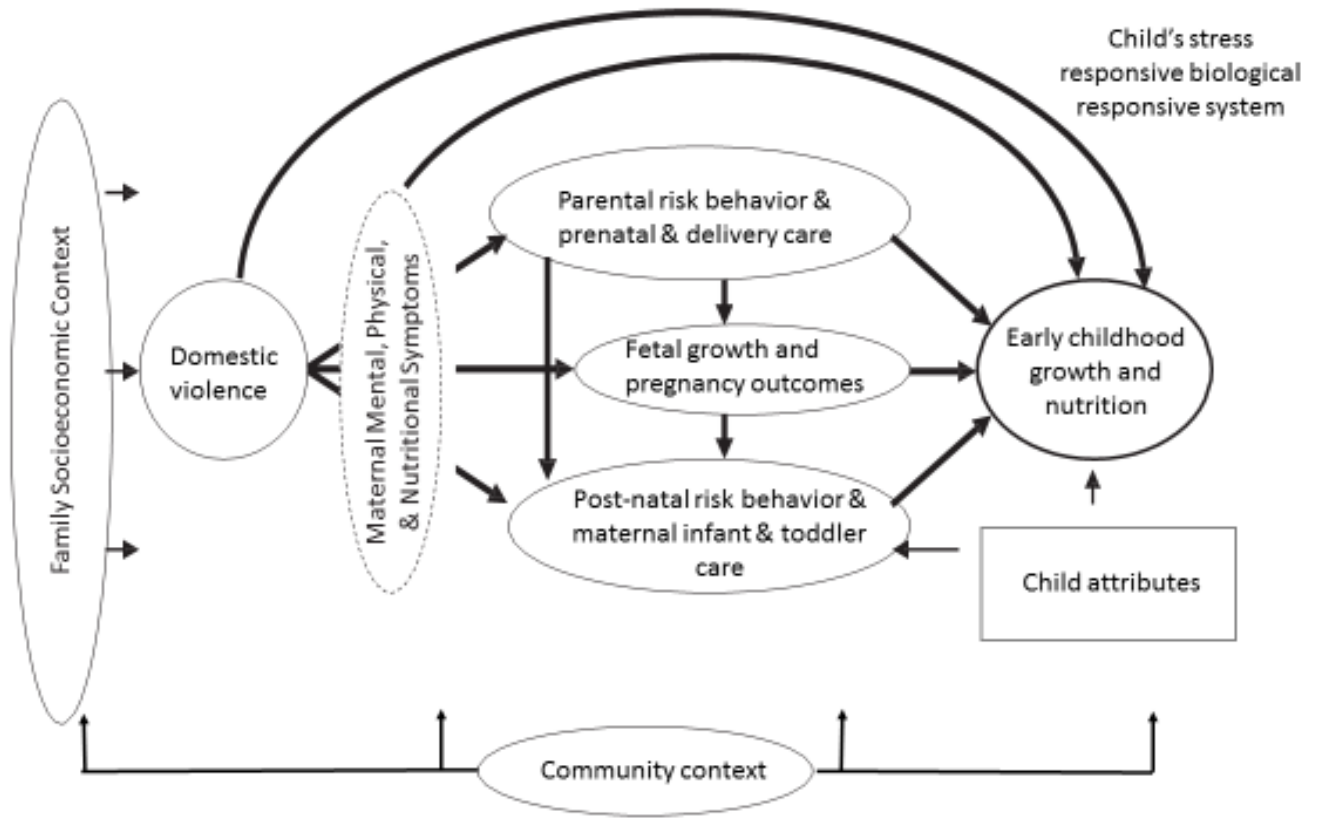

Organization of the Dissertation

Chapter one of the dissertation provides a background and information of FTT, briefly describes the measures used to assess FTT and also introduces the purpose of the 
dissertation and the specific aims of the study. Chapter two is the first manuscript, a literature review on growth problems in children exposed to intimate partner violence assessed with anthropomorphic measures. This manuscript will be submitted to Journal of Interpersonal Violence. Chapter three will describe the methodology used in the study. Chapter four is the second manuscript, assessing maternal and child characteristics that influence child growth. This manuscript will be submitted to Archives of Disease in Childhood-BMJ journal. Chapter five is the third manuscript assessing maternal intimate partner violence, depression and child growth. This manuscript will be submitted to Social Science and Medicine Journal-Elsevier. Chapter six is a discussion of the research findings from this dissertation, their relevance to the greater body of FTT literature as well as their contributions to nursing science. This chapter also addresses the limitations of the dissertation and implications for nursing research, practice and policy. 


\section{References}

Clinical preventive services for women: Closing the gaps. (2011). Retrieved from https://iom.nationalacademies.org/Reports/2011/Clinical-Preventive-Services-for-WomenClosing-the-Gaps.aspx

Abidin, R. R. (Ed.). (1995). Parenting stress index: Professional manual. (3rd ed. ed.). Odessa, FL: Psychological Assessment Resources, Inc.

Ackerson, L. K., \& Subramanian, S. V. (2009). Intimate partner violence and death among infants and children in india. Pediatrics, 124(5), e878-89.

Ackerson, L. K., \& Subramanian, S. V. (2008). Domestic violence and chronic malnutrition among women and children in india. American Journal of Epidemiology, 167(10), 11881196.

Agostoni, C., Grandi, F., Gianni, M. L., Silano, M., Torcoletti, M., Giovannini, M., \& Riva, E. (1999). Growth patterns of breast fed and formula fed infants in the first 12 months of life: An italian study. Archives of Disease in Childhood, 81(5), 395-399.

Alhusen, J. L., Lucea, M. B., Bullock, L., \& Sharps, P. (2013). Intimate partner violence, substance use, and adverse neonatal outcomes among urban women. Journal of Pediatrics, 163(2), 471-476. doi:http://dx.doi.org/10.1016/j.jpeds.2013.01.036

Arcos, E., Uarac, M., \& Molina, I. (2003). The impact of domestic violence on children's health [in spanish]. .131, 1454-1462. 
Ashaba, S., Rukundo, G. Z., Beinempaka, F., Ntaro, M., \& LeBlanc, J. C. (2015). Maternal depression and malnutrition in children in southwest uganda: A case control study. BMC Public Health, 15(1), 1303.

Asling-Monemi, K., Naved, R. T., \& Persson, L. A. (2009). Violence against women and the risk of fetal and early childhood growth impairment: A cohort study in rural bangladesh. Archives of Disease in Childhood, 94(10), 775-779.

Bair-Merritt, M. H., Johnson, S. B., Okelo, S., \& Page, G. (2012). Intimate partner violence exposure, salivary cortisol, and childhood asthma. Child Abuse \& Neglect, 36(7-8), 596-601.

Basile, K. C., Smith, S. G., Breiding, M. J., Black, M. C., \& Mahendra, R. R. (2014). Sexual violence surveillance: Uniform definitions and recommended data elements, version 2.0. ( No. Version 2.0). Atlanta, Georgia: National Center for Injury Prevention and Control, Centers for Disease Control and Prevention.

Baumgartner, R. N., Roche, A. F., \& Himes, J. H. (1986). Incremental growth tables: Supplementary to previously published charts. American Journal of Clinical Nutrition, 43(5), 711-722.

Beard, J. L., Hendricks, M. K., Perez, E. M., Murray-Kolb, L. E., Berg, A., Vernon-Feagans, L., . . Tomlinson, M. (2005). Maternal iron deficiency anemia affects postpartum emotions and cognition. Journal of Nutrition, 135(2), 267-272.

Berwick, D. M., Murphy, J. M., Goldman, P. A., Ware, J. E. J., Barsky, A. J., \& Weinstein, M. C. (1991). Performance of a five-item mental health screening test. Medical Care, 29(2), 169176. 
Beydoun, H. A., Beydoun, M. A., Kaufman, J. S., Lo, B., \& Zonderman, A. B. (2012). Intimate partner violence against adult women and its association with major depressive disorder, depressive symptoms and postpartum depression: A systematic review and meta-analysis. Social Science \& Medicine, 75(6), 959-975.

Bifulco, A., Kwon, J., Jacobs, C., Moran, P. M., Bunn, A., \& Beer, N. (2006). Adult attachment style as mediator between childhood neglect/abuse and adult depression and anxiety. Social Psychiatry \& Psychiatric Epidemiology, 41(10), 796-805.

Black, R. E., Allen, L. H., Bhutta, Z. A., Caulfield, L. E., de Onis, M., Ezzati, M., . . Maternal and Child Undernutrition Study Group. (2008). Maternal and child undernutrition: Global and regional exposures and health consequences. Lancet, 371(9608), 243-260. doi:http://dx.doi.org/10.1016/S0140-6736(07)61690-0

Blair, P. S., Drewett, R. F., Emmett, P. M., Ness, A., \& Edmond, A. M. (2004). Family, socioeconomic and prenatal factors associated with failure to thrive in the avon longitudinal study of parents and children (ALSPAC). International Journal of Epidemiology, 33(4), 839-847.

Bonomi, A. E., Thompson, R. S., Anderson, M., Reid, R. J., Carrell, D., Dimer, J. A., \& Rivara, F. P. (2006). Intimate partner violence and women's physical, mental, and social functioning. American Journal of Preventive Medicine, 30(6), 458-466.

Bowen, E. (2015). The impact of intimate partner violence on preschool children's peer problems: An analysis of risk and protective factors. 〈br/>. Child Abuse \& Neglect, 50, 141-150. doi:http://doi.org/10.1016/j.chiabu.2015.09.005 
Boynton-Jarrett, R., Fargnoli, J., Suglia, S. F., Zuckerman, B., \& Wright, R. J. (2010).

Association between maternal intimate partner violence and incident obesity in preschoolaged children: Results from the fragile families and child well-being study. Archives of Pediatrics \& Adolescent Medicine, 164(6), 540-546.

Breiding, M. J., \& Ziembroski, J. S. (2011). The relationship between intimate partner violence and children's asthma in 10 US states/territories. Pediatric Allergy \& Immunology, 22(1 Pt 2), e95-100. doi:http://dx.doi.org/10.1111/j.1399-3038.2010.01087.x

Bullock, L., Everet, D. K., Mullen, P. A., Geden, E., Longo, R. D., \& Madsen, R. (2009a). Baby BEEP: A randomized control trial of nurses' individualized social support for rural pregnant smokers. Matern.Child Health J., 13(3), 395-406.

Bullock, L., Everett, K. D., Mullen, P. D., Geden, E., Longo, D. R., \& Madsen, R. (2009b). Baby BEEP: A randomized controlled trial of nurses' individualized social support for poor rural pregnant smokers. Maternal \& Child Health Journal, 13(3), 395-406.

Burke, J. G., Lee, L. C., \& O'Campo, P. (2008). An exploration of maternal intimate partner violence experiences and infant general health and temperament. Maternal \& Child Health Journal, 12(2), 172-179.

Busch, A. L., \& Lieberman, A. F. (2010). Mothers' adult attachment interview ratings predict preschool children's IQ following domestic violence exposure. Attachment \& Human Development, 12(6), 505-527. doi:http://dx.doi.org/10.1080/14616734.2010.504542

Campbell, J., Jones, A. S., Dienemann, J., Kub, J., Schollenberger, J., O'Campo, P., . . Wynne, C. (2002). Intimate partner violence and physical health consequences. Archives of Internal Medicine, 162(10), 1157-1163. 
Castaldi, J. (1990). $\quad<b r />$ Affective and cognitive patterns in the mother-child relationship during the second year of life. (Unpublished $\mathrm{PhD}$ ). University of Virginia, Charlottesville.

Caufield, L. E., Richard, S. A., Rivera, J. A., Musgrove, P., \& Black, R. E. (2006). Chapter 28: Stunting, wasting and macronutrient defieicency disorders. In D. T. Jameson, J. G. Breman \& A. R. Meshaum (Eds.), Disease control priorities in developing countries (2nd ed., ). Washington DC: International Bank for Reconstruction and Development.

Caulfield, L. E., Bentley, M. E., \& Ahmed, S. (1996). Is prolonged breastfeeding associated with malnutrition? evidence from nineteen demographic and health surveys. International Journal of Epidemiology, 25(4), 693-703.

Cerulli, C., Talbot, N. L., Tang, W., \& Chaudron, L. H. (2011). Co-occurring intimate partner violence and mental health diagnoses in perinatal women. Journal of Women's Health, 20(12), 1797-1803.

Chertok, I. R. A., Luo, J., \& Anderson, R. H. (2011). Association between changes in smoking habits in subsequent pregnancy and infant birth weight in west virginia. Maternal \& Child Health Journal, 15(2), 249-254.

Chiolero, A., Bovet, P., \& Paccaud, F. (2005). Association between maternal smoking and low birth weight in switzerland: The EDEN study. Swiss Medical Weekly, 135(35-36), 525-530.

Chung, E. K., McCollum, K. F., Elo, I. T., Lee, H. J., \& Culhane, J. F. (2004). Maternal depressive symptoms and infant health practices among low-income women. Pediatrics, 113(6), e523-9. Retrieved from 
http://ovidsp.ovid.com/ovidweb.cgi?T=JS\&CSC=Y\&NEWS=N\&PAGE=fulltext\&D=med5 $\underline{\mathrm{AN}}=15173532$

Cole, S. Z., \& Lanham, J. S. (2011). Failure to thrive: An update. American Family Physician, 83(7), 829-834.

Cummings, E. M., El-Sheikh, M., Kouros, C. D., \& Buckhalt, J. A. (2009). Children and violence: The role of children's regulation in the marital aggression-child adjustment link. Clinical Child \& Family Psychology Review, 12(1), 3-15. doi:http://dx.doi.org/10.1007/s10567-009-0042-7

Dallman, M. F. (2010). Stress-induced obesity and the emotional nervous system. Trends in Endocrinology and Metabolism: TEM, 21(3), 159-165. doi:10.1016/j.tem.2009.10.004 [doi]

Daniel, M., Kleis, L., \& Cemeroglu, A. P. (2008). Etiology of failure to thrive in infants and toddlers referred to a pediatric endocrinology outpatient clinic. Clinical Pediatrics, 47(8), $762-765$.

Danner, E., Joeckel, R., Michalak, S., Phillips, S., \& Goday, P. S. (2009). Weight velocity in infants and children. Nutrition in Clinical Practice, 24(1), 76-79. doi:http://dx.doi.org/10.1177/0884533608329663

Daoud, N., Urquia, M. L., O'Campo, P., Heaman, M., Janssen, P. A., Smylie, J., \& Thiessen, K. (2012). Prevalence of abuse and violence before, during, and after pregnancy in a national sample of canadian women. American Journal of Public Health, 102(10), 1893-1901.

Davies, C. A., Evans, S. E., \& and DiLillo, D. K. (2008). Exposure to domestic violence: A metaanalysis of child and adolescent outcomes.13, 131-140. 
de Onis, M., Siyam, A., Borghi, E., Onyango, A. W., Piwoz, E., \& Garza, C. (2011). Comparison of the world health organization growth velocity standards with existing US reference data. Pediatrics, 128(1), e18-26.

Deater-Deckard, k., Pinkerton, R., \& Scarr, S. (1996). Child care quality and children's behavioral adjustment: A four-year longitudinal study. Journal of Child Psychology \& Psychiatry \& Allied Disciplines, 38(8), 937-48.

Deleuze Ntandou Bouzitou, G., Fayomi, B., \& Delisle, H. (2005). [Child malnutrition and maternal overweight in same households in poor urban areas of benin]. [Malnutrition infantile et surpoids maternel dans des menages urbains pauvres au Benin.] Sante, 15(4), 263-270.

Deshpande, N. A., \& Lewis-O'Connor, A. (2013). Screening for intimate partner violence during pregnancy. Revue Obstetricale Et Gynecologique, 6(3-4), 141-148.

Devries, K. M., Mak, J. Y., Bacchus, L. J., Child, J. C., Falder, G., Petzold, M., . . Watts, C. H. (2013). Intimate partner violence and incident depressive symptoms and suicide attempts: A systematic review of longitudinal studies. PLoS Medicine / Public Library of Science, 10(5), e1001439.

Devries, K. M., Kishor, S., Johnson, H., Stockl, H., Bacchus, L. J., Garcia-Moreno, C., \& Watts, C. (2010). Intimate partner violence during pregnancy: Analysis of prevalence data from 19 countries. Reproductive Health Matters, 18(36), 158-170. doi:http://dx.doi.org/10.1016/S0968-8080(10)36533-5

Devries, K. M., Watts, C., Yoshihama, M., Kiss, L., Schraiber, L. B., Deyessa, N., . . WHO Multi-Country Study Team. (2011). Violence against women is strongly associated with 
suicide attempts: Evidence from the WHO multi-country study on women's health and domestic violence against women. Social Science \& Medicine, 73(1), 79-86.

Deyessa, N., Berhane, Y., Emmelin, M., Ellsberg, M. C., Kullgren, G., \& Hogberg, U. (2010). Joint effect of maternal depression and intimate partner violence on increased risk of child death in rural ethiopia. Archives of Disease in Childhood, 95(10), 771-775.

Doak, C. M., Adair, L. S., Bentley, M., Monteiro, C., \& Popkin, B. M. (2005). The dual burden household and the nutrition transition paradox. International Journal of Obesity, 29(1), 129136.

Donahue, S. M. A., Kleinman, K. P., Gillman, M. W., \& Oken, E. (2010). Trends in birth weight and gestational length among singleton term births in the united states: 1990-2005. Obstetrics \& Gynecology, 115(2 Pt 1), 357-364. doi:http://dx.doi.org/10.1097/AOG.0b013e3181cbd5f5

Doumas, D. M., Pearson, C. L., Elgin, J. E., \& McKinley, L. L. (2008). Adult attachment as a risk factor for intimate partner violence: The "mispairing" of partners' attachment styles. Journal of Interpersonal Violence, 23(5), 616-634.

Drewett, R., Blair, P., \& Emond, A. (2004). Failure to thrive in the term and preterm infants of mothers depressed in the post natal period a population based birth cohort study. Journal of Child Psychology \& Psychiatry \& Allied Disciplines, 45, 359-366.

Dubowitz, H., Prescott, L., Feigelman, S., Lane, W., \& Kim, J. (2008). Screening for intimate partner violence in a pediatric primary care clinic. Pediatrics, 121(1), e85-91.

Durand, J. G., Schraiber, L. B., Franca-Junior, I., \& Barros, C. (2011). Impact of exposure to intimate partner violence on children's behavior. Revista De Saude Publica, 45(2), 355-364. 
Edwards, B., Galletly, C., Semmler-Booth, T., \& Dekker, G. (2008). Does antenatal screening for psychosocial risk factors predict postnatal depression? A follow-up study of 154 women in adelaide, south australia. Australian \& New Zealand Journal of Psychiatry, 42(1), 51-55.

Ellsberg, M., Jansen, H. A. F. M., Heise, L., Watts, C. H., Garcia-Moreno, C., \& WHO Multicountry Study on Women's Health and Domestic Violence against Women Study Team. (2008). Intimate partner violence and women's physical and mental health in the WHO multi-country study on women's health and domestic violence: An observational study. Lancet, 371(9619), 1165-1172.

Field, T. (2011). Prenatal depression effects on early development: A review. Infant Behavior \& Development, 34(1), 1-14.

Field, T., Diego, M., Hernandez-Reif, M., Figueiredo, B., Schanberg, S., \& Kuhn, C. (2007). Sleep disturbances in depressed pregnant women and their newborns. Infant Behavior \& Development, 30(1), 127-133.

Frank, D. A., \& Zeisel, S. H. (1988). Failure to thrive. Pediatric Clinics of North America, 35(6), 1187-1206.

Gale, S., \& Harlow, B. L. (2003). Postpartum mood disorders: A review of clinical and epidemiological factors. J Psychosom Obstet Gynaecol, 24, 257-66. doi:10.3109/01674820309074690

Garcia-Moreno, C., Jansen, H. A., Ellsberg, M., Heise, L., Watts, C. H., \& WHO Multi-country Study on Women's Health and Domestic Violence against Women Study,Team. (2006). Prevalence of intimate partner violence: Findings from the WHO multi-country study on women's health and domestic violence. Lancet, 368(9543), 1260-1269. 
Garoma, S., Fantahun, M., \& Worku, A. (2012). Maternal intimate partner violence victimization and under-five children mortality in western ethiopia: A case-control study. Journal of Tropical Pediatrics, 58(6), 467-474. doi:http://dx.doi.org/10.1093/tropej/fms018

Gazmararian, J. A., Petersen, R., Spitz, A. M., Goodwin, M. M., Saltzman, L. E., \& Marks, J. S. (2000). Violence and reproductive health: Current knowledge and future research directions. Maternal \& Child Health Journal, 4(2), 79-84.

Gibson, E. L. (2006). Emotional influences on food choice: Sensory, physiological and psychological pathways. Physiology \& Behavior, 89(1), 53-61. doi:S0031-9384(06)00010-2 [pii]

Gilbert, A. L., Bauer, N. S., Carroll, A. E., \& Downs, S. M. (2013). Child exposure to parental violence and psychological distress associated with delayed milestones. Pediatrics, 132(6), e1577-83. doi:http://dx.doi.org/10.1542/peds.2013-1020

Giroux, S. C. (2008). $\quad<b r />2008$. Child stunting across schooling and fertility transitions: Evidence from sub-saharan africa. (Demographic and Health Research Papers No. 57). Calverton, MD, USA: Macro International Inc.

Griffiths, L. J., Dezateux, C., \& Cole, T. J. (2007). Differential parental weight and height contributions to offspring birthweight and weight gain in infancy. International Journal of Epidemiology, 36(1), 104-107.

Grote, V., Vik, T., von Kries, R., Luque, V., Socha, J., Verduci, E., . . European Childhood Obesity Trial Study Group. (2010). Maternal postnatal depression and child growth: A european cohort study. BMC Pediatrics, 10, 14. 
Growth retardation indicators in children under 5 years old. (1998). Epidemiological Bulletin, 19(1), 13-16.

Grummer-Strawn, L., Reinold, C., \& Krebs, N. F. (2010). Use of world health organization and CDC growth charts for children aged 0-59 months in the united states. MMWR Recommendations \& Reports, 59(-9), 1-15.

Guo, S., Roche, A. F., Fomon, S. J., Nelson, S. E., Chumlea, W. C., Rogers, R. R., . . Siervogel, R. M. (1991). <br />Reference data on gains in weight and length during the first two years of life. Journal of Pediatrics, 119, 355-362.

Gustafsson, H. C., Coffman, J. L., Harris, L. S., Langley, H. A., Ornstein, P. A., \& Cox, M. J. (2013). Intimate partner violence and children's memory. Journal of Family Psychology, 27(6), 937-944. doi:http://dx.doi.org/10.1037/a0034592

Haskett, M., Scott, S., Willoughby, L., \& Nears, K. (2006). The parent opinion questionnaire and child vignettes for use with abusive parents: Assessment of psychometric properties. $\langle\mathrm{br} /\rangle$. Journal of Family Violence, 21, 137-151.

Hasselmann, M. H., \& Reichenheim, M. E. (2006). Parental violence and the occurrence of severe and acute malnutrition in childhood. Pediatric Perinatal Epidemiology, 20(4), 299311.

Hay, D. F., Pawlby, S., Angold, A., Harold, G. T., \& Sharp, D. (2003). Pathways to violence in the children of mothers who were depressed postpartum. Developmental Psychology, 39(6), 1083-1094. 
Herrenkohl, T. I., Sousa, C., Tajima, E. A., Herrenkohl, R. C., \& Moylan, C. A. (2008).

Intersection of child abuse and children's exposure to domestic violence. Trauma Violence \& Abuse, 9(2), 84-99. doi:http://dx.doi.org/10.1177/1524838008314797

Hockenberry, M. J., \& Wilson, D. (2015). Wong's nursing care of infants and children (10th ed.) Mosby.

Holt, S., Buckley, H., \& Whelan, S. (2008). The impact of exposure to domestic violence on children and young people: A review of the literature. Child Abuse \& Neglect, 32(8), 797810. doi:10.1016/j.chiabu.2008.02.004

Hughes, I. (2007). Confusing terminology attempts to define the undefinable. Archives of Disease in Childhood, 92(2), 97-98.

Hungerford, A., Ogle, R. L., \& Clements, C. M. (2010). Children's exposure to intimate partner violence: Relations between parent-child concordance and children's adjustment. Violence \& Victims, 25(2), 185-201.

Hyde, J. S., Mezulis, A. H., \& Abramson, L. Y. (2008). The ABCs of depression: Integrating affective, biological, and cognitive models to explain the emergence of the gender difference in depression. Psychological Review, 115(2), 291-313.

Kar, B. R., Rao, S. L., \& Chandramouli, B. A. (2008). Cognitive development in children with chronic protein energy malnutrition. Behavioral \& Brain Functions [Electronic Resource]: $B B F, 4,31$.

Kerry, L. L. (2007). Complex posttraumatic stress symptoms among A community sample of battered women. (Unpublished PHD). Michigan State University, Michigan. 
Khalifeh, H., \& Dean, K. (2010). Gender and violence against people with severe mental illness. International Review of Psychiatry, 22(5), 535-546.

Krantz, G., Van Phuong, T., Larsson, V., Thi Bich Thuan, N., \& Ringsberg, K. C. (2005). Intimate partner violence: Forms, consequences and preparedness to act as perceived by healthcare staff and district and community leaders in a rural district in northern vietnam. Public Health, 119(11), 1048-1055.

Krugman, S. D., \& Dubowitz, H. (2003). Failure to thrive. American Family Physician, 68(5), 879.

Kuczmarski, R. J., Ogden, C. L., Grummer-Strawn, L. M., Flegal, K. M., Guo, S. S., Wei, R., . . Johnson, C. L. (2000). CDC growth charts: United states. Advance Data,

Kuhlman, K., Howell, K., \& Graham-Bermann, S. (2012). Physical health in preschool children exposed to intimate partner violence. Journal of Family Violence, 27(6), 499-510. doi:10.1007/s10896-012-9444-2

Kurstjens, S., \& Wolke, D. (2001). Effects of maternal depression on cognitive development of children over the first 7 years of life. Journal of Child Psychology \& Psychiatry \& Allied Disciplines, 42(5), 623-636.

Lee, A. M., Lam, S. K., Sze Mun Lau, S. M., Chong, C. S. Y., Chui, H. W., \& Fong, D. Y. T. (2007). Prevalence, course, and risk factors for antenatal anxiety and depression. Obstetrics \& Gynecology, 110(5), 1102-1112.

Lehrer, J. A., Buka, S., Gortmaker, S., \& Shrier, L. A. (2006). Depressive symptomatology as a predictor of exposure to intimate partner violence among US female adolescents and young adults. Archives of Pediatrics \& Adolescent Medicine, 160(3), 270-276. 
Lieberman, A. F., Van Horn, P., \& Ozer, E. J. (2005). Preschooler witnesses of marital violence: Predictors and mediators of child behavior problems. Development and Psychopathology, $17(2), 385-396$.

Mackner, L. M., Black, M. M., \& Starr, R. H. J. (2003). Cognitive development of children in poverty with failure to thrive: A prospective study through age 6. Journal of Child Psychology \& Psychiatry \& Allied Disciplines, 44(5), 743-751.

Marshall, L. L. (1992). Development of the severity of violence against women scales. Journal of Family Violence, 7, 103-121.

McDonald, R., Jouriles, E. N., \& Skopp, N. A. (2006). Reducing conduct problems among children brought to women's shelters: Intervention effects 24 months following termination of services. Journal of Family Psychology, 20(1), 127-136.

McFarlane, J., Parker, B., Soeken, K., \& Bullock, L. (1992). Assessing for abuse during pregnancy. severity and frequency of injuries and associated entry into prenatal care. JAMA, 267(23), 3176-3178.

McFarlane, J., Willson, P., Malecha, A., \& Lemmey, D. (2000). Intimate partner violence A gender comparison. Journal of Interpersonal Violence, 15(2), 158-169.

McNamee, R. (2005). <br />Regression modelling and other methods to control confounding . . Occup Environ Med, 62, 500-506. doi:10.1136/oem.2002.001115

McPherson, M. D., Delva, J., \& Cranford, J. A. (2007). A longitudinal investigation of intimate partner violence among mothers with mental illness. Psychiatric Services, 58(5), 675-680. 
Mead, H. K., Beauchaine, T. P., \& Shannon, K. E. (2010). Neurobiological adaptations to violence across development. Development \& Psychopathology, 22(1), 1-22.

Meyer, M. B. (1978). How does maternal smoking affect birth weight and maternal weight gain? evidence from the ontario perinatal mortality study. American Journal of Obstetrics \& Gynecology, 131(8), 888-893.

Milgrom, J., Gemmill, A. W., Bilszta, J. L., Hayes, B., Barnett, B., Brooks, J., . . B Buist, A. (2008). Antenatal risk factors for postnatal depression: A large prospective study. Journal of Affective Disorders, 108(1-2), 147-157.

Moraes, C., L., Sd de Oleveira, A., Reichenheim,Michael, E., \& Lobato, G. (2011). Severe physical violence between intimate partners during pregnancy: A risk factor for early cessation of exclusive breast-feeding. Public Health Nutrition, 14(12), 2148-2155. doi:10.1017/S1368980011000802

Murray, L., \& Cooper, P. J. (1997). Postpartum depression and child development. Psychological Medicine, 27(2), 253-260.

Murray, L., Sinclair, D., Cooper, P., Ducournau, P., Turner, P., \& Stein, A. (1999). The socioemotional development of 5-year-old children of postnatally depressed mothers. Journal of Child Psychology \& Psychiatry \& Allied Disciplines, 40(8), 1259-1271.

Nicolson, P. (1990). Understanding postnatal depression: A mother-centred approach. $\langle b r /\rangle$. Journal of Advanced Nursing, 15, 689-95. doi:10.1111/j.1365-2648.1990.tb01892.x.

Norton, L., Peirpert, J. F., Zierler, S., Lima, B., \& Hume, L. (1995). <br />Battering in pregnancy: An assessment of two screening methods. Obstetrics \& Gynecology, 85(3), $321-325$. 
Nunnally, J., \& Bernstein, I. (Eds.). (1994). Psychometric theory (3rd ed.). New York: McGraw Hill.

O'Connor, T. G., Caprariello, P., Blackmore, E. R., Gregory, A. M., Glover, V., Fleming, P., \& ALSPAC Study Team. (2007). Prenatal mood disturbance predicts sleep problems in infancy and toddlerhood. Early Human Development, 83(7), 451-458.

Ogden, C. L., Carroll, M. D., Kit, B. K., \& Flegal, K. M. (2014). Prevalence of childhood and adult obesity in the united states, 2011-2012. JAMA, 311(8), 806-814.

Olsen, E. M. (2006). Failure to thrive: Still a problem of definition. Clinical Pediatrics, 45(1), 16.

Olsen, E. M., Petersen, J., Skovgaard, A. M., Weile, B., Jørgensen, T., \& Wright, C. M. (2007). Failure to thrive: The prevalence and concurrence of anthropometric criteria in a general infant population. Archives of Disease in Childhood, 92(2), 109-114.

Pasricha, S., \& Biggs, B. (2010). Undernutrition among children in south and south-east asia. Journal of Paediatrics \& Child Health, 46(9), 497-503.

Patel, V., DeSouza, N., \& Rodrigues, M. (2003). Postnatal depression and infant growth and development in low income countries: A cohort study from goa, india. $\langle b r /\rangle$. Arch.Dis.Child., 88(1), 34-37. doi:org/10.1136/adc.88.1.34

Perez, E. M., Hendricks, M. K., Beard, J. L., Murray-Kolb, L. E., Berg, A., Tomlinson, M., . . . Vernon-Feagans, L. (2005). Mother-infant interactions and infant development are altered by maternal iron deficiency anemia. Journal of Nutrition, 135(4), 850-855. 
Place, J. m. (2014). Detecting intimate partner violence and post partum depression. Journal of Global Health,

Rahman, M., Poudel, K. C., Yasuoka, J., Otsuka, K., Yoshikawa, K., \& Jimba, M. (2012). Maternal exposure to intimate partner violence and the risk of undernutrition among children younger than 5 years in bangladesh. American Journal of Public Health, 102(7), 1336-1345.

Rahman, A., Lovel, H., Bunn, J., Iqbal, Z., \& Harrington, R. (2004). Mothers' mental health and infant growth: A case-control study from rawalpindi, pakistan. Child: Care, Health \& Development, 30(1), 21-27.

Ramos, C. V., Dumith, S. C., \& César, J. A. (2015). Prevalence and factors associated with stunting and excess weight in children aged 0-5 years from the brazilian semi-arid region. Jornal De Pediatria, 91(2), 175-182. doi:http://dx.doi.org/10.1016/j.jped.2014.07.005

Reichenheim, M. E., \& Moraes, C. L. (2004). Comparison between the abuse assessment screen and the revised conflict tactics scales for measuring physical violence during pregnancy. Journal of Epidemiology \& Community Health, 58(6), 523-527.

Reitman, D., Currier, R. O., \& Stickle, T. R. (2002). A critical evaluation of the parenting stress index-short form (PSI-SF) in a head start population. Journal of Clinical Child \& Adolescent Psychology, 31(3), 384-392.

Repetti, R. L., Taylor, S. E., \& Seeman, T. E. (2002). Risky families: Family social enviornments and the mental and physical health of offspring Psychol.Bull., 128(2002), 330-366.

Rhodes, K., Cerulli, C., Dichter, M., Kothari, C., \& Barg, F. (2010). "I didn't want to put them through that": The influence of children on victim decision-making in intimate partner violence cases. Journal of Family Violence, 25(5), 485-493. doi:10.1007/s10896-010-9310-z 
Rico, E., Fenn, B., Abramsky, T., \& Watts, C. (2011). Associations between maternal experiences of intimate partner violence and child nutrition and mortality: Findings from demographic and health surveys in egypt, honduras, kenya, malawi and rwanda. Journal of Epidemiology \& Community Health, 65(4), 360-367.

Riolo, S. A., Nguyen, T. A., Greden, J. F., \& King, C. A. (2005). Prevalence of depression by race/ethnicity: Findings from the national health and nutrition examination survey III. . American Journal of Public Health, 95, 998-1000. doi:10.2105/AJPH.2004.047225

Roche, A. F., \& Himes, J. H. (1980). < <br/>Incremental growth charts Journal of Clinical Nutrition, 33(9), 2014-2052.

Rodriguez, M. A., Valentine, J., Ahmed, S. R., Eisenman, D. P., Sumner, L. A., Heilemann, M. V., \& Liu, H. (2010). Intimate partner violence and maternal depression during the perinatal period: A longitudinal investigation of latinas. Violence Against Women, 16(5), 543-559.

Rumpf, H. J., Meyer, C., Hapke, U., \& John, U. (2001). Screening for mental health: Validity of the MHI-5 using DSM-IV axis I psychiatric disorders as gold standard. Psychiatry Research, 105(3), 243-253.

Saigal, S., \& Doyle, L. W. (2008). An overview of mortality and sequelae of preterm birth from infancy to adulthood. Lancet, 371(9608), 261-269.

Salazar, M., Hogberg, U., Valladares, E., \& Persson, L. A. (2012). Intimate partner violence and early child growth: A community-based cohort study in nicaragua. BMC Pediatrics, 12, 82.

Saltzman, K. M., Holden, G. W., \& Holahan, C. J. (2005). The psychobiology of children exposed to marital violence. Journal of Clinical Child \& Adolescent Psychology, 34(1), 129139. doi:10.1207/s15374424jccp3401_12 
Santos, I. S., Matijasevich, A., Domingues, M. R., Barros, A. J. D., \& Barros, F. C. F. (2010). Long-lasting maternal depression and child growth at 4 years of age: A cohort study. Journal of Pediatrics, 157(3), 401-406.

Sethuraman, K., Lansdown, R., \& Sullivan, K. (2006). Women's empowerment and domestic violence: The role of sociocultural determinants in maternal and child undernutrition in tribal and rural communities in south india. Food \& Nutrition Bulletin, 27(2), 128-143.

Shah, P. S., Shah, J., \& Knowledge Synthesis Group on Determinants of Preterm/LBW Births. (2010). Maternal exposure to domestic violence and pregnancy and birth outcomes: A systematic review and meta-analyses. Journal of Women's Health, 19(11), 2017-2031.

Sharp, D., Hay, D. F., Pawlby, S., Schmucker, G., Allen, H., \& Kumar, R. (1995). The impact of postnatal depression on boys' intellectual development. Journal of Child Psychology \& Psychiatry \& Allied Disciplines, 36(8), 1315-1336.

Silva, E. P., Ludermir, A. B., Araujo, T. V. B. d., \& Valongueiro, S. A. (2011). Frequency and pattern of intimate partner violence before, during and after pregnancy. Revista De Saude Publica, 45(6), 1044-1053.

Silva, E. P., Valongueiro, S., de Araujo, T. V. B., \& Ludermir, A. B. (2015). Incidence and risk factors for intimate partner violence during the postpartum period. Revista De Saude Publica, 49, 46.

Silverman, J. G., Decker, M. R., Gupta, J., Kapur, N., Raj, A., \& Naved, R. T. (2009). Maternal experiences of intimate partner violence and child morbidity in bangladesh: Evidence from a national bangladeshi sample. Archives of Pediatrics \& Adolescent Medicine, 163(8), 700705. 
Skuse, D. H. (1985). Non-organic failure to thrive: A reappraisal. Archives of Disease in Childhood, 60(2), 173-178.

Sobkoviak, R. M., Yount, K. M., \& Halim, N. (2012). Domestic violence and child nutrition in liberia. Social Science \& Medicine, 74(2), 103-111.

Spilsbury, J. C., Kahana, S., Drotar, D., Creeden, R., Flannery, D. J., \& Friedman, S. (2008). Profiles of behavioral problems in children who witness domestic violence. Violence \& Victims, 23(1), 3-17.

Stettler, N., Bhatia, J., Parish, A., \& Stallings, V. A. (2015). Feeding healthy infants, children, and adolescents. . In R. M. Kliegman, R. E. Behrman, H. B. Jenson \& B. F. Stanton (Eds.), Nelson textbook of pediatrics (20th ed., ). Philadelphia, PA: Sunders Elsevier.

Steward, D. K., Ryan-Wenger, N. A., \& Boyne, L. J. (2003). Selection of growth parameters to define failure to thrive. Journal of Pediatric Nursing, 18(1), 52-59.

Stewart, R. C. (2007). Maternal depression and infant growth: A review of recent evidence. Maternal \& Child Nutrition, 3(2), 94-107.

Subramanian, S. V., Kawachi, I., \& Smith, G. D. (2007). Income inequality and the double burden of under- and overnutrition in india. Journal of Epidemiology \& Community Health, 61(9), 802-809.

Subramanian, S. V., Ackerson, L. K., Subramanyam, M. A., \& Wright, R. J. (2007). Domestic violence is associated with adult and childhood asthma prevalence in india. International Journal of Epidemiology, 36(3), 569-579. 
Suglia, S. F., Duarte, C. S., Sandel, M. T., \& Wright, R. J. (2010). Social and environmental stressors in the home and childhood asthma. Journal of Epidemiology \& Community Health, 64(7), 636-642. doi:http://dx.doi.org/10.1136/jech.2008.082842

Suglia, S. F., Enlow, M. B., Kullowatz, A., \& Wright, R. J. (2009). Maternal intimate partner violence and increased asthma incidence in children: Buffering effects of supportive caregiving. Archives of Pediatrics \& Adolescent Medicine, 163(3), 244-250.

Sullivan, P. B. (2004). Commentary: The epidemiology of failure-to-thrive in infants. International Journal of Epidemiology, 33(4), 847-848.

Surkan, P. J., Kennedy, C. E., Hurley, K. M., \& Black, M. M. (2011). Maternal depression and early childhood growth in developing countries: Systematic review and meta-analysis. $<$ br /> . Bulletin of the World Health Organization, 89, 608-615. doi:10.2471/BLT.11.088187

Tanner, J. M. (1952). The assessment of growth and development in children. Archives of Disease in Childhood, 27(131), 10-33.

Tayie, F. A., \& Powell, C. (2012). Sex differences in the association between prenatal smoking and decreased birthweight, and intensive health care of the neonate. Behavioral Medicine, $38(4), 138-142$.

Torres, S. J., \& Nowson, C. A. (2007). Relationship between stress, eating behavior, and obesity. Nutrition (Burbank, Los Angeles County, Calif.), 23(11-12), 887-894. doi:S08999007(07)00249-3 [pii]

Van Parys, A., Deschepper, E., Michielsen, K., Temmerman, M., \& Verstraelen, H. (2014). Prevalence and evolution of intimate partner violence before and during pregnancy: A crosssectional study. BMC Pregnancy \& Childbirth, 14, 294. 
Vogazianos, P., Fiala, J., \& Vogazianos, M. (2005). The influence of active maternal smoking during pregnancy on birth weights in cyprus. Central European Journal of Public Health, 13(2), 78-84.

Wach, T. D. (2009). Models linking nutritional deficiencies to maternal and child mental health. American Journal of Clinical Nutrition, 89, 935-9. doi:10.3945/ajen.2008.26692B

Wang, Y., \& Chen, H. (2012). Use of pecentiles and Z scores in anthropometry. In V. R. Preedy (Ed.), Handbook of anthropometry: Physical measures 29 of human form in health and disease (pp. 29-42) Springer Science+Business Media. doi:DOI 10.1007/978-1-4419-1788$1 \_2$,

Ware, J. E., \& Gandek, B. (1998). Overview of the SF-36 health survey and the international quality of life assessment (IQOLA) project. Journal of Clinical Epidemiology, 51(11), 903912.

Ware, J. E., \& Gandek, B. (1994). The SF-36 health survey: Development and use in mental health research and the IQOLA project. International Journal of Mental Health, 23(2), 4973. doi:10.1080/00207411.1994.11449283

Waterlow, J. (2007). References and standards for infants and child growth. Public Health Nutr., 10(5), 533-534.

Wojcicki, J. M., Holbrook, K., Lustig, R. H., Epel, E., Caughey, A. B., Munoz, R. F., . . Heyman, M. B. (2011). Chronic maternal depression is associated with reduced weight gain in latino infants from birth to 2 years of age. PLoS ONE [Electronic Resource], 6(2), e16737. 
Wolke, D. (1996). Failure to thrive: The myth of maternal deprivation syndrome. (Newsletter No. Vol 4, No 3 \& 4). The Signal WAIMH.

Worthy, S., Bagwell, B., \& Hudson, T. (2013, February 26). <br />Parent/child stress in families experiencing domestic violence $\langle\mathrm{br} /\rangle\langle\mathrm{br} /\rangle$.

Wright, C. M., Parkinson, K. N., \& Drewett, R. F. (2006). The influence of maternal socioeconomic and emotional factors on infant weight gain and weight faltering (failure to thrive): Data from a prospective birth cohort. A. Adv.Skin Wound Care, 91(4), 312-317. doi:http://doi.org/10.1136/adc.2005.077750

Wright, C. M. (2005). Growth charts for babies. BMJ, 330(7505), 1399-1400.

Yount, K., M., DiGirolamo, A., M., \& Ramakrishnan, U. (2011). Impacts of domestic violence on child growth and nutrition: A conceptual review of the pathways of influence. Social Science \& Medicine, 72(9), 1534-1554. doi:10.1016/j.socscimed.2011.02.042

Zhu, S., \& Valbo, A. (2002). Depression and smoking during pregnancy. Addictive Behaviors, 27(4), 649-658.

Ziaei, S., Naved, R. T., \& Ekstrom, E. (2014). Women's exposure to intimate partner violence and child malnutrition: Findings from demographic and health surveys in bangladesh. Maternal \& Child Nutrition, 10(3), 347-359. doi:http://dx.doi.org/10.1111/j.1740-8709.2012.00432.x

Ziegler, E. E. (2006). Growth of breast-fed and formula-fed infants. Nestle Nutrition Workshop Series.Paediatric Programme, 58, 51-59. 
CHAPTER TWO: LITERATURE REVIEW (Manuscript One)

\title{
Growth problems in children exposed to intimate partner violence assessed with anthropomorphic measures
}

\author{
Abstract \\ Background. An increasing body of evidence shows links between women's intimate \\ partner violence (IPV) victimization and poor child health outcomes. Data from 10 years \\ indicate that the United Nations Children Education Fund estimates that about 275 \\ million children are exposed to intimate partner violence worldwide, with the U.S \\ contributing about $5.7 \%$ (10-15.5 million) annually. Children exposed to IPV are at \\ increased risk for adverse mental and behavioral health outcomes, as has been \\ documented by both systematic reviews and meta-analyses. Studies addressing the \\ physical growth impact of childhood IPV exposure, however, have not been summarized \\ in a manner that might facilitate additional hypothesis-driven research and accelerate the \\ development of targeted interventions.
}

Methods. A comprehensive search of identified databases (Arts \& Humanities Citation Index; BMJ Journals Online; CINAHL; JSTOR; Psychological and Behavioral Sciences Collection; PsycINFO; PubMed index) was conducted using the key words "domestic violence," "intimate partner violence" "family violence," "child," “exposure," "failure to thrive," "malnutrition," "undernutrition" "stunting", and "wasting". This search yielded 18 articles in the initial search, from which online abstract and bibliographic information was used to identify selectively the material that met the inclusion criteria. Ten articles were reviewed. 
Results. Childhood exposure to IPV is related with wasting, stunting and underweight. Minimal data and study limitations preclude comparisons of exposure to violence and impact on child's growth between developed and developing countries.

Conclusion. The impact on physical growth from exposure to IPV during childhood from these studies is overwhelming. Longitudinal studies need to be conducted and protective and risk factors for stunting, wasting, undernutrition and obesity need to be identified.

Future studies should be grounded in a theoretical model that specifies how IPV exposure can affect child physical growth and should adjust for confounders adequately.

Key words: Intimate partner violence, Anthropometry, physical growth.

\section{Introduction and Background}

Intimate partner violence (IPV) is a common type of violence, and is a public health problem that exists in all societies and among people of higher and lowers social strata (Krantz et al., 2005). IPV is physical, emotional or sexual abuse perpetrated against a current or former spouse, sexual partner, girl/boyfriend, or by parties with a child in common (Rhodes et al., 2010). In the recent past, a number of studies have highlighted the fact that IPV not only impacts the health of the mother but that of the baby as well(Alhusen et al., 2013; Cerulli et al., 2011; Garoma et al., 2012; Moraes et al., 2011). Ten years ago the United Nations Children's Education Fund (UNICEF) estimated the number of children exposed to IPV worldwide to be 275 million. This is likely a conservative estimate based on the limitation of the available data; in actuality, millions more children may be exposed (UNICEF, 2006). At the same time in America, it was estimated that 10-15.5 million children were exposed to IPV annually (McDonald et 
al., 2006). No current data are available on the frequency of exposure both in the United States and globally.

World Health Organization (WHO) defines a child as a human being who is between 0-18years ( WHO, 2006). Growth refers to an increase in physical size of the whole body or any of its parts and it can be measured in kilograms, pounds, meters or inches. Development is the progressive increase in skill and functional capacity. It is a qualitative change in child's functioning and it is measured by observation. There are two growth patterns in children, cephalocaudal (head to toe) and proximal distal (inward to outward). There are two types of growth: physical growth, that is measured as height, weight, and chest circumference and physiological growth that is assessed using blood pressure, temperature, heart rate and pulse measurements. The development areas include motor, cognitive, emotional and social developments (Hockenberry \& Wilson, 2015).

The integrated nature of growth and development is largely maintained by a constant interaction of genes, hormones, nutrients, environment, social and other factors. Some of the factors are hereditary in origin; others originate in the environment and simply affect the rate of growth at the time they are acting (Hockenberry \& Wilson, 2015; Stettler, Bhatia, Parish, \& Stallings, 2015). Additionally other factors, such as socioeconomic class, reflect a complicated mixture of hereditary and environmental influences and probably act throughout the whole period of growth. IPV is a social factor and studies have identified various adverse effects of childhood exposure to IPV 


\section{Intimate partner violence and child physical health, cognitive and behavioral}

\section{development}

Children living in families where IPV occurs may be exposed to abuse in a number of ways. They may be direct witnesses to abuse, may suffer harm incidental to the violence, may have their lives disrupted by moving or being separated from parents, may be used by the batterer to manipulate or gain control over the victim, and they themselves are more likely to be abused (Whitfield, Anda, Dube \& Felitti, 2003). IPV could affect child health outcomes through physical or psychological maternal health outcomes that prevent proper care of the child, psychological stress resulting from observation of IPV, or direct physical injury incurred by the child (Campbell et al., 2002; Chung, McCollum, Elo, Lee, \& Culhane, 2004; Herrenkohl, Sousa, Tajima, Herrenkohl, \& Moylan, 2008; Saltzman, Holden, \& Holahan, 2005). IPV exposure also impacts children and often leads to negative short and long-term behavioral, psychological, cognitive and social impacts on children (Rhodes et al., 2010). Witnessing the mental and/or physical abuse of their mother has negative consequences on the children; children living with IPV are at increased risk of developing emotional and behavioral problems (Alhusen et al., 2013; Holt, Buckley, \& Whelan, 2008). A number of studies have been conducted to assess the relationship between exposure to violence and development of asthma in children (Bair-Merritt et al., 2012; Breiding \& Ziembroski, 2011; Subramanian et al., 2007; Suglia et al., 2009; Suglia et al., 2010), early cessation of exclusive breastfeeding (Moraes et al., 2011), low immunization rates (Kuhlman et al., 2012) and high risk for pneumonia (Arcos et al., 2003). Another area that has been carefully studied is the impact of IPV on cognitive development (Busch \& Lieberman, 2010; Cummings et 
al., 2009; Gustafsson et al., 2013; Hungerford et al., 2010) and children's behavior (Lieberman et al., 2005; Spilsbury et al., 2008).

The largely negative effect of IPV on children's behavior, emotional and psychological wellbeing has been well established through a number of large studies (Evans, Davies, \& Dilillo, 2008; Ribeiro, Andreoli, Ferri, Prince, \& Mari, 2009; Holt, Buckley \& Whelean, 2008). A study examining the relationship between IPV and children's dysfunctional behaviors and school problems found that exposure to IPV was associated with three or more dysfunctional behaviors (Durand, Schraiber, Franca-Junior, \& Barros, 2011). Severe IPV is associated with aggressive behavior and school problems, while maternal mental health status is identified as the mediating factor between IPV exposure and dysfunctional behavior especially aggression. Another study revealed that children exposed to IPV exhibit internalizing and externalizing behaviors, which differ by child's gender, mother's education, and child's lifetime exposure to violence (Spilsbury et al., 2008). Internalizing behaviors comes with anxiety, depression and withdrawal from others whereas externalizing behavior consist of a child acting out with aggression, violence, disruptiveness, and defiance (Spilsbury et al., 2008).

Additionally, the relationship between childhood exposure to domestic violence and children's internalizing, externalizing and trauma symptoms revealed a larger weighted effect for the relationship between exposure to domestic violence and childhood trauma symptoms. Analyses for gender demonstrated that exposure to domestic violence and externalizing symptoms is significantly stronger for boys than girls (Davies, Evans, \& and DiLillo, 2008). Furthermore a study conducted on children who were 30 months old exposed to IPV found that maternal exposure to IPV was a significant predictor of 
children's short term, working and deliberate memory at 60 months of age (Gustafsson et al., 2013). Children of parents who reported IPV and parental psychological distress were more likely to fail the following developmental milestones in the first 72 months: language, personal-social and gross motor development (Gilbert, Bauer, Carroll, \& Downs, 2013).

\section{Intimate partner violence and failure to thrive}

While several studies have been conducted on the impact of intimate partner violence and cognitive and behavioral development of the child and general health consequences, few studies have examined the impact of violence on the physical growth of the child. Failure to thrive (FTT) is regarded as an indicator of physical problem in early childhood and is associated with subsequent growth delay and cognitive deficiencies. Early onset FTT has been found to increase children's vulnerability to short stature, poor arithmetic performance and poor work habits (Kar, Rao, \& Chandramouli, 2008).

During infancy, growth is primarily a nutrition dependent function. Age appropriate growth of infants reflects the adequacy of the infant's nutritional intake; therefore the infant's body size can serve as an indirect marker of current nutritional status (Steward, Ryan-Wenger, \& Boyne, 2003). Although the discussion of pediatric growth failure can be traced back over a century in the medical literature, the term failure to thrive (FTT) has only been used in the past several decades and no consensus exists regarding a specific definition (Cole \& Lanham, 2011). A literature review by Olsen indicates that a number of articles reviewed broadly defined FTT as some form of inadequate growth (Olsen, 2006). Further review revealed a large difference in the 
growth parameters used to assess for FTT. Total agreement existed to define FTT solely on anthropometric parameters; however, large differences were seen regarding which growth parameters to use, and whether to use velocities or attained growth. Growth velocities reflect change in grams and centimeters per unit time for weight and height respectively, while attained growth reflects achieved weight and height at a specific time/age (Olsen, 2006).

Proponents of the use of growth velocity consider it a superior quantitative measure of growth compared to attained size for age (Baumgartner, Roche, \& Himes, 1986; Guo et al., 1991; Roche \& Himes, 1980; Tanner, 1952). They point out that, whereas pathogenic factors affect growth velocity directly, their impact on attained size becomes evident only after the altered rate of growth has had time to produce its result (Tanner, 1952). Thus examining growth velocity would lead to earlier identification of failure to thrive, excessive weight gain, or response to treatment than would the examination of attained growth. Despite such advantage, attained growth remain the most widely used means of assessing whether a child's growth pattern deviates from normality (de Onis et al., 2011).

The most frequently used indicators of nutritional status in children are based on height and weight measurements (i.e. attained growth measure). Percentiles and Z-scores are the preferred anthropometric measurements, with the Z-score being the most commonly used: weight-for-height, height-for-age and weight-for-age Z-scores (Wang \& Chen, 2012). These three indicators provide estimates of both current and past under nutrition or of current status of obesity (WHO, 2006). Weight-for-height (WHZ) reflects body mass in relation to body height or length and is sensitive to more recent and severe 
events and shocks. Low WHZ is described as wasting. Height-for-age (HAZ) is a long-term measure of nutritional status and captures linear growth in utero and early childhood. A median height for age of reference population below minus two standard deviations is called stunting. Weight-for-age (WAZ) provides a composite index and gives a general picture of overall nutritional status according to age (WHO, 2006).

The aim of this literature review is to analyze the studies that have utilized anthropometric measurements to assess FTT in children exposed to violence. The age groups of interest for this review are infants, toddlers, and preschoolers (0-60 months) .

\section{Materials and Methods}

A comprehensive search of identified databases (Arts \& Humanities Citation Index; BMJ Journals Online; CINAHL; JSTOR; Psychological and Behavioral Sciences Collection; PsycINFO; PubMed index) was conducted using the key words "domestic violence," "intimate partner violence" "family violence," "child," “exposure," "failure to thrive," "malnutrition," "undernutrition" "stunting", and "wasting". This search yielded 18 articles in the initial search, from which online abstract and bibliographic information was used to identify selectively the material that met the inclusion criteria of: (1) those published within a ten-year framework (2005-2015), articles that were published in English language and (3), those that had children who were five years and below and (4) those that used anthropometric measurement to assess the growth of the child. A total of ten articles met these criteria. 


\section{Results}

Ten articles meeting these criteria were reviewed. The years of publication ranged from 2006-2014, with three being published in 2012. The countries represented in the studies are: the United States, India, Bangladesh, Brazil, Liberia, Nicaragua, Kenya, Malawi, Rwanda, Egypt and Honduras. The variables used to assess child's growth were: Z-scores for weight-for-height/length (WHZ), height-for-age (HAZ), weight-for-age (WAZ) and body mass index (BMI). All of these measures were based on the World Health Organization (WHO) anthropometric reference standards, except for two articles that used Centers for Disease Control and Prevention (CDC) growth references. The ages of children in the ten studies ranged from 0-60 months.

Maternal intimate partner violence was assessed using various instruments. Five studies used the Conflict Tactics Scales (CTS), two studies used a short modified version of the WHO collaborative study questionnaire based on the CTS, two studies used self reports from the mothers (no specific instrument) and one study used questions that the researcher formulated based on physical, sexual and restrictive abuse. Except for two studies that were longitudinal and one that was a case control study, the rest were crosssectional studies. All except one study were conducted in developing countries of which five were conducted in South Asia (see Table 1 for studies referred to above).

\section{Maternal characteristics associated with growth failures}

Maternal age, parity, education level and marital status were assessed in all the studies. Other variables include maternal smoking status, race/ethnicity, mental health and immigration status (Boynton-Jarrett, Fargnoli, Suglia, Zuckerman, \& Wright, 2010); 
maternal decision making, asset score/wealth index and place of residence (rural/urban) (Ackerson \& Subramanian, 2008; Rico et al., 2011; Salazar, Hogberg, Valladares, \& Persson, 2012; Sobkoviak et al., 2012; Ziaei et al., 2014); religion (Ackerson \& Subramanian, 2008; Asling-Monemi et al., 2009); use of illicit drugs and alcohol (Hasselmann \& Reichenheim, 2006); maternal BMI and anemia (Ziaei et al., 2014) ; breastfeeding and bottle use (Boynton-Jarrett et al., 2010).

The maternal demographic factors that were found to be associated with child growth differed from study to study. Boynton (2010) found an association between child obesity and maternal BMI, smoking during pregnancy, marital status as well as child factors such as television watching, birth weight and bottle-feeding. In another study, stunting and underweight were associated with high wealth score and recent child illness (Rahman et al., 2012). Wasting was associated with, maternal decision-making and male gender (Rahman et al., 2012). Higher education and decision-making among mothers were associated with higher WHZ, HAZ, and WAZ scores implying that these children were growing normally or tended towards obesity (Asling-Monemi et al., 2009). A number of studies found low maternal education level associated with low Z-scores (Ackerson \& Subramanian, 2008; Salazar et al., 2012).

Both maternal BMI and maternal age had conflicting associations across studies. Increased maternal BMI was found to be significantly associated with obesity (BoyntonJarrett et al., 2010) or, conversely, stunting, underweight and wasting (Sobkoviak et al., 2012; Ziaei et al., 2014). One study found older maternal age associated with low Zscores (Asling-Monemi et al., 2009). Another study found older age to be protective of 
undernutrion (Sobkoviak et al., 2012). A number of studies found that children of younger mothers had lower Z-scores (Ackerson \& Subramanian, 2008; Rico et al., 2011; Salazar et al., 2012).

Some studies looked at the association between maternal demographics and IPV. There was a positive correlation between parental use of illicit drug and alcohol and the likelihood of IPV (Hasselmann \& Reichenheim, 2006), multiple incidence of violence was related to low maternal BMI and anemia (Ackerson \& Subramanian, 2008; Sobkoviak et al., 2012); young mothers were more likely to be abused (Rico et al., 2011; Salazar et al., 2012; Ziaei et al., 2014); women with low education level, limited decision making and low economic status and living in rural areas were more likely to be abused (Rico et al., 2011; Salazar et al., 2012; Sethuraman, Lansdown, \& Sullivan, 2006; Sobkoviak et al., 2012; Ziaei et al., 2014).

\section{Type/severity of IPV and child growth}

Majority of the studies used CTS or their modified versions, however different studies assed for different types of IPV and perpetrators. A number of studies assessed for physical, emotional and sexual IPV (Asling-Monemi et al., 2009; Salazar et al., 2012; Sobkoviak et al., 2012); physical, sexual, physical and sexual (Boynton-Jarrett et al., 2010; Ziaei et al., 2014); verbal and physical (Hasselmann \& Reichenheim, 2006); physical only (Ackerson \& Subramanian, 2008; Sethuraman et al., 2006). Three studies included controlling behavior (Asling-Monemi et al., 2009; Boynton-Jarrett et al., 2010; Salazar et al., 2012). One study categorized violence into early, late and chronic (Boynton-Jarrett et al., 2010) while another study categorized violence based on severity 
(verbal, minor and severe) (Hasselmann \& Reichenheim, 2006). Perpetrators of violence were categorized into current partner, past partner and both current and past. Stunting was the most common growth failure and it was associated with most types of violence. Wasting was associated with sexual violence, whereas undernutrition was associated with verbal aggression, physical and sexual violence. Obesity was associated with timing of violence while controlling behavior was associated with stunting wasting and undernutrition (See Table 2).

To determine the true impact of IPV, some studies adjusted for demographic factors. Confounding is a major concern in causal studies because it results in biased estimation of exposure effects. A possible approach for data that has already been gathered is to apply a statistical "correction" method during analysis. Such methods produce "adjusted" or "corrected" estimates of the effect of exposure (McNamee, 2005). One study showed that a significant relationship between IPV and undernutrition persisted after adjusting for asset score, maternal education, age, parity and religion (Asling-Monemi et al., 2009). Another study revealed that adjusting for demographics reduced the strength of association for undernutrition but remained marked for wasting and stunting (Ackerson \& Subramanian, 2008). Yet another study found that after adjusting for maternal age, marital status, parity, residency and social economic status, stunting was still significant (Salazar et al., 2012). These findings insinuate that IPV alone has an impact on child's undernutrition, wasting and stunting and that maternal demographic factors may contribute to the severity of the child growth failures. One study found that IPV and its association with wasting and undernutrition lost significance 
after adjusting for confounders. The rest of the studies did not indicate whether confounders were adjusted for in their analysis.

\section{Discussion}

The discussion will focus on the maternal and child demographic factors that are associated with growth failure, type and severity of IPV associated with growth failures and the relationship between demographic factors, IPV and growth failure in children. One finding of interest is that none of the studies in this review referred to growth failure as FTT. This may be due to lack of clear consensus on the anthropometric indices used to assess for FTT. Most studies referred to growth failure by the anthropometric indices that were used to measure growth such as "stunting" "wasting" and "undernutrition". For this discussion therefore wasting will be used for low WHZ score, stunting for low HAZ score and undernutrition for low HAZ and obesity for high BMI.

Maternal demographic factors indicated in this review have shown an association with child growth failures, other studies have found similar association (Black et al., 2008; Pasricha \& Biggs, 2010; Ramos, Dumith, \& César, 2015; Subramanian, Kawachi, \& Smith, 2007). Most of these studies have found an association between maternal demographic factors and growth failures such as stunting, wasting and undernutrition, however one study from the review (Rahman et al., 2012) found that undernutrition and stunting was associated with higher wealth index and BMI (normal or obese). This suggests an emerging pattern of a dual burden of malnutrition in the same households, where the mother is overweight while the child is suffering from chronic malnutrition. A presence of the dual burden in the same household has also been reported in other studies. This coexistence of maternal over nutrition and child undernutrition in the same 
households reflects the rapid nutritional transition in developing countries Deleuze Ntandou Bouzitou, Fayomi, \& Delisle, 2005) and has been reported in middle-income countries such as Indonesia and Russia, where between 9\% and 13\% of households contain both underweight and overweight members (Doak, Adair, Bentley, Monteiro, \& Popkin, 2005). Maternal undernutrition was also identified as a determinant of child undernutrition in this review. Children whose mothers had a low BMI were more likely to be undernourished. Optimum maternal nutrition before and during pregnancy is important for a healthy pregnancy outcome, as low maternal BMI is associated with intrauterine growth restriction and (Black et al. 2003). This review also demonstrates the importance of maternal education for child nutrition outcomes. These findings agree with results of an analysis by Giroux of the effect of maternal education on child stunting (Giroux, 2008). Mothers with high level of education were associated with lower odds of childhood stunting and underweight. Higher maternal education maybe associated with maternal employment and higher household income and other resources.

The interaction between demographic factors, IPV and child growth can be explained in the following pathways; it is possible that maternal low education, low socio-economic status, lack of decision making in the family and having many children affects their ability to provide adequate nutritional care to her infant. Also their dependency on their partners for provision of basic needs and family decision making may give the male partners power and control over their wives and they may use violence to assert more power and control. Maternal anemia and low BMI have been associated maternal mood and low infant interactions (Beard et al., 2005; Perez et al., 2005). Maternal anemia and low BMI maybe as a result of lack of food, food deprivation or 
depression related to violence resulting in low or no appetite. These mothers may suffer from fatigue, impaired concentration, feeling of hopelessness and worthlessness. Such symptoms may lead to functional impairment affecting breastfeeding and weaning.

Stunting is the major growth failure identified in this review. Stunting is associated with under developed brain, with long-lasting harmful consequences, including diminished mental ability and learning capacity, poor school performance in childhood, reduced earnings and increased risks of nutrition related chronic diseases, such as diabetes, hypertension, and obesity in future (Caufield, Richard, Rivera, Musgrove, \& Black, 2006). Stunting starts from pre-conception when an adolescent girl and who later becomes mother is undernourished and anemic; it worsens when infants' diets are poor. It is irreversible by the age of two. Although knowledge about the prevalence of stunting and wasting is preferred, information about underweight is more available globally. The high correlation between stunting and underweight and the low prevalence of wasting mean that the prevalence of underweight directly describes the magnitude of the problem of growth faltering and stunting in young children. The highest prevalence of stunting is in south Asia and Sub-Saharan countries-six studies reviewed came from these regions (Caufield et al., 2006).

\section{Limitations}

The cross sectional studies used existing data to perform secondary data analysis. Secondary data may have advantages such as saving money and accessing readily available data, however data may not facilitate answering particular research questions. Information regarding data collection procedures may be scarce and a single survey item 
or a subset of test items, which can lead to reliability and validity concerns, may operationally define constructs. Minimal data preclude comparisons of exposure to violence and impact on child's growth in developed and developing countries.

\section{Conclusion}

Growth failures in children can be associated with both maternal demographic factors and IPV, however IPV by itself seems to have a big role. Some maternal demographic factors such as low education, low socioeconomic status, multiparity and place of residence (urban versus rural) may aggravate IPV while anemia and BMI may be a result of IPV. This review shows that different types of growth failures are associated with different types/severity of IPV as well as controlling behaviors of the perpetrator. The majority of the studies reviewed were conducted in south Asia, thus findings of this review may largely be applicable to these countries. Given the limited number of studies reviewed on child's physical growth and IPV, it can be concluded that more studies need to be conducted to determine the effect on IPV and FTT, especially those that are less that two years of age. Early childhood is a crucial period for growth and development, early identification and treatment will result in better outcomes in children suffering from growth failures.

\section{Implications}

- Intimate partner violence is associated with various growth and developmental problems. Identifying those children that are exposed, and the impact of IPV on their lives and subsequently providing interventions for both mother and child will greatly improve the health of both. The Institute of Medicine (IOM) requires 
all insurance companies to reimburse for screening and counseling for interpersonal and domestic violence (Clinical preventive services for women: Closing the gaps. 2011). Well child clinics should take advantage of this and use existing tools such as Abuses Assessment Screen (AAS) to screen for IPV in the well child clinic. Having all these services under one roof will be beneficial to mothers and the health care providers.

- There is need to conduct more longitudinal studies to closely study the relationship of IPV and physical growth outcomes of children less than two years of age. Physical growth is crucial during this age because any growth deviation from the normal may pose a risk of permanent mental, emotional or physical delays.

- Future studies should be grounded in a theoretical model that specifies how IPV exposure can affect child physical growth and should adjust for confounders adequately. 


\section{Tables}

Table 1: Summary findings

\begin{tabular}{|c|c|c|c|c|c|c|}
\hline Author & Year & Country & Measure & Age & IPV measure & Type of study \\
\hline $\begin{array}{l}\text { Boynton-Jarret, } \\
\text { Fargnoli, suglia, } \\
\text { Zuckerman \& } \\
\text { Wright }\end{array}$ & 2010 & USA & $\begin{array}{l}\text { BMI (CDC) } \\
\text { Z-scores }\end{array}$ & 36 and 60 months & $\begin{array}{l}\text { Questions on } \\
\text { physical, } \\
\text { sexual and } \\
\text { restrictive } \\
\text { abuse }\end{array}$ & Longitudinal \\
\hline $\begin{array}{l}\text { Hasselman \& } \\
\text { Reichenheim }\end{array}$ & 2006 & Brazil & WHZ & 1-24 months & CTS & $\begin{array}{l}\text { Case control } \\
\text { study }\end{array}$ \\
\hline Rahman et al. & 2012 & Bangladesh & $\begin{array}{l}\text { WHZ, HAZ, } \\
\text { WAZ }\end{array}$ & $\begin{array}{l}\text { Younger than } 5 \\
\text { years. }\end{array}$ & CTS & \\
\hline $\begin{array}{l}\text { AslingMonemi et } \\
\text { al. }\end{array}$ & 2009 & Bangladesh & $\begin{array}{l}\text { WHZ, HAZ, } \\
\text { WAZ }\end{array}$ & $0-24$ & $\begin{array}{l}\text { WHO modified } \\
\text { based on CTS }\end{array}$ & Longitudinal \\
\hline $\begin{array}{l}\text { Ackerson \& } \\
\text { Subramanian }\end{array}$ & 2008 & India & $\begin{array}{l}\text { WHZ, HAZ, } \\
\text { WAZ BMI }\end{array}$ & $12-35$ months & Self reports & Cross sectional \\
\hline $\begin{array}{l}\text { Sethuraman, } \\
\text { Lansdown \& } \\
\text { Sullivan }\end{array}$ & 2006 & India & $\begin{array}{l}\text { WHZ, HAZ, } \\
\text { WAZ based } \\
\text { on NCHS }\end{array}$ & 6-24 months & Self-reports & Cross sectional \\
\hline $\begin{array}{l}\text { Rico, Fenn, } \\
\text { Ambamsky \& } \\
\text { Watts }\end{array}$ & 2011 & $\begin{array}{l}\text { Egypt, } \\
\text { Honduras, } \\
\text { Rwanda } \\
\text { Malawi and } \\
\text { Kenya }\end{array}$ & $\begin{array}{l}\text { WHZ and } \\
\text { HAZ }\end{array}$ & 6-59 months & CTS & Cross-sectional \\
\hline $\begin{array}{l}\text { Salazar, Hogberg, } \\
\text { Valladeres \& } \\
\text { Persson }\end{array}$ & 2012 & Nicaragua & HAZ & $40-46$ months & $\begin{array}{l}\text { WHO modified } \\
\text { based on CTS }\end{array}$ & Cross-sectional \\
\hline $\begin{array}{l}\text { Sobkoviak, Yount } \\
\text { \& Halim }\end{array}$ & 2012 & Liberia & $\begin{array}{l}\text { WHZ, HAZ, } \\
\text { WAZ }\end{array}$ & Under 5 years & CTS & Cross sectional \\
\hline $\begin{array}{l}\text { Ziaei, Naved \& } \\
\text { Ekstrom }\end{array}$ & 2014 & Bangladesh & $\begin{array}{l}\text { WHZ, HAZ, } \\
\text { WAZ }\end{array}$ & Under 5 years & CTS & Cross sectional \\
\hline
\end{tabular}


Table 2: Significant findings from the studies

\begin{tabular}{|c|c|c|c|}
\hline Author & Country & Cut off measure & Findings \\
\hline $\begin{array}{l}\text { Boynton-Jarret, } \\
\text { Fargnoli, suglia, } \\
\text { Zuckerman \& } \\
\text { Wright, } 2010\end{array}$ & USA & $\begin{array}{l}\text { Z-scores and } \\
\text { percentile, no cut } \\
\text { off value } \\
\text { mentioned }\end{array}$ & $\begin{array}{l}\text { Children whose mothers reported chronic IPV were } \\
80 \% \text { more likely to be obese. }\end{array}$ \\
\hline $\begin{array}{l}\text { Hasselman \& } \\
\text { Reichenheim, } \\
2006\end{array}$ & Brazil & Z-score <-2 & $\begin{array}{l}\text { Severe acute malnutrition (SAM) is not associated } \\
\text { with all types of IPV, but children exposed to severe } \\
\text { and recurrent events are more likely to be admitted } \\
\text { for SAM. }\end{array}$ \\
\hline $\begin{array}{l}\text { Rahman et al., } \\
2012\end{array}$ & Bangladesh & $\begin{array}{l}\text { Z-score } 2 \text { standard } \\
\text { deviations below } \\
\text { the median of the } \\
\text { WHO reference } \\
\text { population }\end{array}$ & $\begin{array}{l}\text { Maternal experience of any physical or sexual IPV } \\
\text { was associated with an increased risk of stunting and } \\
\text { underweight but was not significantly associated with } \\
\text { wasting. }\end{array}$ \\
\hline
\end{tabular}

AslingMonemi

et al., 2009

Ackerson \&

Subramanian,

2008

Sethuraman,

Lansdown \&

Sullivan, 2006

Rico, Fenn, Ambamsky \&

Watts, 2011

\section{Bangladesh}

Cut off point not mentioned

Cut off point not mentioned

Cut off point not mentioned

Egypt, $\quad$ Z-score $<-2$
Honduras,
Rwanda
Malawi
and Kenya

Exposure to any form of violence was negatively associated with weight and length at birth and weight-for-age and height-for-age SD scores at 24 months of age, as well as a change in weight and height SD score from birth to 24 months of age.

Children exposed to violence experienced high levels of malnourishment: 70 percent had anemia, over half were stunted 42.7 percent were wasted, 16.2 percent were underweight for age and 11.9 percent had low body mass index for age.

Maternal experience of psychological abuse and sexual coercion increased the risk of malnutrition in mothers and children.

For moderate child stunting, significance with IPV were only observed in Kenya if the mother was exposed to physical and sexual violence. In Kenya, severe stunting showed a stronger association with physical violence whereas in Honduras and Malawi, it was associated more with physical violence and 
sexual violence respectively.

Salazar,

Hogberg,

Valladeres \&

Persson, 2012
Nicaragua

Cut off point not mentioned

Sobkoviak,

Liberia

Yount \& Halim,

2012

Ziaei, Naved \&

Ekstrom, 2014

Bangladesh Cut off point not

mentioned
Maternal exposure to any IPV during pregnancy was associated with 0.24 lower mean height-for-age Zscores. A separate analysis of each IPV type showed that emotional, physical or sexual IPV during pregnancy were not significantly associated with lower mean height-for-age Z-scores, whereas ever exposure to controlling behavior by the father of the child was related to 0.29 lower mean height-for-age Z-scores. When stratified by gender, these associations remained significant only for young girl

Z-score 2 standard Maternal reports of sexual domestic violence in the deviations below prior year predicted lower adjusted z-scores for the median height-for-age and weight-for-height as well as higher odds of stunting and underweight

Women were more likely to have a stunted child if they had lifetime experience of physical IPV 


\section{References}

Clinical preventive services for women: Closing the gaps. (2011). Retrieved from https://iom.nationalacademies.org/Reports/2011/Clinical-Preventive-Services-forWomen-Closing-the-Gaps.aspx

Ackerson, L. K., \& Subramanian, S. V. (2008). Domestic violence and chronic malnutrition among women and children in India. American Journal of Epidemiology, 167(10), 1188-1196.

Alhusen JL, Lucea MB, Bullock L, \& Sharps P. (2013). Intimate partner violence, substance use, and adverse neonatal outcomes among urban women. Journal of Pediatrics, 163(2), 471-476.

Arcos, E., Uarac, M., \& Molina, I. (2003). The impact of domestic violence on children's health [in Spanish]. .131, 1454-1462.

Asling-Monemi, K., Naved, R. T., \& Persson, L. A. (2009). Violence against women and the risk of fetal and early childhood growth impairment: A cohort study in rural Bangladesh. Archives of Disease in Childhood, 94(10), 775-779.

Bair-Merritt, M. H., Johnson, S. B., Okelo, S., \& Page, G. (2012). Intimate partner violence exposure, salivary cortisol, and childhood asthma. Child Abuse \& Neglect, 36(7-8), 596-601. 
Baumgartner, R. N., Roche, A. F., \& Himes, J. H. (1986). Incremental growth tables: Supplementary to previously published charts. American Journal of Clinical Nutrition, 43(5), 711-722.

Beard, J. L., Hendricks, M. K., Perez, E. M., Murray-Kolb, L. E., Berg, A., VernonFeagans, L., ... Tomlinson, M. (2005). Maternal iron deficiency anemia affects postpartum emotions and cognition. Journal of Nutrition, 135(2), 267-272.

Black, M. M., Dubowitz, H., Krishnakumar, A., \& Starr, R. H. J. (2007). Early intervention and recovery among children with failure to thrive: Follow-up at age 8. Pediatrics, 120(1), 59-69.

Black, R. E., Allen, L. H., Bhutta, Z. A., Caulfield, L. E., de Onis, M., Ezzati, M., .. . Maternal and Child Undernutrition Study Group. (2008). Maternal and child undernutrition: Global and regional exposures and health consequences. Lancet, 371(9608), 243-260.

Boynton-Jarrett, R., Fargnoli, J., Suglia, S. F., Zuckerman, B., \& Wright, R. J. (2010). Association between maternal intimate partner violence and incident obesity in preschool-aged children: Results from the fragile families and child well-being study. Archives of Pediatrics \& Adolescent Medicine, 164(6), 540-546.

Breiding, M. J., \& Ziembroski, J. S. (2011). The relationship between intimate partner violence and children's asthma in 10 US states/territories. Pediatric Allergy \& Immunology, 22(1 Pt 2), e95-100. 
Busch, A. L., \& Lieberman, A. F. (2010). Mothers' adult attachment interview ratings predict preschool children's IQ following domestic violence exposure. Attachment \& Human Development, 12(6), 505-527.

Campbell, J., Jones, A. S., Dienemann, J., Kub, J., Schollenberger, J., O'Campo, P., . . . Wynne, C. (2002). Intimate partner violence and physical health consequences. Archives of Internal Medicine, 162(10), 1157-1163.

Caufield, L. E., Richard, S. A., Rivera, J. A., Musgrove, P., \& Black, R. E. (2006). Chapter 28: Stunting, wasting and macronutrient defieicency disorders. In D. T. Jameson, J. G. Breman \& A. R. Meshaum (Eds.), Disease control priorities in developing countries (2nd ed., ). Washington DC: International Bank for Reconstruction and Development.

Cerulli, C., Talbot, N. L., Tang, W., \& Chaudron, L. H. (2011). Co-occurring intimate partner violence and mental health diagnoses in perinatal women. Journal of Women's Health, 20(12), 1797-1803.

Chung, E. K., McCollum, K. F., Elo, I. T., Lee, H. J., \& Culhane, J. F. (2004). Maternal depressive symptoms and infant health practices among low-income women. Pediatrics, 113(6), e523-9. Retrieved from

Cummings, E. M., El-Sheikh, M., Kouros, C. D., \& Buckhalt, J. A. (2009). Children and violence: The role of children's regulation in the marital aggression-child adjustment link. Clinical Child \& Family Psychology Review, 12(1), 3-15. 
Davies, C. A., Evans, S. E., \& and DiLillo, D. K. (2008). Exposure to domestic violence: A meta-analysis of child and adolescent outcomes.13, 131-140.

de Onis, M., Siyam, A., Borghi, E., Onyango, A. W., Piwoz, E., \& Garza, C. (2011). Comparison of the world health organization growth velocity standards with existing US reference data. Pediatrics, 128(1), e18-26.

Deleuze Ntandou Bouzitou, G., Fayomi, B., \& Delisle, H. (2005). [Child malnutrition and maternal overweight in same households in poor urban areas of Benin]. [Malnutrition infantile et surpoids maternel dans des menages urbains pauvres au Benin.] Sante, 15(4), 263-270.

Doak, C. M., Adair, L. S., Bentley, M., Monteiro, C., \& Popkin, B. M. (2005). The dual burden household and the nutrition transition paradox. International Journal of Obesity, 29(1), 129-136.

Durand, J. G., Schraiber, L. B., Franca-Junior, I., \& Barros, C. (2011). Impact of exposure to intimate partner violence on children's behavior. Revista De Saude Publica, 45(2), 355-364.

Garoma, S., Fantahun, M., \& Worku, A. (2012). Maternal intimate partner violence victimization and under-five children mortality in western Ethiopia: A case-control study. Journal of Tropical Pediatrics, 58(6), 467-474. 
Gilbert, A. L., Bauer, N. S., Carroll, A. E., \& Downs, S. M. (2013). Child exposure to parental violence and psychological distress associated with delayed milestones. Pediatrics, 132(6), e1577-83.

Giroux, S. C. (2008). 2008. Child stunting across schooling and fertility transitions: Evidence from sub-saharan africa. (Demographic and Health Research Papers No. 57). Calverton, MD, USA: Macro International Inc.

Guo, S., Roche, A. F., Fomon, S. J., Nelson, S. E., Chumlea, W. C., Rogers, R. R., . . Siervogel, R. M. (1991). Reference data on gains in weight and length during the first two years of life. Journal of Pediatrics, 119, 355-362.

Gustafsson, H. C., Coffman, J. L., Harris, L. S., Langley, H. A., Ornstein, P. A., \& Cox, M. J. (2013). Intimate partner violence and children's memory. Journal of Family Psychology, 27(6), 937-944.

Hasselmann, M. H., \& Reichenheim, M. E. (2006). Parental violence and the occurrence of severe and acute malnutrition in childhood. Pediatric Perinatal Epidemiology, 20(4), 299-311.

Herrenkohl, T. I., Sousa, C., Tajima, E. A., Herrenkohl, R. C., \& Moylan, C. A. (2008). Intersection of child abuse and children's exposure to domestic violence. Trauma Violence \& Abuse, 9(2), 84-99.

Hockenberry, M. J., \& Wilson, D. (2015). Wong's nursing care of infants and children (10th ed.) Mosby. 
Holt, S., Buckley, H., \& Whelan, S. (2008). The impact of exposure to domestic violence on children and young people: A review of the literature. Child Abuse \& Neglect, 32(8), 797-810. doi:10.1016/j.chiabu.2008.02.004

Hungerford, A., Ogle, R. L., \& Clements, C. M. (2010). Children's exposure to intimate partner violence: Relations between parent-child concordance and children's adjustment. Violence \& Victims, 25(2), 185-201.

Kar, B. R., Rao, S. L., \& Chandramouli, B. A. (2008). Cognitive development in children with chronic protein energy malnutrition. Behavioral \& Brain Functions [Electronic Resource]: $B B F, 4,31$.

Krantz, G., Van Phuong, T., Larsson, V., Thi Bich Thuan, N., \& Ringsberg, K. C. (2005). Intimate partner violence: Forms, consequences and preparedness to act as perceived by healthcare staff and district and community leaders in a rural district in northern Vietnam. Public Health, 119(11), 1048-1055.

Kuhlman, K., Howell, K., \& Graham-Bermann, S. (2012). Physical health in preschool children exposed to intimate partner violence. Journal of Family Violence, 27(6), 499-510. doi:10.1007/s10896-012-9444-2

Lieberman, A. F., Van Horn, P., \& Ozer, E. J. (2005). Preschooler witnesses of marital violence: Predictors and mediators of child behavior problems. Development and Psychopathology, 17(2), 385-396. 
McDonald, R., Jouriles, E. N., \& Skopp, N. A. (2006). Reducing conduct problems among children brought to women's shelters: Intervention effects 24 months following termination of services. Journal of Family Psychology, 20(1), 127-136.

McNamee, R. (2005). Regression modelling and other methods to control confounding. Occupy Environ Med, 62, 500-506. doi:10.1136/oem.2002.001115

Moraes, C., L., Sd, Reichenheim, M., E., \& Lobato, G. (2011). Severe physical violence between intimate partners during pregnancy: A risk factor for early cessation of exclusive breast-feeding. Public Health Nutrition, 14(12), 2148-2155. doi:10.1017/S1368980011000802

Olsen, E. M. (2006). Failure to thrive: Still a problem of definition. Clinical Pediatrics, 45(1), 1-6.

Pasricha, S., \& Biggs, B. (2010). Undernutrition among children in south and south-east asia. Journal of Paediatrics \& Child Health, 46(9), 497-503.

Perez, E. M., Hendricks, M. K., Beard, J. L., Murray-Kolb, L. E., Berg, A., Tomlinson, M., . . Vernon-Feagans, L. (2005). Mother-infant interactions and infant development are altered by maternal iron deficiency anemia. Journal of Nutrition, 135(4), 850-855.

Rahman, M., Poudel, K. C., Yasuoka, J., Otsuka, K., Yoshikawa, K., \& Jimba, M. (2012). Maternal exposure to intimate partner violence and the risk of undernutrition 
among children younger than 5 years in Bangladesh. American Journal of Public Health, 102(7), 1336-1345.

Ramos, C. V., Dumith, S. C., \& César, J. A. (2015). Prevalence and factors associated with stunting and excess weight in children aged 0-5 years from the Brazilian semiarid region. Jornal De Pediatria, 91(2), 175-182.

Rhodes, K., Cerulli, C., Dichter, M., Kothari, C., \& Barg, F. (2010). "I didn't want to put them through that": The influence of children on victim decision-making in intimate partner violence cases. Journal of Family Violence, 25(5), 485-493. doi:10.1007/s10896-010-9310-z

Rico, E., Fenn, B., Abramsky, T., \& Watts, C. (2011). Associations between maternal experiences of intimate partner violence and child nutrition and mortality: Findings from demographic and health surveys in Egypt, Honduras, Kenya, Malawi and Rwanda. Journal of Epidemiology \& Community Health, 65(4), 360-367.

Roche, A. F., \& Himes, J. H. (1980). Incremental growth charts Journal of Clinical Nutrition, 33(9), 2014-2052.

Salazar, M., Hogberg, U., Valladares, E., \& Persson, L. A. (2012). Intimate partner violence and early child growth: A community-based cohort study in Nicaragua. BMC Pediatrics, 12, 82. 
Saltzman, K. M., Holden, G. W., \& Holahan, C. J. (2005). The psychobiology of children exposed to marital violence. Journal of Clinical Child \& Adolescent Psychology, 34(1), 129-139. doi:10.1207/s15374424jccp3401_12

Sethuraman, K., Lansdown, R., \& Sullivan, K. (2006). Women's empowerment and domestic violence: The role of sociocultural determinants in maternal and child undernutrition in tribal and rural communities in south India. Food \& Nutrition Bulletin, 27(2), 128-143.

Sobkoviak, R. M., Yount, K. M., \& Halim, N. (2012). Domestic violence and child nutrition in Liberia. Social Science \& Medicine, 74(2), 103-111.

Spilsbury, J. C., Kahana, S., Drotar, D., Creeden, R., Flannery, D. J., \& Friedman, S. (2008). Profiles of behavioral problems in children who witness domestic violence. Violence \& Victims, 23(1), 3-17.

Stettler, N., Bhatia, J., Parish, A., \& Stallings, V. A. (2015). Feeding healthy infants, children, and adolescents. . In R. M. Kliegman, R. E. Behrman, H. B. Jenson \& B. F. Stanton (Eds.), Nelson textbook of pediatrics (20th ed., ). Philadelphia, PA: Sunders Elsevier.

Steward, D. K., Ryan-Wenger, N. A., \& Boyne, L. J. (2003). Selection of growth parameters to define failure to thrive. Journal of Pediatric Nursing, 18(1), 52-59. 
Subramanian, S. V., Kawachi, I., \& Smith, G. D. (2007). Income inequality and the double burden of under- and overnutrition in India. Journal of Epidemiology \& Community Health, 61(9), 802-809.

Subramanian, S. V., Ackerson, L. K., Subramanyam, M. A., \& Wright, R. J. (2007). Domestic violence is associated with adult and childhood asthma prevalence in India. International Journal of Epidemiology, 36(3), 569-579.

Suglia, S. F., Duarte, C. S., Sandel, M. T., \& Wright, R. J. (2010). Social and environmental stressors in the home and childhood asthma. Journal of Epidemiology \& Community Health, 64(7), 636-642.

Suglia, S. F., Enlow, M. B., Kullowatz, A., \& Wright, R. J. (2009). Maternal intimate partner violence and increased asthma incidence in children: Buffering effects of supportive caregiving. Archives of Pediatrics \& Adolescent Medicine, 163(3), 244250.

Tanner, J. M. (1952). The assessment of growth and development in children. Archives of Disease in Childhood, 27(131), 10-33.

Wang, Y., \& Chen, H. (2012). Use of pecentiles and Z-scores in anthropometry. In V. R. Preedy (Ed.), Handbook of anthropometry: Physical measures 29 of human form in health and disease (pp. 29-42) Springer Science+Business Media. doi:DOI 10.1007/978-1-4419-1788-1_2, 
Ziaei, S., Naved, R. T., \& Ekstrom, E. (2014). Women's exposure to intimate partner violence and child malnutrition: Findings from demographic and health surveys in Bangladesh. Maternal \& Child Nutrition, 10(3), 347-359. 


\section{CHAPTER 3: METHODOLOGY}

This is a quantitative longitudinal study that follows mothers and infants for a period from pregnancy up to 24 months post delivery. The overall objective for this study is to determine whether maternal exposure or non-exposure to intimate partner violence (IPV) is associated with potential development of failure to thrive (FTT) in children and whether these associations are modified by maternal and child characteristics.

\section{Data}

Existing data from R01 NR 05313 Nursing Smoking Cessation Intervention during pregnancy (Baby BEEP) and R01 HD0045542 Nursing support: Better infant outcomes in violent homes (BBK) were utilized in this study. Participants in Baby BEEP program were pregnant, low-income women recruited from Women, Infant, and Children (WIC) Nutrition Supplement Program clinics in 21 rural counties in Missouri. WIC target population is low-income and nutritionally at risk such as: pregnant women, breastfeeding women (up to infant's 1st birthday), non-breastfeeding postpartum women (up to 6 months after the birth of an infant or after pregnancy ends) and infants. WIC's mission is to safeguard the health of low-income women, infants, and children up to age 5 who are at nutrition risk by providing nutritious foods to supplement diets, information on healthy eating, and referrals to health care. WIC is effective in improving the health of pregnant women, new mothers, and their infants. A 1990 study showed that women who participated in the program during their pregnancies had lower Medicaid costs for themselves and their babies than did women who did not participate. WIC participation was also linked with longer gestation periods, higher birth weights and lower infant 
mortality (http://www.fns.usda.gov/wic/about-wic-wics-mission). Trained nurses interviewed the mother to obtain demographic information, information about the child and took weight and height measurements of the child at 5-11, 12-18 and 19-26 months. Mothers and infants in the BBK study were drawn from Baby BEEP study.

\section{Instruments and their Psychometric properties}

\section{Demographic Information Form (DIF)}

The study team developed a demographic questionnaire for the purpose of collecting general health and personal information from each participant. Information collected at baseline (during pregnancy) included, but was not limited to, the following: baby's date of birth (month/day/year); mother's ethnicity number of times a mother has been pregnant, marital status and mother's age. Maternal demographic data was derived from the Baby BEEP data set, and the child's data from the BBK study. Completion time for demographic items was less than 5 minutes.

\section{Age-Appropriate Weight and Recumbent Length}

Weight and recumbent length was taken and recorded by the research nurse on the standard length for weight charts. Recumbent length mat device was used to measure infant's recumbent length in inches by holding the child's head midline and flat against the headboard. Infant's knees were then pressed down until the legs are fully extended and the feet were firmly against the footboard. Recumbent length was recorded in fraction of inches. The Visiting Nurse Scale was used to measure infant weight. The scale measures infants up to 45 pounds (SR scales, 2011). To weigh the child, the nurse placed a nude child in a lying or sitting position. Weight was recorded in pounds and ounces. 


\section{Abuse Assessment Screen (AAS)}

The Abuse Assessment Screen was developed by the Nursing Research Consortium on Violence and Abuse to assess for the presence of abuse in pregnant and non-pregnant women (McFarlane et al., 1992). The instrument measures past and present instances of physical and sexual abuse, as well as who was the perpetrator and location of the physical abuse. The instrument was intended to assess for violence by being straightforward and direct, providing the potential for more accurate identification of abuse through ease of administration (McFarlane et al., 1992).

Scoring. The AAS consists of five items that assess the presence (yes or no) over time (current, ever, last year, during pregnancy), perpetrator (husband, ex-husband, boyfriend, stranger, other, multiple). One question assesses whether the abuse was sexual and one question assesses whether the respondent is currently afraid of any potential perpetrators. Positive responses to questions two, three or four are considered positive for abuse.

Administration. The administration time for the AAS is less than five minutes.

The instrument has been used effectively in populations with educational levels less than or equal to high school equivalency. Compliance for the instrument is high, but may vary depending upon the setting in which the instrument is administered. It is essential that the instrument be administered in a private and confidential manner to optimize reliability and validity (McFarlane et al., 1992).

Psychometric testing. Psychometric testing for the AAS began in 1992 and continued through 2004 (McFarlane et al., 1992; Reichenheim \& Moraes, 2004). Reliability and 
validity for the AAS was examined in low-income pregnant women of Latina, AfricanAmerican and Caucasian ethnicities $(n=1,203)$ using a test-retest approach and hypothesis testing. When compared with the other standardized assessments of abuse, the AAS showed internal consistencies of 0.79 with Conflict Tactic Scale (CTS), 0.93 with Index of Spouse Abuse (ISA) and 0.84 with Danger Assessment (DA). Reliability was assessed using test-retest methods with two samples of 40 women, with agreement in one sample reaching $83 \%$ and in the other $100 \%$. (McFarlane et al., 1992). To establish a criterion-related validity, a hypothesis about the instrument's validity in identifying the presence, severity, frequency and ability to detect abuse during pregnancy were tested and found adequate when compared with the CTS, ISA and DA. Investigation of the AAS in international settings has identified the need for continued psychometric testing (Reichenheim \& Moraes, 2004). Overall, the AAS has been widely used and accepted over the past two decades as an accurate measure of abuse, especially in identifying the prevalence of instances of severe abuse (Reichenheim \& Moraes, 2004). Feasibility for the AAS has been established for low-income, diverse, pregnant populations through its administration among a variety of samples (Bullock et al., 2009a; McFarlane et al., 1992; Norton, Peirpert, Zierler, Lima, \& Hume, 1995; Reichenheim \& Moraes, 2004). Reliability for the AAS has exceeded the standard level designated by Nunnally and Berstein (1994) of 0.70. Because it measures data at a nominal level, cut off values for the instrument are not required. For this study, positive responses to questions two, three or four are considered positive for abuse.

\section{Mental Health Inventory-5 (MHI-5)}

The MHI-5 was initially part of the short form health survey (SF-36 Health 
Survey) (Ware \& Gandek, 1998; Ware \& Gandek, 1994). This survey was designed as a multidimensional measure of general health status with eight subscales that make up a physical and mental health summary. As measured by the SF-36, the physical component of health is comprised of physical functioning, role-physical, bodily pain and general health. The mental component is comprised of vitality, social functioning, and emotional and mental health. The MHI-5 is the subscale for mental health in the SF-36. The SF- 36 has undergone extensive psychometric evaluation through the International Quality of Life Assessment (IQOLA) Project, undertaken by Ware and Gandek $(1994,1998)$ to justify and systematically oversee the translation of the SF-36 for international use.

Scoring. The MHI-5 consists of five items that evaluate the subject's mood through a 5point Likert scale. A total scale score is obtained by summation of all the items and multiplying by four. The level of measurement is interval level, but can be dichotomized into risk for mood or anxiety disorders, with scores under 65 having a sensitivity of 0.87 and specificity of 0.70 for detecting mood disorders (Rumpf, Meyer, Hapke, \& John, 2001). The possible range of scores is $0-100$, with higher scores indicating better mental health.

Administration. The administration time for the MHI-5 is under five minutes.

The instrument has been used since 1991 in a variety of populations with no known reports of difficulty understanding either the instructions or items (Ware \& Gandek, 1998)

Psychometric testing: Psychometric testing for the SF-36 was guided by the standards of the American Psychological Association. Reliability for the MHI-5 has been examined in 
over 20 patient groups with varying diagnoses and levels of socio-demographic characteristics. In all cases, reliability coefficients have been greater than 0.70 or 0.80 (Berwick et al., 1991). Content validity has been established empirically through the systematic comparison of the SF-36 subscales to other measures of general health and health concepts. When compared with other measures of health status in the U.K., U.S. and Sweden, the SF-36 subscales were able to explain two-thirds of the total variance in scores. Construct validity has been demonstrated with factor analysis in a variety of countries and populations, including the U.S. general population. This indicates that the two summary scales, mental and physical health, account for $80-85 \%$ of the variance in the eight subscales, including the MHI-5. Additionally, the item-to-total correlations have been shown to be 0.04 or greater. Criterion-related validity for the MHI-5 has been established as it has been measured against actual DSM-IV Axis I diagnoses of mood and anxiety disorders and Diagnostic Interview Schedule disorders in the general population (Berwick et al., 1991; Rumpf et al., 2001; Ware \& Gandek, 1998).

Feasibility for the low-income, rural population has been established as the instrument has been administered to a variety of populations, including those with sociodemographic diversity. Reliability for the MHI-5 has exceeded the standard level of 0.70 as designated by Nunnallly and Berstein (Nunnally \& Bernstein, 1994). Norms for the MHI-5 have been established in the U.S. general population with a mean of 74.7 (SD 18.1) (Ware \& Gandek, 1998). Cut off values predictive of mood or anxiety disorders for the scale vary, depending on desired sensitivity and specificity. For the purposes of this study to detect maternal depression, a cut off value of 60 points or less is chosen. This has a sensitivity of 0.83 and specificity of 0.78 in detecting DSMIV Axis I mood 
disorders (Rumpf et al., 2001).

\section{Parenting Stress Index Short form (PSI-SF)}

The PSI-SF was developed based on factor analysis of the Parenting Stress Index (PSI) (Abidin, 1995). This version was developed in response to clinicians' and researchers' need for a shorter measure of parenting stress and was based on Castaldi's factor analysis of the original PSI (Castaldi, 1990). The PSI-SF is a self-report instrument that measures stress directly associated with the parenting role. It has three domains: Parent Distress, Difficult Child, and Parent-Child Dysfunctional Interaction. The Parent Distress subscale measures distress parents feel about their parenting role in light of other personal stresses. The Difficult Child subscale represents behaviors that children often engage in that may make parenting easier or more difficult (this subscales will be used for this study). Parent- Child Dysfunctional Interaction subscale focuses on the degree to which the child is reinforcing to the parent and the degree to which the child meets the parent's expectations. The PSI-SF targets Parents of children ages 12 years and below (Abidin, 1995).

Scoring: The PSI-SF consists of 36 statements, and parents respond to each statement using a 5-point scale to indicate the degree to which that item has been disturbing to them in the past week. It yields a total stress score plus parent domain subscales scores for depression, attachment, role restriction, competence, isolation, spouse, and health. Child domain subscale scores include adaptability, acceptability, demandingness, mood, distractibility/ hyperactivity, and reinforces parent. The raw score is converted to percentiles scores. For each sub-scale, a score that falls between the 15 th and 80 th percentile is considered typical. High scores are those at or above the $85^{\text {th }}$ percentile 
Administration: PSI-SF takes less than 20 minutes for parents to complete and requires 5th grade reading level. There have been more than 200 studies using the PSI-SF available with no known reports of difficulty understanding either the instructions or items.

Psychometric testing: The PSI-SF is the most widely used measure of parenting stress in psychological research. The PSI has been validated with diverse populations and has been normed on more than 2,500 parents. Reliability and Validity: The coefficient alpha reliability coefficients for the total stress score were 0.90 or greater; for the Child Domain the coefficient alpha ranged from 0.70 to 0.84 and the Parent Domain from 0.70 to 0.84 . Test-retest reliability of the PSI-SF was calculated in a sample of 800 parents over a 6month retest interval. The coefficient alpha was reported at 0.85 for Parent Distress, 0.68 for Parent-Child Dysfunctional Interaction, 0.78 for Difficult Child and 0.84 for Total Stress (Abidin, 1995). In another study of 196 preschool children aged three to five and their mothers, the following internal consistencies were obtained: parental distress, 0.88 ; parent-child dysfunctional interaction, 0.88; difficult child, 0.89; and total stress, 0.95 (Reitman, Currier, \& Stickle, 2002). The criterion validity of the PSI/SF was established by correlations with the PSI. Total Stress on the PSI correlated 0.94 with the PSI-SF. The Parent Distress scale correlated 0.73 and 0.50 with the Child Domain and the Parent Domain on the PSI. The Difficult Child Subscale correlated with the Child Domain on the PSI $(r=0.87)$ (Abidin, 1995). In terms of discriminant validity, a study conducted by Deater-Deckard and Scarrs of 185 married fathers and mothers showed difficult child subscales were more strongly associated with parent's report of labiality and misbehavior than measures of marital dissatisfaction and spousal support (Deater-Deckard, Pinkerton, 
\& Scarr, 1996). Overall the PSI-SF has strong psychometric properties, with an internal consistency reliability coefficient of .91 and 6-month test- retest reliability coefficient of .84 (Haskett, Scott, Willoughby, \& Nears, 2006) and has exceeded the standard level designated by Nunnally and Berstein (1994) of 0.70. Child difficult domain will be used for this study. A difficult child will be ranked at $85^{\text {th }}$ percentile and above.

Severity of Violence Against Women Scale (SVAWS): The SVAWS is a 46-item questionnaire designed to measure two major dimensions: behaviors that threaten physical violence and actual physical violence (Marshall, 1992). Examples of behaviors that threaten physical violence include, "Does the person threaten to destroy property, hurt you, or kill himself or herself?" Examples of behaviors that represent actual physical violence are "kicked, choked, burned, beat up." Included are nine factors or subscales that have been demonstrated valid through factor analytic techniques: symbolic violence and mild, moderate, and serious threats (threats of violence dimension); and mild, minor, moderate, serious, and sexual violence (actual violence dimension).

Scoring: For each behavior, the woman responds using a 4-point scale to indicate how often the behavior occurred (i.e., $1=$ never, $2=$ once, $3=$ few times, $4=$ many times). Scores are calculated by assigning weights (mean severity score for aggressiveness threat and violence) to each of the items. Weights are multiplied by the frequency given for the item and summed to yield a score for each dimension. Values can also be added to produce single scores for each of the two dimensions. Point values given in response to each item in the subscale are summed to create the subscale score. Higher score are indicative of greater abuse. 
Administration: The SVAWS is estimated to take 10-15 minutes to complete.

Psychometric testing: Initial internal consistency reliability estimates (coefficient alpha) reported by Marshal (1992) ranged from .92 to .96 for a sample of 707 college female students and from .89 to .96 for a sample of 208 community women. A study conducted to examine complex posttraumatic stress symptoms among a community sample of battered women found coefficient factors for the whole scale ranged from .92 to .99 (Kerry, 2007). Another study found the reliability (coefficient alpha) to be .92 for the threats of violence dimension and .97 for the actual violence dimension (McFarlane, Willson, Malecha, \& Lemmey, 2000). Dutton et al, found significant correlates between women abused on the SVAWS and their partners report on abuse according to the propensity of abuse scale providing evidence for the validity of SVAW. For this study the overall scale will be used with the following sub scales: Severity of violence and type of violence.

The variables, their concept and level of measurement are shown in Table 1 below.

Table 1: Study variables their concepts and operational definition

\begin{tabular}{|c|l|l|l|l|}
\hline \multicolumn{2}{|c|}{ Independent variable } \\
\hline Concept & Variable & $\begin{array}{l}\text { Operational } \\
\text { definition }\end{array}$ & Measure/Values & Instrument \\
\hline $\begin{array}{c}\text { Abuse during } \\
\text { pregnancy }\end{array}$ & Abuse & $\begin{array}{c}\text { Presence/absence of } \\
\text { abuse during } \\
\text { pregnancy }\end{array}$ & $\begin{array}{c}\text { Categorical } \\
0 . \text { No } \\
1 . \text { Yes }\end{array}$ & AAS \\
\hline $\begin{array}{c}\text { Follow up IPV after } \\
\text { birth of child }\end{array}$ & Follow up IPV & $\begin{array}{c}\text { Presence/absence of } \\
\text { follow up IPV after } \\
\text { the birth of index } \\
\text { child }\end{array}$ & $\begin{array}{c}\text { Categorical } \\
0 \text { No } \\
1 . \text { Yes }\end{array}$ & SVAWS \\
\hline
\end{tabular}




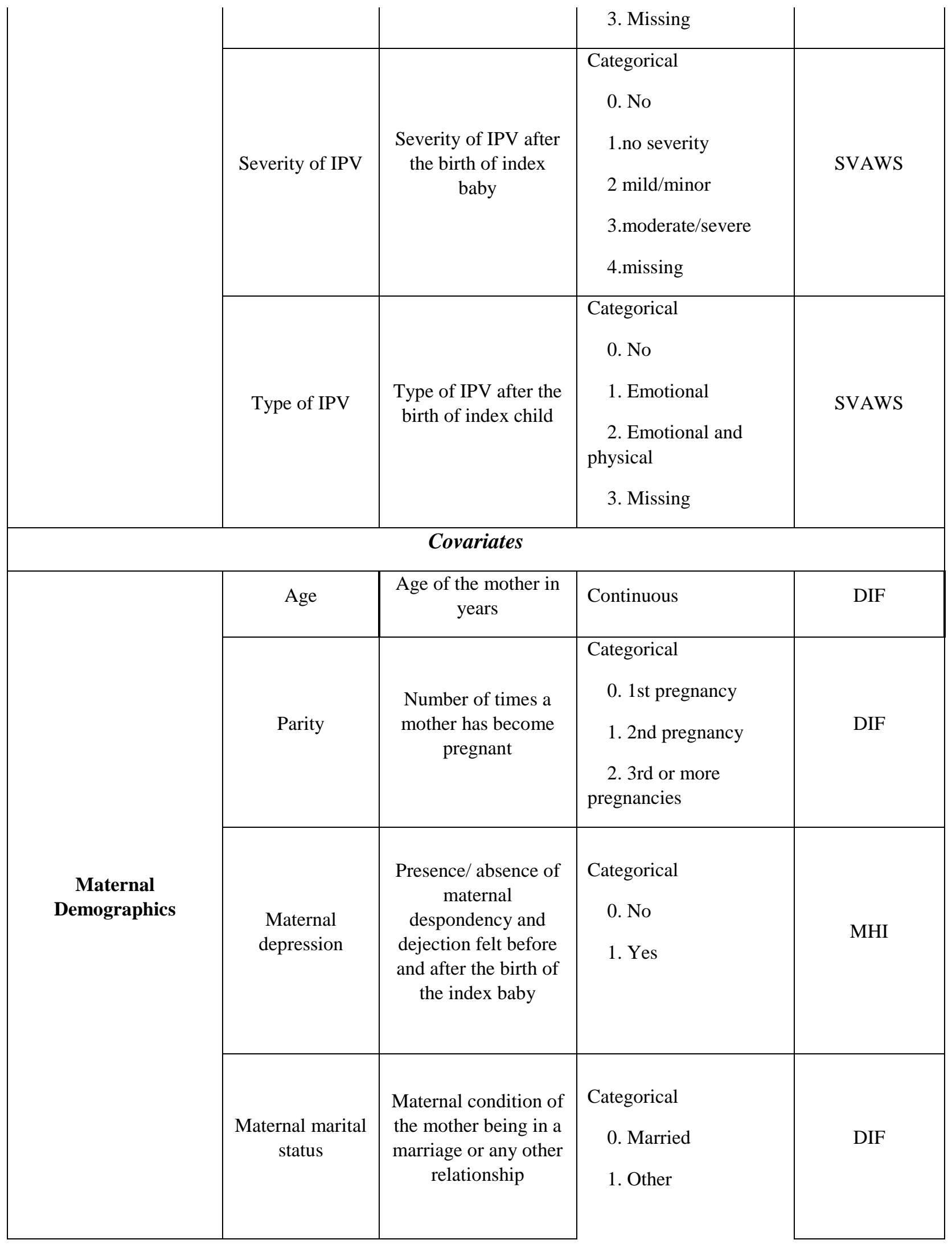




\begin{tabular}{|c|c|c|c|c|}
\hline \multirow{5}{*}{ Child demographics } & Age & Child age in months & Continuous & DIF \\
\hline & Weight & $\begin{array}{l}\text { Childs weight in } \\
\text { kilograms }\end{array}$ & Continuous & Weighing scale \\
\hline & Height & $\begin{array}{l}\text { Child's height in } \\
\text { centimeters }\end{array}$ & Continuous & Tape measure \\
\hline & $\begin{array}{l}\text { Breastfeeding } \\
\text { status }\end{array}$ & $\begin{array}{l}\text { Whether the child } \\
\text { was breastfed or not }\end{array}$ & $\begin{array}{c}\text { Categorical } \\
\text { 0. No } \\
\text { 1. Yes }\end{array}$ & DIF \\
\hline & $\begin{array}{l}\text { Child difficult } \\
\text { scores }\end{array}$ & $\begin{array}{l}\text { How easy or difficult } \\
\text { the Parent perceives } \\
\text { their child }\end{array}$ & $\begin{array}{l}\text { Categorical } \\
\text { 0. Not difficult } \\
\text { 1. Difficult } \\
\text { 2. Missing }\end{array}$ & PSI-SF \\
\hline \multicolumn{5}{|c|}{ Dependent variable } \\
\hline \multirow{2}{*}{ Failure to thrive } & $\begin{array}{l}\text { Weight-for- } \\
\text { height/length Z- } \\
\text { score (WHZ) }\end{array}$ & $\begin{array}{l}\text { Compounded weight } \\
\text { and height compared } \\
\text { to the general } \\
\text { population }\end{array}$ & Continuous & $\begin{array}{c}\text { WHO } \\
\text { anthropometric } \\
\text { calculator }\end{array}$ \\
\hline & $\begin{array}{l}\text { Height-for-age } \\
\text { Z- score (HAZ) }\end{array}$ & $\begin{array}{l}\text { Compounded height } \\
\text { and age compared to } \\
\text { the general } \\
\text { population }\end{array}$ & Continuous & $\begin{array}{c}\text { WHO } \\
\text { anthropometric } \\
\text { calculator }\end{array}$ \\
\hline
\end{tabular}

\section{Procedures}

Data cleaning and reorganization: Baseline data: maternal age, prenatal abuse, marital status, parity, baseline depression and race were obtained from the Baby BEEP data. For prenatal depression the last score before the birth of the child was utilized. Abuse was assessed using AAS, which was administered three times and the final score was used. The child's, birth date and birth weight and height were also obtained from the 
post-partum (4 - 6 weeks post-delivery) Baby BEEP interview. Follow up depression and violence; child's weight and height, difficult child scores and breastfeeding status were obtained from BBK data at each of the three time points (5-11, 12-18 and 19-24 months). Weight and height were converted from pounds and inches to kilograms and centimeters respectively. These variables were checked for completeness and accuracy. Those children that did not have weight or height at any of the three time points were excluded. Child's age was calculated in exact month and days.

Interpolation: Measurements taken within 15 days of the designated visit month (i.e., $6,15,24)$ were kept for analysis. Those beyond \pm 15 days were interpolated to align to the designated month. For interpolation, the measurements available within \pm 2 months of the designated month are used to get the value in the designated month. Those that have a measurement greater than \pm 2 were considered missing. The rationale for imputing was to have one time point for each child for comparison purpose as opposed to having a range of months. Rationale for keeping \pm 15 days of the designated month is because the average weight gained by males aged between 6-9 months in 15 days is 180 grams, while that of females is 150 grams. Both sexes aged between 9-24 months gain approximately 120 grams in 15 days. On height, infants between 0-12 months will gain $25 \mathrm{~cm}(2.083 \mathrm{~cm}$ a month; $1.042 \mathrm{~cm}$ in 15 days $)$ and $10 \mathrm{~cm}$ between $12-24$ months $(0.833$ cm a month and 0.416 in 15 days) (Danner, Joeckel, Michalak, Phillips, \& Goday, 2009; Hockenberry \& Wilson, 2015). Thus \pm 15 days measurement will not have significant difference with the weight/height taken at the exact month $(6,15,24)$.

\section{Z-scores: World Health Organization Anthropometric calculator (WHO} ANTHRO 2011) was used to convert weight and height measurements into weight-for- 
height and height-for-age Z-scores. Weight-for height Z-score was used to evaluate nutritional status (wasting/overweight) while height-for-age index was used to evaluate linear growth (stunting).

\section{Sample size}

The Baby BEEP had a sample of 695 participants, with 631 resulting in live births; about 50\% (325) of these participants were enrolled in the BBK study (this study will be based on the BKK study), however 20 participants were excluded because they had premature infant or death of the infant. There were 304 dyads between $5-11$ months, 12 were excluded because the child's birth length was less than $45 \mathrm{~cm}$ and thus a Z-score could not be calculated for them, 26 were excluded because they did not have a value for weight or height and 30 were excluded after interpolation, the final sample size at six after interpolation was 236 dyads. There were 279 dyads between 12-18 months, 12 were excluded because the child's birth length was less than $45 \mathrm{~cm}$ and thus a Z-score could not be calculated for them, 15 were excluded because they have missing value for weight or height measure, 26 were lost during interpolation and 12 were excluded because they did not have baseline measurement. The final sample size for 15 months after interpolation was 208 dyads. There were 255 dyads between 19-24 months, 12 were excluded because their birth length was less than $45 \mathrm{~cm}$ and thus a Z-score could not be calculated for them, 8 were excluded because the child was older than 24.5 months, 10 had either weight or height missing and 18 were lost during interpolation. The final sample size at 24 months after interpolation was 207. 


\section{Data analysis}

The Statistical Package for Social Sciences (Version 23; SPSS Inc., Chicago, IL) was used to analyze the data. Univariate and multivariate linear regression was used to assess the association between maternal abuse status (abused/not abused), presence of follow up violence, type and severity of follow up violence maternal follow up depression and difficult child scores and weight-for-age and height-for-age Z-scores. In addition, both univariate and multivariate analyses are stratified by the child's gender. Frequency and percentages are reported for categorical variables, while means and standard deviation are reported for continuous variables. Coefficients and standard error is reported for both univariate and multivariate linear regression. A p value of less than 0.05 is considered significant for student's t test, Chi square, univariate and multivariate analyses. Only 24 months analysis will be reported in this study. This is because the 6 months data has a big number of follow up violence missing and does not also have difficult child score. Preliminary analysis did not show any major significance in 15 months data compared to 24 months

\section{Validity}

Validity and trustworthiness of the study was enhanced through the following methods. First, availability of the restructured data sets, and codebook, explanation of the process and procedures used and the analysis allows for the replication of the process by other researchers to verify and validate findings. Second, the researcher checked and rechecked and assessed data for accuracy. Whenever there was a doubt, the hard copies 
of the data were accessed and used for verification.

\section{Limitations}

Limitations encountered using this data was related to missing values.

Length/height had some missing values. Without length/height, a Z-score, which was a major outcome for this study, could not be calculated. IPV scores and difficult child scores were also missing in 5-11 months. Because of the missing values, analysis for this time period was omitted.

\section{Ethics}

Federal regulations require that all research involving human subjects at the University of Virginia undergoes review by the University's Institutional Review Board (IRB). In accordance with this policy, this study was submitted to Social and Behavioral Sciences IRB for review and was classified as "exempt" by the IRB. In accordance with IRB policy, this research must be conducted within four years from review date, which was March 14, 2014. The data was de-identified to provide further protection to human subjects and preserve the anonymity of the participants. 


\section{References}

Abidin, R. R. (Ed.). (1995). Parenting stress index: Professional manual. (3rd ed. ed.). Odessa, FL: Psychological Assessment Resources, Inc.

Berwick, D. M., Murphy, J. M., Goldman, P. A., Ware, J. E. J., Barsky, A. J., \& Weinstein, M. C. (1991). Performance of a five-item mental health screening test. Medical Care, 29(2), 169-176.

Bullock, L., Everet, D. K., Mullen, P. A., Geden, E., Longo, R. D., \& Madsen, R. (2009). Baby BEEP: A randomized control trial of nurses' individualized social support for rural pregnant smokers. Matern.Child Health J., 13(3), 395-406.

Castaldi, J. (1990). Affective and cognitive patterns in the mother-child relationship during the second year of life. (Unpublished $\mathrm{PhD}$ ). University of Virginia, Charlottesville.

Danner, E., Joeckel, R., Michalak, S., Phillips, S., \& Goday, P. S. (2009). Weight velocity in infants and children. Nutrition in Clinical Practice, 24(1), 76-79.

Deater-Deckard, k., Pinkerton, R., \& Scarr, S. (1996). Child care quality and children's behavioral adjustment: A four-year longitudinal study. Journal of Child Psychology \& Psychiatry \& Allied Disciplines, 38(8), 937-48. 
Haskett, M., Scott, S., Willoughby, L., \& Nears, K. (2006). The parent opinion questionnaire and child vignettes for use with abusive parents: Assessment of psychometric properties. Journal of Family Violence, 21, 137-151.

Hockenberry, M. J., \& Wilson, D. (2015). Wong's nursing care of infants and children (10th ed.) Mosby.

Kerry, L. L. (2007). Complex posttraumatic stress symptoms among A community sample of battered women. (Unpublished PHD). Michigan State University, Michigan.

Marshall, L. L. (1992). Development of the severity of violence against women scales. Journal of Family Violence, 7, 103-121.

McFarlane, J., Parker, B., Soeken, K., \& Bullock, L. (1992). Assessing for abuse during pregnancy. severity and frequency of injuries and associated entry into prenatal care. JAMA, 267(23), 3176-3178.

McFarlane, J., Willson, P., Malecha, A., \& Lemmey, D. (2000). Intimate partner violence A gender comparison. Journal of Interpersonal Violence, 15(2), 158-169.

Norton, L., Peirpert, J. F., Zierler, S., Lima, B., \& Hume, L. (1995). Battering in pregnancy: An assessment of two screening methods. Obstetrics \& Gynecology, $85(3), 321-325$.

Nunnally, J., \& Bernstein, I. (Eds.). (1994). Psychometric theory (3rd ed.). New York: McGraw Hill. 
Reichenheim, M. E., \& Moraes, C. L. (2004). Comparison between the abuse assessment screen and the revised conflict tactics scales for measuring physical violence during pregnancy. Journal of Epidemiology \& Community Health, 58(6), 523-527.

Reitman, D., Currier, R. O., \& Stickle, T. R. (2002). A critical evaluation of the parenting stress index-short form (PSI-SF) in a head start population. Journal of Clinical Child \& Adolescent Psychology, 31(3), 384-392.

Rumpf, H. J., Meyer, C., Hapke, U., \& John, U. (2001). Screening for mental health: Validity of the MHI-5 using DSM-IV axis I psychiatric disorders as gold standard. Psychiatry Research, 105(3), 243-253.

Ware, J. E., \& Gandek, B. (1998). Overview of the SF-36 health survey and the international quality of life assessment (IQOLA) project. Journal of Clinical Epidemiology, 51(11), 903-912.

Ware, J. E., \& Gandek, B. (1994). The SF-36 health survey: Development and use in mental health research and the IQOLA project. International Journal of Mental Health, 23(2), 49-73. doi:10.1080/00207411.1994.11449283 


\title{
CHAPTER FOUR: FINDINGS (Manuscript 2)
}

\section{Maternal and child characteristics that influence child growth}

\begin{abstract}
Aim: The aim for this study was twofold, to describe maternal and child characteristics, child's mean weight-for-height (WHZ) and height-for-age (HAZ) Z-scores in those exposed to IPV and those not exposed. The second aim was to describe the relationship between maternal characteristics and child characteristics and subsequent child growth.
\end{abstract}

Methods: Anthropometric data were collected from 207 children at birth, between 5-11, 12-18 and 19-24. These data were interpolated to align with 6, 15 and 24 months of age, which were the months of interest. Weight and height were converted to WHO growth standard SD scores (WHZ and HAZ). Z-scores at birth and at 24 months were assessed in relation to women's exposure status (exposed/not exposed) prenatally. Linear regression was used to assess the association between baseline variable and postnatal variables and WHZ and HAZ.

Results: Overall, there was no difference in maternal prenatal abuse status and WHZ and HAZ scores. Although not significant, there were 118 women with symptoms of depression prenatally, out of these 70 were not exposed to prenatal abuse. There was an association between male children and their birth order $(\mathrm{p}=0.023)$, prenatal depression $(\mathrm{p}=0.021)$, breastfeeding status $(\mathrm{p}=0.034)$ and postnatal depression $(\mathrm{p}=0.049)$ and WHZ. There was an association between postnatal violence $(\mathrm{p}=0.030)$ specifically emotional violence (0.050) and HAZ score. An association between female children who were 
breastfed $(\mathrm{p}=0.011)$ and whose mothers were not in a marriage relationship (0.009) and HAZ was also seen.

Conclusion: Overall maternal exposure to pre and postnatal depression, breastfeeding status and being a second child affected boys more than it did girls in relation to WHZ. Because of the homogeneous nature of the data used for this study, it is not possible to infer these findings to the general population. These findings set the stage for conducting future studies with a more diverse sample.

Key words: Abuse, weight-for-height (WHZ) and height-for-age (HAZ) 


\section{Background}

Intimate partner violence (IPV) includes physical, sexual, emotional abuse and controlling behaviors by an intimate partner. Intimate partner violence occurs in all settings and among all socio economic, religious and cultural groups (Breiding, Smith, Basile, Walters, Chen, \& Merrick, 2011). Although women can be violent in relationships with men often in self-defense, the overwhelming global burden of IPV is borne by women (Breiding et al., 2011). The most recent United States (U.S) data, from the 2011 National Intimate Partner and Sexual Violence Survey (NISVS), indicate that over 10 million women in the United States experience physical violence each year by a current or former intimate partner. Further, over 1 in 5 women $(22.3 \%)$ have experienced severe physical violence by an intimate partner at some point in their lifetime, translating to nearly 29 million U.S. women (Breiding et al, 2011).

Intimate partner violence has lifelong consequences. Studies have shown that beyond injury and even death, victims of IPV are more likely to report a range of negative mental and physical health outcomes that are acute and chronic in nature (Black, 2011; Breiding, Black \&Ryan, 2008). Current research suggests that the influence of abuse can persist long after the violence has stopped. The more severe the abuse, the greater its impact on a woman's physical and mental health, and the impact over time of different types and multiple episodes of abuse appears to be cumulative (Heise \& Gracia Moreno, 2002).

\section{Violence during pregnancy}

Studies have found substantial levels of physical IPV during pregnancy in settings 
around the world. A review of studies from 19 countries found prevalence ranging from $2 \%$ in settings such as Australia, Denmark and Cambodia, to $13.5 \%$ in Uganda, with the majority ranging between $4 \%$ and $9 \%$ (Devries et al., 2010). Violence during pregnancy has been associated with miscarriage, late entry into the prenatal care, stillbirth, premature labor fetal injury and low birth weight or small for gestational age infants (Devries et al., 2010)

\section{Intimate partner Violence effect on Children}

Studies have found an association between IPV against women and negative social and health consequences for children, including anxiety, depression, poor school performance and negative health outcomes (Black et al., 2008)Two studies from Nicaragua and Bangladesh found that children who are exposed to violence are less likely to be immunized, are at high risk of diarrheal diseases and are most likely to die before the age of 5 years (Asling-Monemi et al., 2009; Silverman et al., 2009).

Impaired growth is an important health determinant in children and has been associated with higher morbidity and mortality in children less than 5 years of age (Black et al., 2008). Different forms of violence have been shown to impair the growth of children in diverse countries specially the low-income countries. An example is one Indian cross sectional study that reported a relationship between IPV and child stunting, wasting and severe under nutrition(Ackerson \& Subramanian, 2009). Additionally, a case study conducted in Brazil found that severe physical partner abuse in the previous 12 months increased the risk of severe malnutrition in children age one to 24 months (Hasselmann \& Reichenheim, 2006). A community based cohort study in Bangladesh found that exposure to IPV was associated with lower weight-for-height (WHZ), weight- 
for-age (WAZ) and height-for-age (HAZ) Z scores at birth and at 24 months especially in boys (Asling-Monemi et al., 2009). Few longitudinal studies have been conducted to analyze the effect of IPV and child growth and little is known about IPV and child growth in the United States.

\section{Conceptual Framework}

Child growth and survival can be determined by an intersection between social, economic, environmental and individual factors that interact in several ways to create different pathways affecting the child's and the child's mother's health which in turn will affect the growth of the child (Yount, DiGirolamo, \& Ramakrishnan, 2011). Yount et al., 2011, identified several pathways in which IPV can impair early child growth in a landmark review of 31 articles from around the world. The pathway of interest for this study is the domestic violence-child stress-responsive biological regulatory systems, which suggest that violence exposure in utero and during infancy may dysregulate a child's stress-responsive systems thereby impairing growth and nutrition through the toddler years. (Yount et al., 2011) (Figure 1). 
Fig1 Pathways linking children exposure to domestic violence (CEDV) to growth and nutrition in utero and early childhood conceptual framework

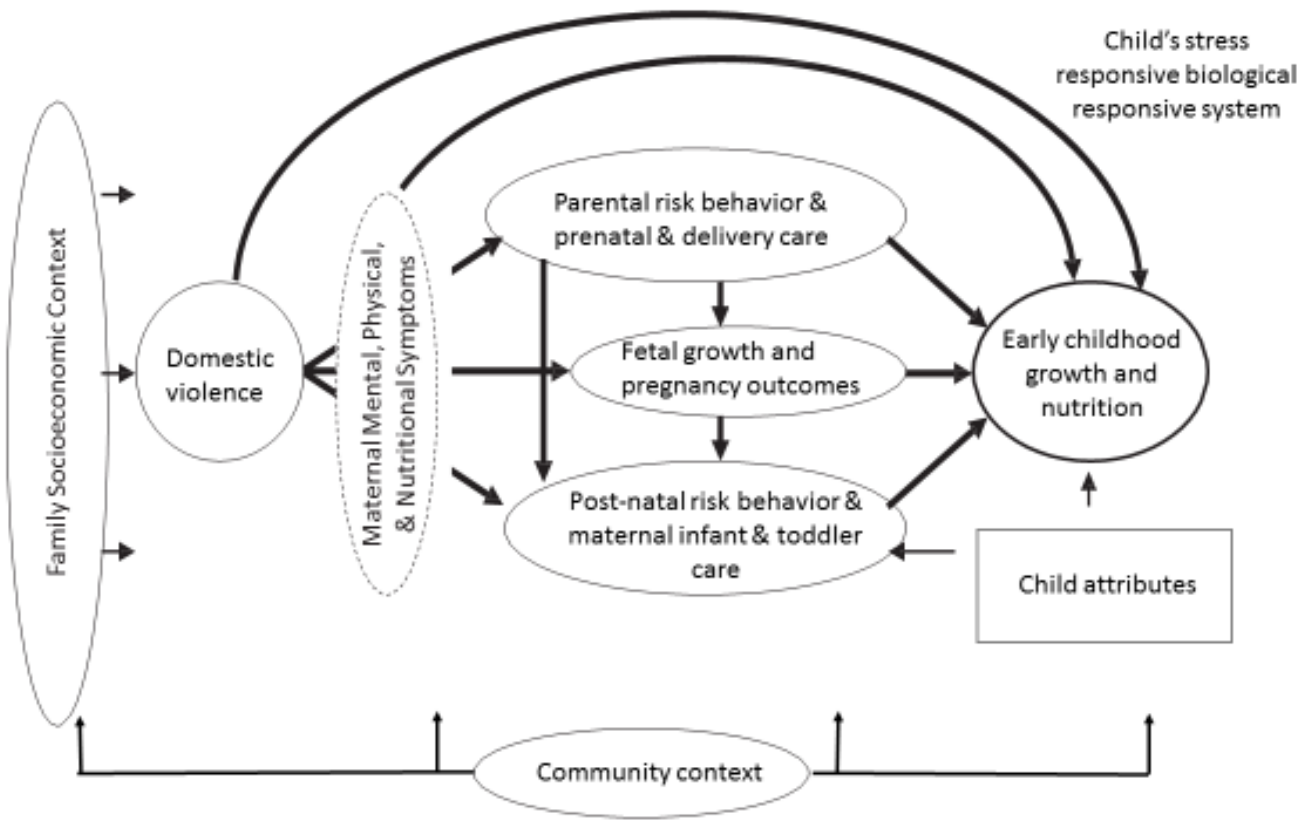

Rational

Findings from a national study, albeit from more than ten years ago, indicate that 15.5 million U.S. children live in families in which partner violence occurred at least once in the past year and seven million children live in families in which severe partner violence occurred (McDonald et al., 2006). The United Nation's Secretary-General's Study on Violence Against Children conservatively estimates that 275 million children worldwide are exposed to violence in the home [The United Nations Children's Fund (UNICEF), 2006]. This is likely a conservative estimate based on limited data; in actuality many more children may be exposed. There are few longitudinal studies that have been conducted on the effect of violence on the growth of the child. Thus the aim 
of this study is twofold. First to describe maternal and child characteristics, child's mean weight-for-height (WHZ) and height-for-age (HAZ) Z-scores in those exposed to IPV and those not exposed. The second aim is to describe the relationship between maternal characteristics and child characteristics and subsequent child growth.

\section{Material and Methods}

\section{Data}

Existing data from two prior studies was used for this analysis: R01NR 05313: Nursing smoking cessation intervention during pregnancy (Baby BEEP) and RO1HD0045542: Nursing support better infant outcomes in violent homes (BBK). Women attending rural Women, Infant, and Children Nutrition Supplement Program (WIC) in 21 counties in a Midwestern state who reported smoking at least one cigarette per day, spoke English and were 18 years or older less than 24 weeks gestation were recruited between January 2002 and October 2005 to participate in the Baby BEEP trial (Bullock et al., 2009b). Mothers and infants in the BBK study were drawn from Baby BEEP study beginning May 2004 when they were due for their sixth month assessment. Research nurses who worked on both the Baby BEEP and BBK studies interviewed all mothers to obtain demographic information and obtained weight and height measurements of the index child at 5-11, 12-18 and 19-26 months.

\section{Data analysis}

The periods of interest were 6,15 and 24 months; however data were actually collected between 5-11 months, 12-18 months and 19-24 months. For comparison purposes, weight and height was interpolated to 6,15 and 24 months 
respectively. Measurements taken within 15 days of the designated visit month (i.e., 6 , $15,24)$ were kept for analysis. Those beyond \pm 15 days were interpolated to align to the designated month. For interpolation, the measurements available within \pm 2 months of the designated month were used to get the value in the designated month. Those that had a measurement greater than \pm 2 months were considered missing. The rationale for imputing was to have one time point for each child for comparison purpose as opposed to having a range of months. Rationale for keeping \pm 15 days of the designated month is because the average weight gained by males aged between 6-9 months in 15 days is 180 grams, while that of females is 150 grams. Both sexes aged between 9-24 months gain approximately 120 grams in 15 days. On height, infants between $0-12$ months will gain $25 \mathrm{~cm}(2.083 \mathrm{~cm}$ a month; $1.042 \mathrm{~cm}$ in 15 days $)$ and $10 \mathrm{~cm}$ between $12-24$ months $(0.833$ cm a month and 0.416 in 15 days) (Danner et al., 2009; Hockenberry \& Wilson, 2015). Thus \pm 15 days measurement will not be significantly different from the weight/height taken at the exact month $(6,15,24)$.

Z-scores are the preferred way to express anthropometric indices because they are used to calculate summary statistics (Wang \& Chen 2012). The program ANTHRO 2011 (WHO, 2011) was used to convert weight and height follow-up measurements into weight-for-height and height-for-age Z-scores. The weight-for height Z-score was used to evaluate nutritional status (wasting/overweight) while the height-for-age Z-score was used to evaluate linear growth (stunting). Low values were associated with impaired long-term growth. The student's t-test was used to compare differences in maternal abuse status (abused/not abused) and child's gender for continuous variables and chi-square for categorical variables. 
Univariate and multivariate linear regression were used to assess the association between prenatal maternal abuse status (abused/not abused) and presence of postnatal violence, type and severity of postnatal violence, maternal postnatal depression, difficult child scores, and weight-for-age and height-for-age Z-scores. In addition, both univariate and multivariate analyses were stratified by child's gender. The Statistical Package for Social Sciences (Version 23; SPSS Inc., Chicago, IL) was used to analyze the data. Frequency and percentages were reported for categorical variables, while means and standard deviation were reported for continuous variables. Coefficients and standard error were reported for both univariate and multivariate logistic regression. A p-value of less than 0.05 was considered significant for student's t-test, chi-square, and univariate and multivariate analyses.

\section{Ethics}

The Ethics Research Committee of University of Virginia approved the study protocol.

\section{Results}

\section{Sample size}

There were 255 dyads between 19-24 months. Twelve were excluded because their recorded birth length was less than $45 \mathrm{~cm}$ and thus a Z-score could not be calculated for them. Eight were excluded because the child was older than 24.5 months. Ten had either weight or height missing and 18 were lost during interpolation. The final sample size at 24 months after interpolation was 207. 


\section{Characteristics of the mothers}

Ninety-one percent (188/207) of women were white and the overall mean age was 23.84 years $( \pm 4.90 \mathrm{SD})$. Six out of ten women had symptoms indicative of depression during pregnancy $(118 / 207)$, out of these $52.2 \%$ (70/118) were not exposed to prenatal abuse. The index child was the first pregnancy for 47\% (97/207) and second pregnancy for 44\% (91/207). Fifty-eight percent (119/207) had symptoms of depression after giving birth. Abuse exposure during pregnancy was 35\% (73/207). Overall, 46\% (96/207) of mother experienced violence (emotional, physical, sexual) after birth. There was no significant difference in baseline variables, follow up variables or abuse status (Table 1).

\section{Characteristics of the child}

More than half of the sample was male (108/207). More males (62/118) were exposed to prenatal depression compared to females (56/118). The mean birth weight was $3.28 \mathrm{~kg}$; female children had a slightly lower mean weight at $3.20 \mathrm{~kg}$ compared to males (3.34kg). Mean birth height was $50.07 \mathrm{~cm}$; girls had a higher mean height of $50.27 \mathrm{~cm}$ compared to boys $(49.89 \mathrm{~cm})$. Girls exposed to prenatal abuse had higher mean birth height of $50.61 \mathrm{~cm}$. Girls had a lower WHZ score (-0.84) compared to boys $(-0.54)$ and a higher HAZ score (0.61) at birth compared to boys (0.37). Ninety six percent of children were exposed to post natal IPV, both male and female had similar exposure. Sixteen percent $(33 / 207)$ of children were perceived to be difficult by their parents with majority being boys (20/33). Overall, there was no significant difference in baseline and follow-up variables and abuse status (Tables $1 \& 2$ ).

Children whose mothers were exposed to abuse had a larger difference (baseline and 24 months) in weight $10.21 \mathrm{~kg}( \pm 1.69)$, height $38.48 \mathrm{~cm}( \pm 5.14)$, WHZ 1.81( \pm 1.76$)$ 
and HAZ $-0.03( \pm 1.54)$ compared to those who were not abused; weight $9.73( \pm 1.61)$, height $37.85( \pm 5.17)$, WHZ $1.39( \pm 1.92)$ and HAZ $-0.21( \pm 1.42)$. These differences were however not statistically significant. When stratified by gender, both male and females who were exposed to abuse had a large difference (baseline and 24 months) in weight, height, WHZ and HAZ compared to those not exposed to abuse. Males had a higher difference in the aforementioned variables except for WHZ. These differences were not statistically significant (Tables $3 \& 4$ ).

\section{Association between baseline and follow up/postnatal predictors with weight-for}

\section{height Z-score (WHZ)}

After adjusting for baseline WHZ score and child's gender, there was a significant association between 2nd pregnancy (0.023) and WHZ at 24 months. Second born child had a lower WHZ compared to the first child at 24 months. There was no significant association between any other variables and WHZ at 24 months.

After stratifying by gender, there was a significant relationship between $2^{\text {nd }}$ pregnancy and WHZ at 24 months for males $(\mathrm{p}=0.027)$ second born male child had a lower WHZ score compared to first-born male child. After adjusting for baseline variables and IPV after birth, child's gender $(p=0.012)$ and $2^{\text {nd }}$ pregnancy $(p=0.012)$ had a significant relationship with WHZ at 24 months. Girls had a lower WHZ compared to boys and $2^{\text {nd }}$ born children also had a low WHZ compared to firstborns.

After replacing IPV with maternal depression at 24 months, difficult child scores, severity and type of violence one at a time, none was significantly associated with lower WHZ at 24 months (Tables 5, $6 \& 7$ ). When stratified by gender, depression at baseline $(\mathrm{p}=0.021), 2^{\text {nd }}$ pregnancy $(\mathrm{p}=0.005)$, breastfeeding status $(\mathrm{p}=0.034)$ and 
maternal depression postnatal $(\mathrm{p}=0.049)$ were significantly associated with a lower WHZ at 24 months for male children. Male children who were second born, who breastfed and whose mothers had prenatal depression had low WHZ compared to their counterparts, however those children whose mothers were exposed to postnatal depression had a higher WHZ compared to their unexposed counterparts (Table 8). Association between baseline and follow up predictors with height-for-age $\mathrm{Z}$ score (HAZ)

After adjusting for baseline height-for-age (HAZ) Z-score, there was no significant relationship between maternal baseline variables and HAZ at 24 months. After stratifying by gender, there was a significant relationship between IPV exposure of the mother after birth and HAZ at 24 months for the male child ( $\mathrm{p}=0.031)$. Male children whose mothers were exposed to IPV after birth had a higher HAZ compared to those not exposed. (Tables 9). After adjusting for baseline variables and IPV after birth and replacing follow up variables one at a time with IPV, there was no significant relationship between these variables and HAZ at 24 months. However when stratified by gender, breastfeeding status $(\mathrm{p}=.011)$ and maternal relationship status $(\mathrm{p}=0.009)$ were significantly associated with $\mathrm{HAZ}$ at 24 for females. Female children who were breastfed and children whose mothers indicated that they were not in a marriage-like relationship had a lower HAZ compared to their counterparts. Intimate partner violence after birth $(\mathrm{p}=0.044)$ and emotional violence $(\mathrm{p}=0.043)$ were significantly associated with HAZ at 24 months for males. Male children who experienced IPV after birth, specifically emotional violence, had a higher HAZ compared to their counterparts (Table 10). 


\section{Discussion}

The first aim for this study was to describe maternal and child characteristics in relation to prenatal abuse exposure. Overall there were no significant differences in maternal and child characteristics based on prenatal abuse status. Maternal characteristics addressed in this study include mothers' age during current pregnancy, depression status during pregnancy and after the birth of the child (presence /absence of symptoms of depression) marital status, ethnicity, and violence after birth of baby. Child characteristics included birth weight and height, wasting, stunting and whether a mother perceived their child to be difficult. Previous studies (Ackerson \& Subramanian, 2008; Asling-Monemi et al., 2009; Hasselmann \& Reichenheim, 2006; Rico et al., 2011; Salazar et al., 2012) found significant difference in mothers' age during current pregnancy, mothers' ability to make decisions in the family, education level, Basal Metabolic Index (BMI), family's economic status, religion, place of residence, total household members, age at which the mother was first married and the number of pregnancies the mother has had and abuse status. These studies also found a difference based on mothers exposure to abuse in child's birth weight, height, wasting, stunting, under nutrition and anemia.

Previous studies mentioned were conducted in Brazil (Hasselmann \& Reichenheim, 2006), Bangladesh (Asling-Monemi et al., 2009), Nicaragua (Salazar et al., 2012), Egypt, Honduras, Rwanda, Malawi and Kenya (Rico et al., 2011). These countries are considered developing countries. Mothers and child characteristics assessed in studies from these countries may not be comparable to this study conducted in the United States because of the difference in health care access, availability of food 
and clean water, level of literacy, Gross Domestic Product (GDP), number of children per woman and women's autonomy. This is the first study in the United States to assess the effect of mothers abuse exposure on child growth using WHO anthropometric measurements.

Although not statistically significant some findings are worth noting. First this study seem to suggest that children exposed to abuse had a bigger difference in weight and height gain between birth and 24 months Mothers and children in this study participated in the WIC program. WIC provides nutritious foods to supplement diet, information on healthy eating and referrals to health care. Availability of nutritious food to both mother and child may explain the reason for positive weight and height gain and subsequently Zscores between birth and 24 months. The reasons for more weight gain in children whose mothers experienced prenatal abuse, especially boys, are not clear and can be a subject for further inquiry.

Second the mean birth weight for the overall sample was $3.28 \mathrm{~kg}$ which is slightly lower that the national average of $3.44 \mathrm{~kg}$ (Donahue, Kleinman, Gillman, \& Oken, 2010)Both boys and girls exposed to abuse had a birth weight of $3.26 \mathrm{~kg}$ and $3.21 \mathrm{~kg}$ respectively. Studies have consistently demonstrated that abuse during pregnancy is a risk factor for low birth weight (LBW) babies (Chertok, Luo, \& Anderson, 2011; Chiolero, Bovet, \& Paccaud, 2005; Tayie \& Powell, 2012). Additionally smoking during pregnancy is estimated to account for $20 \%$ to $30 \%$ of low birth weight babies (Meyer, 1978; Vogazianos, Fiala, \& Vogazianos, 2005). The difference in this study's finding and those from previous studies may be related to recruitment process. Babies who had a birth height below $45 \mathrm{~cm}$ and subsequently low weight were excluded because a WHZ 
score could not be calculated for them. This exclusion means that only children with average birth weight and height were included in this study, which brought the means closer to the national average. Additionally, the weight and height of the parents of these children is not known. Parental weight and height correlate with offspring birth weight and weight gain (Griffiths, Dezateux, \& Cole, 2007) WIC participation has also been linked with longer gestation periods and higher birth weights (http://www.fns.usda.gov/wic/about-wic-wics-mission).

Third the number of women who had symptoms of depression was higher during pregnancy and after the birth of the child in those that did not experience abuse during pregnancy. While previous studies have demonstrated a relationship between abuse and prenatal and postnatal depression (Place, 2014; Rodriguez et al., 2010), evidence also exist to show that smokers, both current and former, are more likely to report depressive symptoms than never smokers (Zhu \& Valbo, 2002). Women in this study were recruited when they were already smokers. The reason for smoking is unclear and may be hypothesized that these women were experiencing symptoms of depression from unidentified stressful life events. Additionally women are particularly prone to postpartum depression because of hormonal changes associated with childbirth and stressors associated with parenting (Gale \& Harlow, 2003; Nicolson, 1990). Devries et al. suggests that IPV exposure can lead to subsequent depression or depression causes subsequent IPV(Devries et al., 2013). Findings from this study may suggest that childbirth and parenting have contributed to mothers having symptoms of depression after the birth of the child and may also explain the increase in the incidence of violence after the birth of child. Causes of mothers' experiences of depressive 
symptoms during pregnancy need to be explored to more fully understand this finding.

Lastly there was an increase in the number of mothers exposed to postnatal violence compared to prenatal exposure to abuse. Different tools used to assess for abuse may have contributed to this difference during pregnancy and after the birth of child figures. The Abuse Assessment Screen (AAS) which was used during the prenatal period measures past and present instances of physical and sexual abuse, as well as who was the perpetrator and location of the physical abuse. The Severity of Violence Against Women Scales (SVAWS) measures behaviors that threaten physical violence and actual physical violence. SVAWS may have elicited more responses based on threats as opposed to actual violence and hence the increase in incidences of violence in the postnatal period.

\section{Z-scores}

World Health Organization recommended cut off points for Z-scores are +2 and 2, which corresponds to the $2.3^{\text {rd }}$ and $97.7^{\text {th }}$ percentiles. These cut off points are chosen to classify problematic growth and /or nutritional status such as malnutrition or obesity (Wang \& Chen, 2012). The present study did not dichotomize WHZ or HAZ because there were too few participants with Z-scores of -2 or below. Thus low WHZ or HAZ scores in this study do not necessarily mean that the child was wasted or stunted.

\section{Assessment for wasting and stunting}

\section{Wasting}

Low WHZ in second born male child compared to firstborns suggests that second born male children were prone to lower weight gain compared to firstborn male children. This findings supports findings from a previous study suggests a child with a higher birth order is associated with lower weight gain and has higher odds of wasting (Sobkoviak et 
al., 2012)although direct comparisons between to the studies need to be undertaken cautiously because of differences in study design.

Exposure to prenatal depression for the male child also yielded lower weight for height than in male children whose mothers did not experience prenatal depression. Likewise, a study to assess the long term effects of maternal IPV and child growth at four years found that depression was positively associated with wasting and stunting in children (Santos, Matijasevich, Domingues, Barros, \& Barros, 2010). But as mentioned earlier, it is difficult to compare this dissertation research to the work of Santos and colleagues because of difference in study designs.

Another finding that was significant was the relationship between breastfed male children and lower WHZ compared to male children that were not breastfed. Previous study from Southern Asia and Sub-Saharan Africa suggest that weight and ultimately WHZ scores of children who are breastfed start to decline after the age of 12 months (Agostoni et al., 1999). In a hypothesis proposed to explain an interaction between age and duration of breastfeeding on nutritional status in a large multinational study in developing countries (Caulfield, Bentley, \& Ahmed, 1996), it was found that older, still breastfed children were shorter and lighter than those no longer breastfed, an association which did not appear until 12-18 months of age and became greater over time. Another study (Ziegler, 2006) found that infants that were breastfed were more likely to be leaner that those that were formula fed. Children and their mothers in this dissertation study had food and formula supplementation though WIC. This may explain the difference in weight between those that were breastfed and those that were formula fed. As noted earlier, low WHZ do not equate to wasting in this study. 
A striking finding was the association between maternal depression after birth and WHZ. Children who were exposed to depression after birth had higher WHZ compared to those not exposed. A study conducted in Europe (Grote et al., 2010) found that a high maternal postnatal depression score does not have any major effects on offspring growth in high-income countries. Findings from the study conducted by Grote et al. suggest that children's weight in those exposed and those not exposed to depression after birth should be similar. Increased weight gain in those exposed to depression after pregnancy may be explained by the fact that stress influences feeding behaviors including type, quantity and patterns of eating (Dallman, 2010; Gibson, 2006; Torres \& Nowson, 2007).

Glucocorticoids produced during depression may drive intake of palatable or "comfort" foods that decrease feelings of stress and reinforce habitual behavior at the expense of homeostatic regulators (Gibson, 2006). The mother may be feeding her child every time she eats. This is a finding that warrants further exploration, given the significant health effects of overweight.

\section{Stunting}

Male children exposed to postnatal IPV (overall) and emotional violence had a higher HAZ compared to their counterpart. It is important to note that "emotional" violence as measured by the SVAWS includes threats of actual violence that could be more clearly called psychological aggression (Basile, Smith, Breiding, Black, \& Mahendra, 2014)This finding suggests that these children were growing taller than those not exposed to postnatal IPV. This finding conflicts with findings from previous studies that demonstrate a relationship between IPV and stunting (Asling-Monemi et al., 2009; Hasselmann \& Reichenheim, 2006; Rico et al., 2011; Salazar et al., 2012). As noted 
earlier, it is difficult to compare this study to other studies because of different study designs. Availability of nutritious food though the WIC program may have mitigated the effects of postnatal IPV on the child hence the high HAZ score, however this finding needs to be investigated further.

Female children who breastfed and whose mothers were not in marriage relationship had lower HAZ compared to their counterpart. Previous studies have shown a risk factor for stunting in children in single motherhood (Salazar et al., 2012).

\section{Limitations}

It is difficult to compare findings from this study to other studies. The majority of studies that have been conducted are from Southern Asia and other developing countries. Additionally use of different tools to assess for violence in this study and previous studies make it difficult to compare their findings objectively. This study did not use cut off points to determine growth. This is because very few children had WHZ less than -2(1) and HAZ (6) at 24 months. WHZ and HAZ are described in trends and cannot conclusively determine whether a child was wasted or undernourished, overweight or obese. Previous studies used cut off points to describe the Z-scores in terms of wasting, stunting or undernutrition.

\section{Conclusion}

Overall children in this study seem to be within normal limits of weight and height with some tending towards overweight and tall stature. Maternal exposure to preand postnatal depression, breastfeeding status and being a second child affected boys more than it did girls in relation to average weight-for-height. Findings from this study 
may not be generalized to the general population because of its homogeneous nature. The fact that all mothers were smokers and all participated in the WIC program may have had an influence on the growth of the child. Findings from this study make an important contribution to the literature on the impact of IPV on child growth for rural low-income women in the United States. Although some of the findings were not statistically significant, there are interesting trends that can guide future studies. There is a need to conduct longitudinal studies in more diverse samples to better understand the true impact of IPV on children's growth in the United States. 
Tables

Table 1: Baseline demographic data of the sample stratified by Abuse

\begin{tabular}{|c|c|c|c|c|}
\hline & $\begin{array}{c}\text { Total sample } \mathrm{N}= \\
207\end{array}$ & Abused & $\begin{array}{c}\text { Not Abused } n= \\
134\end{array}$ & $P$ value \\
\hline Baseline variables & $n(\%)$ & $n(\%)$ & $n(\%)$ & \\
\hline \multicolumn{5}{|l|}{ Gender } \\
\hline Male & $108(52.2)$ & $37(50.7)$ & $71(53)$ & \multirow[t]{2}{*}{0.752} \\
\hline Female & $99(47.8)$ & $36(49.3)$ & $63(47)$ & \\
\hline \multicolumn{5}{|l|}{$\begin{array}{l}\text { Maternal Depression at } \\
\text { baseline }\end{array}$} \\
\hline Not depressed & $89(43)$ & $25(34.2)$ & $64(47.8)$ & \multirow[t]{2}{*}{0.061} \\
\hline Depressed & $118(57)$ & $48(65.8)$ & $70(52.2)$ & \\
\hline \multicolumn{5}{|l|}{ Pregnancies } \\
\hline 1st pregnancy & 97 (46.9) & $33(45.2)$ & $64(47.8)$ & \multirow{3}{*}{0.872} \\
\hline 2nd pregnancy & $91(44.0)$ & $33(45.2)$ & $58(43.3)$ & \\
\hline 3rd or more pregnancies & $19(9.2)$ & $7(9.6)$ & $12(9.0)$ & \\
\hline \multicolumn{5}{|l|}{ Breastfeeding Status } \\
\hline Yes & $111(53.6)$ & $39(53.4)$ & $72(53.7)$ & \multirow[t]{2}{*}{0.966} \\
\hline No & $96(46.4)$ & $34(46.6)$ & $62(46.3)$ & \\
\hline
\end{tabular}




\begin{tabular}{|c|c|c|c|c|}
\hline \multicolumn{5}{|l|}{ Mothers Ethnicity } \\
\hline White & $188(90.8)$ & $63(86.3)$ & $125(93.3)$ & 0.096 \\
\hline \multirow[t]{2}{*}{ Other } & $19(9.2)$ & $10(13.7)$ & $9(6.7)$ & \\
\hline & Mean (SD) & Mean (SD) & Mean $(S D)$ & \\
\hline \multicolumn{5}{|l|}{ Maternal relationship status } \\
\hline Married & $145(70)$ & $48(65.8)$ & $97(72.4)$ & 0.319 \\
\hline Other & $62(30)$ & $25(34.2)$ & $37(27.6)$ & \\
\hline Mothers age (years)* & $23.84(4.90)$ & $23.52(4.39)$ & $24.01(5.18)$ & 0.49 \\
\hline Baby's weight $(\mathrm{kg})^{*}$ & $3.28(0.46)$ & $3.24(0.43)$ & $3.30(0.48)$ & 0.371 \\
\hline Baby's height $(\mathrm{cm})^{*}$ & $50.07(0.66)$ & $50.02(4.61)$ & $50.10(4.71)$ & 0.900 \\
\hline Weight-for-height Z-score* & $-0.68(1.65)$ & $-0.79(1.67)$ & $-0.63(1.66)$ & 0.498 \\
\hline Height- for - age Z-score* & $0.48(1.39)$ & $0.49(1.41)$ & $0.48(1.38)$ & 0.974 \\
\hline \multicolumn{5}{|c|}{ Follow up/post natal Data stratified by Abuse } \\
\hline & $\begin{array}{c}\text { Total sample } \mathrm{N}= \\
207\end{array}$ & Abused $\quad n=73$ & $\begin{array}{c}\text { Not Abused } n= \\
134\end{array}$ & P value* \\
\hline Follow up variables & $n(\%)$ & $n(\%)$ & $n(\%)$ & \\
\hline \multicolumn{5}{|l|}{ Intimate partner violence } \\
\hline None & $78(37.7)$ & $23(31.5)$ & $55(41)$ & \\
\hline Yes & $96(46.4)$ & $39(53.4)$ & $57(42.5)$ & 0.301 \\
\hline Missing & $33(15.9)$ & $11(15.1)$ & $22(16.4)$ & \\
\hline
\end{tabular}




\begin{tabular}{|c|c|c|c|c|}
\hline \multicolumn{5}{|l|}{ Maternal Depression } \\
\hline Not Depressed & $88(42.5)$ & $31(42.5)$ & $57(42.5)$ & \multirow{2}{*}{0.992} \\
\hline Depressed & $119(57.5)$ & $42(57.5)$ & $77(57.5)$ & \\
\hline \multicolumn{5}{|l|}{ Difficult child scores } \\
\hline Not difficult & $160(77.3)$ & $57(78.1)$ & $103(76.9)$ & \multirow{3}{*}{0.178} \\
\hline Difficult & $33(15.9)$ & $14(19.2)$ & $19(14.2)$ & \\
\hline Missing & $14(6.8)$ & $2(2.7)$ & $12(9.0)$ & \\
\hline \multicolumn{5}{|l|}{ Severity of violence } \\
\hline None & $78(37.7)$ & $23(31.5)$ & $55(41)$ & \multirow{5}{*}{0.414} \\
\hline No severity & $47(22.7)$ & $17(23.3)$ & $30(22.4)$ & \\
\hline Mild to minor & $17(8.2)$ & $9(12.3)$ & $8(6.0)$ & \\
\hline Moderate to severe & $32(15.9)$ & $13(17.85)$ & $19(14.2)$ & \\
\hline Missing & $33(15.9)$ & $11(15.1)$ & $22(16.4)$ & \\
\hline \multicolumn{5}{|l|}{ Type of violence } \\
\hline None & $78(37.7)$ & $23(31.5)$ & $55(41)$ & \multirow{4}{*}{0.466} \\
\hline Emotional & $49(23.7)$ & $19(26)$ & $30(22.4)$ & \\
\hline Emotional and physical & $47(22.7)$ & $20(27.4)$ & $27(20.1)$ & \\
\hline Missing & $33(15.9)$ & $11(15.1)$ & $22(16.4)$ & \\
\hline
\end{tabular}

* Student t test, all other Chi square test. 
Table 2: Baseline demographic data of the sample stratified by Abuse and gender

\begin{tabular}{|c|c|c|c|c|c|c|c|c|c|}
\hline & \multicolumn{5}{|c|}{ Male } & \multicolumn{4}{|c|}{ Female } \\
\hline & $\begin{array}{l}\text { Total sample } \\
\mathbf{n = 2 0 7}\end{array}$ & $\begin{array}{c}\text { Sample } \\
n=108\end{array}$ & $\begin{array}{c}\text { Abused } \\
\mathbf{n}=\mathbf{3 7}\end{array}$ & $\begin{array}{l}\text { Not Abused } \\
\quad n=71\end{array}$ & $\begin{array}{c}\mathbf{P} \\
\text { value }\end{array}$ & $\begin{array}{c}\text { Sample } n= \\
99\end{array}$ & $\begin{array}{c}\text { Abused } \\
\mathbf{n}=36\end{array}$ & $\begin{array}{l}\text { Not Abused } \\
\quad n=63\end{array}$ & $\begin{array}{c}\mathbf{P} \\
\text { value }\end{array}$ \\
\hline & $n(\%)$ & $n(\%)$ & $n(\%)$ & $n(\%)$ & & $n(\%)$ & $n(\%)$ & $n(\%)$ & \\
\hline \multicolumn{10}{|l|}{$\begin{array}{l}\text { Maternal Depression at } \\
\text { baseline }\end{array}$} \\
\hline Not Depressed & $89(43)$ & $46(42.6)$ & $14(37.8)$ & $32(45.1)$ & 0.471 & $43(43.4)$ & $11(30.6)$ & $32(50.8)$ & 0.051 \\
\hline Depressed & $118(57)$ & $62(57.4)$ & $23(62.2)$ & $39(54.9)$ & & $56(56.6)$ & $25(69.4)$ & $31(49.2)$ & \\
\hline \multicolumn{10}{|l|}{ Pregnancies } \\
\hline 1st pregnancy & $97(46.9)$ & $49(45.4)$ & $16(43.2)$ & $33(46.5)$ & \multirow{2}{*}{0.872} & $48(48.5)$ & $17(47.2)$ & $31(49.2)$ & \multirow{2}{*}{0.774} \\
\hline 2nd pregnancy & $91(44.0)$ & $46(42.6)$ & $17(45.9)$ & $29(40.8)$ & & $45(45.5)$ & $16(44.4)$ & $29(46.0)$ & \\
\hline 3rd or more pregnancies & $19(9.2)$ & $13(12)$ & $4(10.8)$ & $9(12.7)$ & & $6(6.15)$ & $3(8.3)$ & $3(4.8)$ & \\
\hline \multicolumn{10}{|l|}{ Breastfeeding Status } \\
\hline Yes & $111(53.6)$ & $50(46.3)$ & $17(45.9)$ & $33(45.5)$ & \multirow[t]{2}{*}{0.958} & $61(61.6)$ & $22(61.1)$ & $39(61.9)$ & \multirow[t]{2}{*}{0.938} \\
\hline No & $96(46.4)$ & $58(53.7)$ & $20(54.1)$ & $38(53.5)$ & & $38(38.4)$ & $14(38.9)$ & $24(38.1)$ & \\
\hline \multicolumn{5}{|l|}{ Mothers Ethnicity } & \multirow{2}{*}{0.409} & & & & \multirow{2}{*}{0.109} \\
\hline White & $188(90.8)$ & $97(89.8)$ & $32(86.5)$ & $65(91.5)$ & & $91(91.9)$ & $31(86.1)$ & $60(95.2)$ & \\
\hline
\end{tabular}


Other

$$
19(9.2)
$$

$11(10.2)$

$5(13.5)$

$6(8.5)$

$8(8.1)$

$5(13.9)$

$3(4.8)$

Maternal relationship status

\begin{tabular}{|c|c|c|c|c|c|c|c|c|c|}
\hline Married & $145(70)$ & $76(70.4)$ & $26(70.3)$ & $50(70.4)$ & 0.987 & $69(69.7)$ & $22(61.1)$ & $47(74.6)$ & 0.16 \\
\hline \multirow[t]{2}{*}{ Other } & $62(30)$ & $32(29.6)$ & $11(29.7)$ & $21(29.6)$ & & $30(30.3)$ & $14(38.9)$ & $16(25.4)$ & \\
\hline & Mean (SD) & $\operatorname{Mean}(S D)$ & $\begin{array}{c}\text { Mean } \\
(S D)\end{array}$ & $\operatorname{Mean}(S D)$ & & $\operatorname{Mean}(S D)$ & $\operatorname{Mean}(S D)$ & $\operatorname{Mean}(S D)$ & \\
\hline Mothers age (years)* & $23.84(4.90)$ & $23.75(4.90)$ & $\begin{array}{l}23.16 \\
(4.43)\end{array}$ & $24.06(5.03)$ & 0.371 & $23.94(4.94)$ & $23.89(4.16)$ & $23.97(5.35)$ & 0.939 \\
\hline Baby's weight $(\mathrm{kg})^{*}$ & $3.28(.46)$ & $3.34(.50)$ & $3.26(.47)$ & $3.39(.51)$ & 0.202 & $3.20(.41)$ & $3.21(.38)$ & $3.19(.43)$ & 0.824 \\
\hline Baby's height $(\mathrm{cm})^{*}$ & $50.07(.66)$ & $49.89(5.99)$ & $\begin{array}{l}49.44 \\
(5.91)\end{array}$ & $50.12(6.06)$ & 0.581 & $50.27(2.54)$ & $50.61(2.67)$ & $50.09(2.47)$ & 0.329 \\
\hline WHZ* & $-0.68(1.65)$ & $-0.54(1.73)$ & $\begin{array}{c}-0.58 \\
(1.85)\end{array}$ & $-0.52(1.67)$ & 0.856 & $-0.84(1.57)$ & $-1.00(1.45)$ & $-0.75(1.63)$ & 0.438 \\
\hline HAZ* & $0.48(1.39)$ & $0.37(1.40)$ & $0.20(1.34)$ & $0.46(1.44)$ & 0.359 & $0.61(1.36)$ & $0.78(1.43)$ & $0.78(1.43)$ & 0.327 \\
\hline
\end{tabular}

Follow up variables stratified by abuse and gender

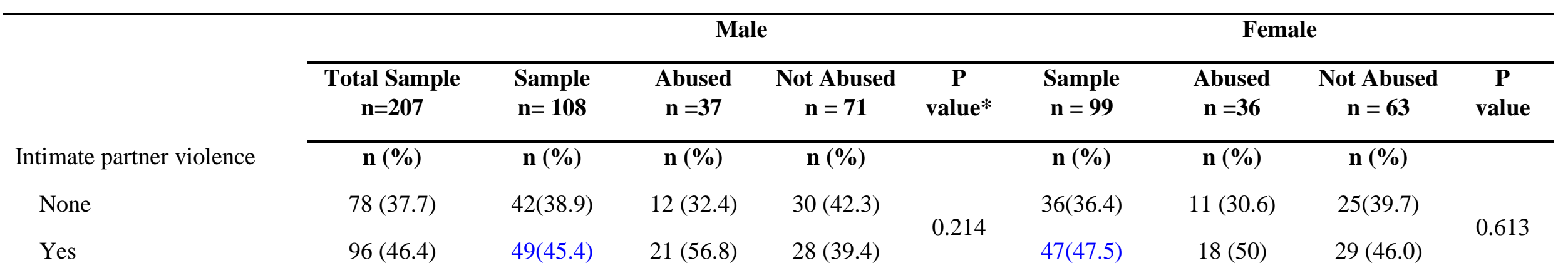




\begin{tabular}{|c|c|c|c|c|c|c|c|c|c|}
\hline Missing & $33(15.9)$ & $17(15.7)$ & $4(10.8)$ & $13(18.3)$ & & $16(16.2)$ & 7 (19.4) & $9(14.3)$ & \\
\hline \multicolumn{10}{|l|}{ Maternal Depression } \\
\hline Not Depressed & $88(42.5)$ & $50(46.3)$ & $16(43.2)$ & $34(47.9)$ & \multirow{2}{*}{0.646} & $38(38.4)$ & $15(41.7)$ & $23(36.50$ & \multirow{2}{*}{0.612} \\
\hline Depressed & $119(57.5)$ & $58(53.7)$ & $21(56.8)$ & $37(52.1)$ & & $61(61.6)$ & $21(58.3)$ & $40(63.5)$ & \\
\hline \multicolumn{10}{|l|}{ Difficult child scores } \\
\hline Not difficult & $160(77.3)$ & $80(74.1)$ & $27(73)$ & $53(74.6)$ & \multirow{3}{*}{0.257} & $80(80.8)$ & $30(83.3)$ & $50(79.4)$ & \multirow{3}{*}{0.584} \\
\hline Difficult & $33(15.9)$ & $20(18.5)$ & $9(24.3)$ & $11(15.5)$ & & $13(13.1)$ & $5(13.9)$ & $8(12.7)$ & \\
\hline Missing & $14(6.8)$ & $8(7.4)$ & $1(2.7)$ & $7(9.9)$ & & $6(6.1)$ & $1(2.8)$ & $5(7.9)$ & \\
\hline \multicolumn{10}{|l|}{ Severity of violence } \\
\hline None & $78(37.7)$ & $42(38.9)$ & $12(32.4)$ & $30(42.3)$ & \multirow{5}{*}{0.445} & $36(36.4)$ & $11(30.6)$ & $25(39.7)$ & \multirow{5}{*}{0.474} \\
\hline No severity & $47(22.7)$ & $24(22.2)$ & $9(24.3)$ & $15(21.1)$ & & $23(23.2)$ & $8(22.2)$ & $15(23.8)$ & \\
\hline Mild to minor & $17(8.2)$ & $13(12)$ & $6(16.2)$ & $7(9.9)$ & & $4(4.0)$ & $3(8.3)$ & $1(1.6)$ & \\
\hline Moderate to severe & $32(15.9)$ & $12(11.1)$ & $6(16.2)$ & $6(8.5)$ & & $20(20.2)$ & $7(19.4)$ & $13(20.6)$ & \\
\hline Missing & $33(15.9)$ & $17(15.7)$ & $4(10.8)$ & $13(18.3)$ & & $16(16.2)$ & 7 (19.4) & $9(14.3)$ & \\
\hline \multicolumn{10}{|l|}{ Type of violence } \\
\hline None & $78(37.7)$ & $42(38.9)$ & $12(32.4)$ & $30(42.3)$ & \multirow{4}{*}{0.446} & $36(36.4)$ & $11(30.6)$ & $25(39.7)$ & \multirow{4}{*}{0.684} \\
\hline Emotional & $49(23.7)$ & $29(26.9)$ & $12(32.4)$ & $17(23.9)$ & & $20(20.2)$ & $7(19.4)$ & 13(20.6) & \\
\hline Emotional and physical & $47(22.7)$ & $21(19.4)$ & $9(24.3)$ & $12(16.9)$ & & $26(26.3)$ & $11(30.6)$ & $15(23.8)$ & \\
\hline Missing & $33(15.9)$ & $17(15.7)$ & $4(10.8)$ & $13(18.3)$ & & $16(16.2)$ & $7(19.4)$ & $9(14.3)$ & \\
\hline
\end{tabular}


* Student's t test, all other Chi square

Table 3: Mean difference in weight, height, WHZ and HAZ-scores between baseline and 24 months

\begin{tabular}{|c|c|c|c|c|}
\hline & Total sample & Abused & Not Abused & P value* \\
\hline \multirow[t]{2}{*}{ Baseline } & $\mathrm{N}=\mathbf{2 0 7}$ & $n=73$ & $n=134$ & \\
\hline & $\operatorname{Mean}(S D)$ & $\operatorname{Mean}(S D)$ & $\operatorname{Mean}(S D)$ & \\
\hline Baby's weight (kg) & $3.28(.46)$ & $3.24(.43)$ & $3.30(.48)$ & 0.371 \\
\hline Baby's height (cm) & $50.07(4.66)$ & $50.02(4.61)$ & $50.10(4.71)$ & 0.9 \\
\hline WHZ score & $-.68(1.65)$ & $-.79(1.67)$ & $-.63(1.66)$ & 0.498 \\
\hline HAZ score & $0.48(1.39)$ & $.49(1.41)$ & $.48(1.38)$ & 0.974 \\
\hline \multicolumn{5}{|l|}{24 months } \\
\hline Baby's weight difference $(\mathrm{kg})$ & $9.90(1.69)$ & $10.21(1.81)$ & $9.73(1.61)$ & 0.053 \\
\hline Baby's height difference $(\mathrm{cm})$ & $38.07(5.16)$ & $38.48(5.14)$ & $37.85(5.17)$ & 0.402 \\
\hline WHZ score difference & $1.54(1.87)$ & $1.81(1.76)$ & $1.39(1.92)$ & 0.127 \\
\hline HAZ score difference & $-.15(1.46)$ & $-.03(1.54)$ & $-.21(1.42)$ & 0.4 \\
\hline
\end{tabular}

\footnotetext{
* Student's t test
} 
Table 4: Mean difference in weight, height, WHZ, HAZ between baseline and 24 months stratified by maternal abuse and gender

\begin{tabular}{|c|c|c|c|c|c|c|c|c|}
\hline & \multicolumn{4}{|c|}{ Male } & \multicolumn{4}{|c|}{ Female } \\
\hline & Sample N & Abused & Not Abused & P value* & Sample & Abused & Not Abused & $\begin{array}{c}\mathbf{P} \\
\text { value* }\end{array}$ \\
\hline \multirow[t]{2}{*}{ Baseline } & $\mathrm{n}=\mathbf{1 0 8}$ & $\mathbf{n}=\mathbf{3 7}$ & $n=71$ & & $\mathbf{n}=99$ & $\mathrm{n}=36$ & $n=63$ & \\
\hline & $\operatorname{Mean}(S D)$ & $\operatorname{Mean}(S D)$ & $\operatorname{Mean}(S D)$ & & $\operatorname{Mean}(S D)$ & Mean $(S D)$ & $\operatorname{Mean}(S D)$ & \\
\hline Baby's weight (kg) & $3.34(.50)$ & $3.26(.47)$ & $3.39(.51)$ & 0.202 & $3.20(.41)$ & $3.21(.38)$ & $3.19(.43)$ & 0.824 \\
\hline Baby's height (cm) & $49.89(5.99)$ & $49.44(5.91)$ & $50.12(6.06)$ & 0.581 & $50.27(2.54)$ & $50.61(2.67)$ & $50.09(2.47)$ & 0.329 \\
\hline WHZ score & $-.54(1.73)$ & $-.58(1.85)$ & $-.52(1.67)$ & 0.856 & $-.84(1.57)$ & $-1.00(1.45)$ & $-.75(1.63)$ & 0.438 \\
\hline HAZ score & $.37(1.40)$ & $.20(1.34)$ & $.46(1.44)$ & 0.359 & $.61(1.36)$ & $.78(1.43)$ & $.78(1.43)$ & 0.327 \\
\hline \multicolumn{9}{|l|}{24 months } \\
\hline Weight difference (kg) & $10.29(1.63)$ & $10.57(1.79)$ & $10.14(1.52)$ & 0.182 & $9.48(1.67)$ & $9.82(1.78)$ & $9.28(1.59)$ & 0.113 \\
\hline Height difference $(\mathrm{cm})$ & $38.84(6.20)$ & $39.31(6.11)$ & $38.59(6.27)$ & 0.572 & $37.23(5.56)$ & $37.63(3.81)$ & $37.01(3.41)$ & 0.407 \\
\hline WHZ score difference & $1.61(1.75)$ & $1.79(1.59)$ & $1.52(1.83)$ & 0.441 & $1.46(2.01)$ & $1.82(1.95)$ & $1.25(2.03)$ & 0.172 \\
\hline HAZ score difference & $-.06(1.47)$ & $.14(1.47)$ & $-.17(1.47)$ & 0.308 & $-.25(1.47)$ & $-.21(1.61)$ & $-.27(1.37)$ & 0.858 \\
\hline
\end{tabular}

* Student's t test 
Table 5: Univariate association between baseline predictors and follow up predictors with WHZ-score at 24 months

\begin{tabular}{|c|c|c|c|}
\hline & Estimates & SE & $P$ value \\
\hline Weight-for-height Z-score at baseline & 0.081 & 0.047 & 0.084 \\
\hline Gender (boy vs. girl) & -0.423 & 0.155 & $0.007 *$ \\
\hline \multicolumn{4}{|l|}{ Baseline predictors } \\
\hline \multicolumn{4}{|l|}{ Pregnancies (1st preg is ref) } \\
\hline 2nd pregnancy & -0.352 & 0.154 & $0.023 *$ \\
\hline 3rd or more pregnancies & -0.071 & 0.268 & 0.792 \\
\hline
\end{tabular}

Note: Each of the predictors (baseline and follow up) are adjusted for WHZ score at baseline and gender

Significant at $\mathrm{p}=0.05$ 
Table 6: Univariate association between baseline predictors and follow up predictors with WHZ at 24 stratified by gender

\begin{tabular}{|c|c|c|c|c|c|c|}
\hline & \multicolumn{3}{|c|}{ Female } & \multicolumn{3}{|c|}{ Male } \\
\hline & Estimates & SE & $P$ value & Estimates & SE & $P$ value \\
\hline WHZ score at baseline & -0.065 & 0.072 & 0.37 & 0.176 & 0.065 & 0.008 \\
\hline \multicolumn{7}{|l|}{ Baseline predictors } \\
\hline \multicolumn{7}{|l|}{ Pregnancies (1st preg is ref) } \\
\hline 2nd pregnancy & -0.24 & 0.226 & 0.29 & -0.464 & 0.207 & $0.027 *$ \\
\hline 3rd or more pregnancies & -0.548 & 0.469 & 0.246 & 0.085 & 0.321 & 0.792 \\
\hline
\end{tabular}

Note: Each of the predictors (baseline and follow up) are adjusted for WHZ score at baseline and gender

$*$ Significant at $\mathrm{p}=0.05$ 
Table 7: Multivariate association of baseline predictors and WHZ score at 24

\begin{tabular}{lcc}
\hline & Estimates & SE value \\
Baseline predictors & & 0.049 \\
WHZ at baseline & 0.072 & 0.143 \\
Mother's Abuse (Yes vs. No) & 0.312 & 0.164 \\
Gender (girl vs. boy) & -0.398 & 0.158 \\
Pregnancies (1st preg is ref) & & 0.059 \\
$\quad$ 2nd pregnancy & -0.476 & 0.189 \\
$\quad$ 3rd or more pregnancies & -0.338 & 0.352 \\
\hline
\end{tabular}

Note: Follow up predictors were included in the model individually together with baseline predictors

* Significant at $\mathrm{p}=0.05$ 


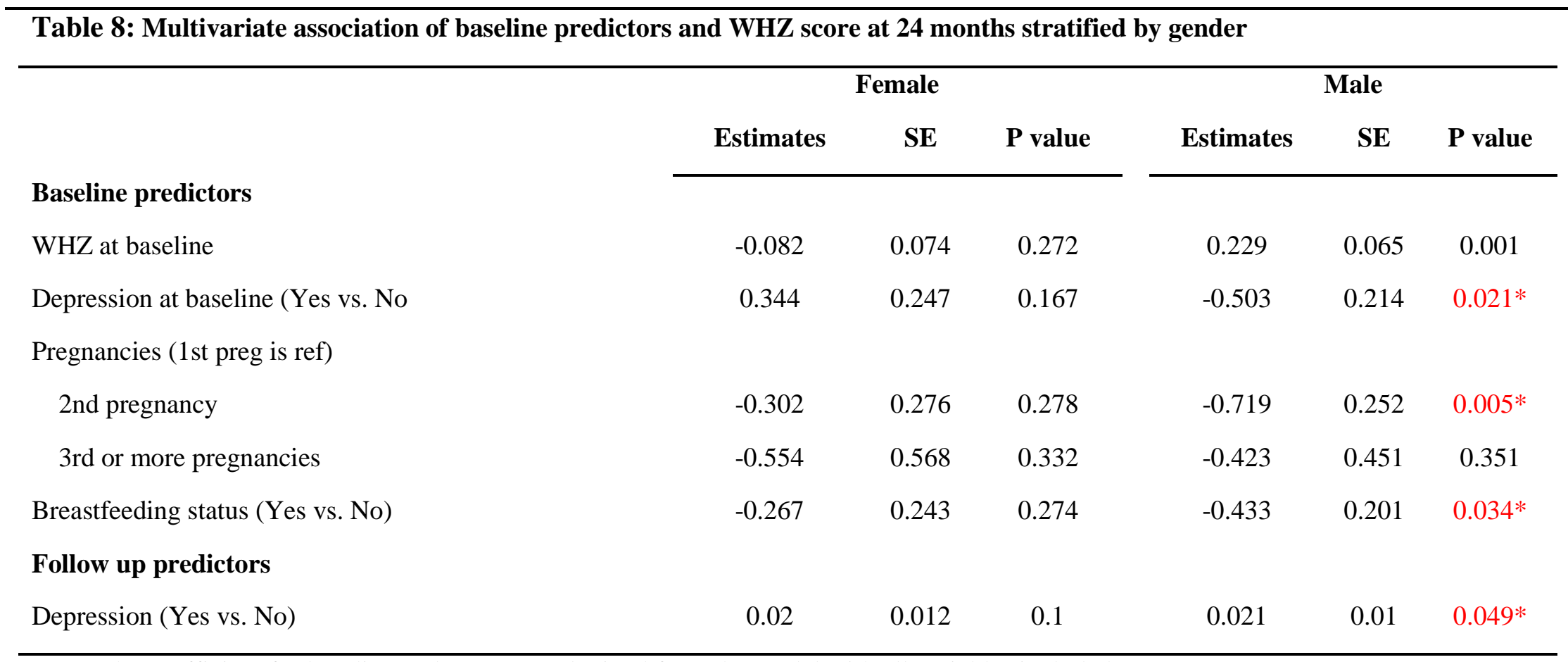

Note: The coefficient for baseline and IPV were obtained from the model with all variables included.

Results from follow up predictors were obtained by replacing IPV with each of the follow up variables.

* Significant at $\mathrm{p}=0.05$ 
Table 9: Multivariate association of baseline predictors and HAZ score at 24 stratified by gender

\begin{tabular}{|c|c|c|c|c|c|c|}
\hline \multirow[b]{3}{*}{ Baseline predictors } & \multicolumn{3}{|c|}{ Female } & \multicolumn{3}{|c|}{ Male } \\
\hline & Estimates & SE & P value & Estimates & SE & $P$ value \\
\hline & & & & & & \\
\hline HAZ score at baseline & 0.146 & 0.069 & 0.036 & 0.307 & 0.08 & $<.001$ \\
\hline Mother's Abuse (Yes vs. No) & 0.313 & 0.2 & 0.121 & 0.121 & 0.234 & 0.606 \\
\hline Breastfeeding status (Yes vs. No) & -0.51 & 0.196 & $0.011^{*}$ & -0.116 & 0.22 & 0.599 \\
\hline Relationship status (married/ Other) & -0.562 & 0.21 & $0.009 *$ & -0.046 & 0.249 & 0.854 \\
\hline \multicolumn{7}{|l|}{ Follow up Predictors } \\
\hline \multicolumn{7}{|l|}{ Intimate partner violence (No is the ref) } \\
\hline Yes & -0.09 & 0.213 & 0.674 & 0.501 & 0.246 & $0.044^{*}$ \\
\hline Missing & 0.252 & 0.277 & 0.365 & 0.191 & 0.342 & 0.579 \\
\hline \multicolumn{7}{|l|}{ Type of violence (None is ref) } \\
\hline Emotional & -0.228 & 0.268 & 0.398 & 0.574 & 0.28 & $0.043^{*}$ \\
\hline Emotional and physical & -0.127 & 0.248 & 0.611 & 0.393 & 0.321 & 0.224 \\
\hline Missing & 0.216 & 0.276 & 0.437 & 0.198 & 0.346 & 0.568 \\
\hline
\end{tabular}

Note: The coefficient for baseline and IPV were obtained from the model with all variables included.

Results from follow up predictors were obtained by replacing IPV with each of the follow up variables. 
* Significant at $\mathrm{p}=0.05$

Table 9: Univariate association between baseline predictors and follow up predictors with HAZ at 24 months stratified by gender

\begin{tabular}{|c|c|c|c|c|c|c|}
\hline & \multicolumn{3}{|c|}{ Female } & \multicolumn{3}{|c|}{ Male } \\
\hline & Estimates & SE & $P$ value & Estimates & SE & $P$ value \\
\hline HAZ score at baseline & 0.171 & 0.07 & 0.016 & 0.303 & 0.076 & $<.001$ \\
\hline \multicolumn{7}{|l|}{ Baseline predictors } \\
\hline Mother's Abuse (Yes vs. No) & 0.282 & 0.197 & 0.156 & 0.111 & 0.225 & 0.624 \\
\hline \multicolumn{7}{|l|}{ Follow up predictors } \\
\hline \multicolumn{7}{|l|}{$\begin{array}{l}\text { Intimate partner violence (No is } \\
\text { the ref) }\end{array}$} \\
\hline Yes & -0.058 & 0.211 & 0.785 & 0.505 & 0.231 & $0.030 *$ \\
\hline Missing & 0.272 & 0.284 & 0.34 & 0.216 & 0.315 & 0.494 \\
\hline \multicolumn{7}{|l|}{ Type of violence (None is ref) } \\
\hline Emotional & -0.147 & 0.269 & 0.586 & 0.528 & 0.266 & $0.050 *$ \\
\hline Emotional and physical & -0.103 & 0.243 & 0.674 & 0.48 & 0.297 & 0.108 \\
\hline Missing & 0.239 & 0.283 & 0.402 & 0.223 & 0.318 & 0.483 \\
\hline
\end{tabular}

Note: Each of the predictors (baseline and follow up) are adjusted for weight-for-height Z-score at baseline and gender 
* Significant at $\mathrm{p}=0.05$

Table 10: Multivariate association of baseline predictors and HAZ score at 24 stratified by gender

\begin{tabular}{|c|c|c|c|c|c|c|}
\hline \multirow[b]{3}{*}{ Baseline predictors } & \multicolumn{3}{|c|}{ Female } & \multicolumn{3}{|c|}{ Male } \\
\hline & Estimates & SE & P value & Estimates & SE & $P$ value \\
\hline & & & & & & \\
\hline HAZ score at baseline & 0.146 & 0.069 & 0.036 & 0.307 & 0.08 & $<.001$ \\
\hline Mother's Abuse (Yes vs. No) & 0.313 & 0.2 & 0.121 & 0.121 & 0.234 & 0.606 \\
\hline Breastfeeding status (Yes vs. No) & -0.51 & 0.196 & $0.011^{*}$ & -0.116 & 0.22 & 0.599 \\
\hline Relationship status (married/ Other) & -0.562 & 0.21 & $0.009 *$ & -0.046 & 0.249 & 0.854 \\
\hline \multicolumn{7}{|l|}{ Follow up Predictors } \\
\hline \multicolumn{7}{|l|}{ Intimate partner violence (No is the ref) } \\
\hline Yes & -0.09 & 0.213 & 0.674 & 0.501 & 0.246 & $0.044 *$ \\
\hline Missing & 0.252 & 0.277 & 0.365 & 0.191 & 0.342 & 0.579 \\
\hline
\end{tabular}


Type of violence (None is ref)

\begin{tabular}{lccccccc} 
Emotional & -0.228 & 0.268 & 0.398 & 0.574 & 0.28 & $0.043^{*}$ \\
Emotional and physical & -0.127 & 0.248 & 0.611 & 0.393 & 0.321 & 0.224 \\
Missing & 0.216 & 0.276 & 0.437 & 0.198 & 0.346 & 0.568 \\
\hline
\end{tabular}

Note: The coefficient for baseline and IPV were obtained from the model with all variables included.

Results from follow up predictors were obtained by replacing IPV with each of the follow up variables.

* Significant at $\mathrm{p}=0.05$ 


\section{References}

Ackerson, L. K., \& Subramanian, S. V. (2009). Intimate partner violence and death among infants and children in India. Pediatrics, 124(5), e878-89.

Ackerson, L. K., \& Subramanian, S. V. (2008). Domestic violence and chronic malnutrition among women and children in India. American Journal of Epidemiology, 167(10), 1188-1196.

Agostoni, C., Grandi, F., Gianni, M. L., Silano, M., Torcoletti, M., Giovannini, M., \& Riva, E. (1999). Growth patterns of breast fed and formula fed infants in the first 12 months of life: An Italian study. Archives of Disease in Childhood, 81(5), 395-399.

Asling-Monemi, K., Naved, R. T., \& Persson, L. A. (2009). Violence against women and the risk of fetal and early childhood growth impairment: A cohort study in rural Bangladesh. Archives of Disease in Childhood, 94(10), 775-779.

Basile, K. C., Smith, S. G., Breiding, M. J., Black, M. C., \& Mahendra, R. R. (2014). Sexual violence surveillance: Uniform definitions and recommended data elements, version 2.0. ( No. Version 2.0). Atlanta, Georgia: National Center for Injury Prevention and Control, Centers for Disease Control and Prevention.

Black, R. E., Allen, L. H., Bhutta, Z. A., Caulfield, L. E., de Onis, M., Ezzati, M., . . Maternal and Child Undernutrition Study Group. (2008). Maternal and child undernutrition: Global and regional exposures and health consequences. Lancet, 371(9608), 243-260. doi:http://dx.doi.org/10.1016/S0140-6736(07)61690-0 
Bullock, L., Everett, K. D., Mullen, P. D., Geden, E., Longo, D. R., \& Madsen, R. (2009). Baby BEEP: A randomized controlled trial of nurses' individualized social support for poor rural pregnant smokers. Maternal \& Child Health Journal, 13(3), $395-406$.

Caulfield, L. E., Bentley, M. E., \& Ahmed, S. (1996). Is prolonged breastfeeding associated with malnutrition? evidence from nineteen demographic and health surveys. International Journal of Epidemiology, 25(4), 693-703.

Chertok, I. R. A., Luo, J., \& Anderson, R. H. (2011). Association between changes in smoking habits in subsequent pregnancy and infant birth weight in west Virginia. Maternal \& Child Health Journal, 15(2), 249-254.

Chiolero, A., Bovet, P., \& Paccaud, F. (2005). Association between maternal smoking and low birth weight in Switzerland: The EDEN study. Swiss Medical Weekly, $135(35-36), 525-530$.

Dallman, M. F. (2010). Stress-induced obesity and the emotional nervous system. Trends in Endocrinology and Metabolism: TEM, 21(3), 159-165. doi:10.1016/j.tem.2009.10.004 [doi]

Danner, E., Joeckel, R., Michalak, S., Phillips, S., \& Goday, P. S. (2009). Weight velocity in infants and children. Nutrition in Clinical Practice, 24(1), 76-79. doi:http://dx.doi.org/10.1177/0884533608329663 
Devries, K. M., Mak, J. Y., Bacchus, L. J., Child, J. C., Falder, G., Petzold, M., . .

Watts, C. H. (2013). Intimate partner violence and incident depressive symptoms and suicide attempts: A systematic review of longitudinal studies. PLoS Medicine, 10(5), e1001439. doi:10.1371/journal.pmed.1001439 [doi]

Devries, K. M., Kishor, S., Johnson, H., Stockl, H., Bacchus, L. J., Garcia-Moreno, C., \& Watts, C. (2010). Intimate partner violence during pregnancy: Analysis of prevalence data from 19 countries. Reproductive Health Matters, 18(36), 158-170. doi:http://dx.doi.org/10.1016/S0968-8080(10)36533-5

Donahue, S. M. A., Kleinman, K. P., Gillman, M. W., \& Oken, E. (2010). Trends in birth weight and gestational length among singleton term births in the united states: 19902005. Obstetrics \& Gynecology, 115(2 Pt 1), 357-364. doi:http://dx.doi.org/10.1097/AOG.0b013e3181cbd5f5

Gale, S., \& Harlow, B. L. (2003). Postpartum mood disorders: A review of clinical and epidemiological factors. J Psychosom Obstet Gynaecol, 24, 257-66. doi:10.3109/01674820309074690

Gibson, E. L. (2006). Emotional influences on food choice: Sensory, physiological and psychological pathways. Physiology \& Behavior, 89(1), 53-61. doi:S00319384(06)00010-2 [pii]

Griffiths, L. J., Dezateux, C., \& Cole, T. J. (2007). Differential parental weight and height contributions to offspring birth weight and weight gain in infancy. International Journal of Epidemiology, 36(1), 104-107. 
Grote, V., Vik, T., von Kries, R., Luque, V., Socha, J., Verduci, E., . . European Childhood Obesity Trial Study Group. (2010). Maternal postnatal depression and child growth: A European cohort study. BMC Pediatrics, 10, 14.

Hasselmann, M. H., \& Reichenheim, M. E. (2006). Parental violence and the occurrence of severe and acute malnutrition in childhood. Pediatric Perinatal Epidemiology, 20(4), 299-311.

Hockenberry, M. J., \& Wilson, D. (2015). Wong's nursing care of infants and children (10th ed.) Mosby.

McDonald, R., Jouriles, E. N., \& Skopp, N. A. (2006). Reducing conduct problems among children brought to women's shelters: Intervention effects 24 months following termination of services. Journal of Family Psychology, 20(1), 127-136.

Meyer, M. B. (1978). How does maternal smoking affect birth weight and maternal weight gain? evidence from the Ontario perinatal mortality study. American Journal of Obstetrics \& Gynecology, 131(8), 888-893.

Nicolson, P. (1990). Understanding postnatal depression: A mother-centred approach. Journal of Advanced Nursing, 15, 689-95. doi:10.1111/j.1365-2648.1990.tb01892.x.

Place, J. m. (2014). Detecting intimate partner violence and post partum depression. Journal of Global Health,

Rahman, M., Poudel, K. C., Yasuoka, J., Otsuka, K., Yoshikawa, K., \& Jimba, M. (2012). Maternal exposure to intimate partner violence and the risk of undernutrition 
among children younger than 5 years in Bangladesh. American Journal of Public Health, 102(7), 1336-1345.

Rico, E., Fenn, B., Abramsky, T., \& Watts, C. (2011). Associations between maternal experiences of intimate partner violence and child nutrition and mortality: Findings from demographic and health surveys in Egypt, Honduras, Kenya, Malawi and Rwanda. Journal of Epidemiology \& Community Health, 65(4), 360-367.

Rodriguez, M. A., Valentine, J., Ahmed, S. R., Eisenman, D. P., Sumner, L. A., Heilemann, M. V., \& Liu, H. (2010). Intimate partner violence and maternal depression during the perinatal period: A longitudinal investigation of Latinas. Violence Against Women, 16(5), 543-559.

Salazar, M., Hogberg, U., Valladares, E., \& Persson, L. A. (2012). Intimate partner violence and early child growth: A community-based cohort study in Nicaragua. BMC Pediatrics, $12,82$.

Santos, I. S., Matijasevich, A., Domingues, M. R., Barros, A. J. D., \& Barros, F. C. F. (2010). Long-lasting maternal depression and child growth at 4 years of age: A cohort study. Journal of Pediatrics, 157(3), 401-406.

Silverman, J. G., Decker, M. R., Gupta, J., Kapur, N., Raj, A., \& Naved, R. T. (2009). Maternal experiences of intimate partner violence and child morbidity in Bangladesh: Evidence from a national Bangladeshi sample. Archives of Pediatrics \& Adolescent Medicine, 163(8), 700-705. 
Sobkoviak, R. M., Yount, K. M., \& Halim, N. (2012). Domestic violence and child nutrition in Liberia. Social Science \& Medicine, 74(2), 103-111.

Tayie, F. A., \& Powell, C. (2012). Sex differences in the association between prenatal smoking and decreased birth weight, and intensive health care of the neonate. Behavioral Medicine, 38(4), 138-142.

Torres, S. J., \& Nowson, C. A. (2007). Relationship between stress, eating behavior, and obesity. Nutrition (Burbank, Los Angeles County, Calif.), 23(11-12), 887-894. doi:S0899-9007(07)00249-3 [pii]

Vogazianos, P., Fiala, J., \& Vogazianos, M. (2005). The influence of active maternal smoking during pregnancy on birth weights in Cyprus. Central European Journal of Public Health, 13(2), 78-84.

Wang, Y., \& Chen, H. (2012). Use of percentiles and Z scores in anthropometry. In V. R. Preedy (Ed.), Handbook of anthropometry: Physical measures 29 of human form in health and disease (pp. 29-42) Springer Science+Business Media. doi:DOI 10.1007/978-1-4419-1788-1_2,

Yount, K., M., DiGirolamo, A., M., \& Ramakrishnan, U. (2011). Impacts of domestic violence on child growth and nutrition: A conceptual review of the pathways of influence. Social Science \& Medicine, 72(9), 1534-1554.

doi:10.1016/j.socscimed.2011.02.042 
CHAPTER FIVE:FINDINGS (Manuscript 3)

\title{
Intimate partner violence, depression and child growth
}

\begin{abstract}
The aim of this study was to investigate the relationship between maternal pre and postnatal depression, intimate partner violence (IPV) and Weight-for-height (WHZ) Z-sores of children at 24 month of age. The prevalence of prenatal and postpartum depression was over half in this sample size (118/207 and 119/207) respectively. Logistic linear regression utilizing both univariate and multivariate analyses were used to assess the association between WHZ at 24 months and exposure or non-exposure to prenatal depression and prenatal abuse. Increased weight was associated with children who were exposed to prenatal and postnatal depression without exposure to prenatal abuse. Lower WHZ was associated with child exposed to prenatal abuse and children perceived to be difficult by their parents. These findings mandate more research to assess the impact of depression on children's weight gain and the relationship between child's weight and prenatal abuse exposure and difficult child scores in low-income mothers who are smokers.
\end{abstract}

Key words: Abuse, Depression, Weight-for-Height Z-score, difficult child score 


\section{Background}

Depression is an overwhelming feeling of sadness and hopelessness that can last for months or years (Devries et al., 2013). Depression is responsible for a substantial proportion of global disease burden, it affects more than 350 million people worldwide. It is the eleventh leading cause of global disability-adjusted life-years and it affects one in six people at some time during their lives. Globally, about a million people commit suicide every year, usually because they have depression or some other mental illness. (Devries et al., 2013). Experience of intimate partner violence (IPV) is strongly and consistently associated with both depressive symptoms and depressive disorder in women of both high and low socio-economic status (Beydoun, Beydoun, Kaufman, Lo, \& Zonderman, 2012; Bonomi et al., 2006; Devries et al., 2011; Deyessa et al., 2010; Ellsberg et al., 2008). IPV is reported by $15-71 \%$ of women worldwide in their lifetime (Devries et al., 2011) IPV is defined as physical, sexual, or psychological harm by a current or former partner or spouse (Garcia-Moreno et al., 2006).

While it is easy to assume that IPV is casually related to subsequent depression, evidence suggests a more complex relationship. Devries (2013) suggests three models: (1) IPV exposure leads to subsequent depression, (2) depression causes subsequent IPV and (3) there are common risk factors for both IPV and depression that explain the association between them. In the first model, it is suggested that stress caused by IPV may be the cause of depression. Traumatic events can lead to isolation, fear and stress that may lead to depression (Hyde, Mezulis, \& Abramson, 2008). A meta analysis of three longitudinal studies to determine IPV as a risk factor for depression provides support for this association (Beydoun et al., 2012). Conversely, other studies suggest that 
women with severe mental problems are more likely to experience violence (Khalifeh \& Dean, 2010; McPherson, Delva, \& Cranford, 2007). A study conducted in the United States with middle and high school students suggest that depression precedes a first incident of dating violence (Lehrer, Buka, Gortmaker, \& Shrier, 2006). To explain the third model, early exposure to violence and other trauma may play a role in predicting both violence and depression (Bifulco et al., 2006; Doumas, Pearson, Elgin, \& McKinley, 2008).

The risk of depression in women is approximately twofold higher than in men (Riolo, Nguyen, Greden, \& King, 2005) and women are particularly prone in the postpartum period because of hormonal changes associated with childbirth and stressors associated with parenting (Gale \& Harlow, 2003; Nicolson, 1990). The combination of women's vulnerability to depression, their responsibility for childcare and the high prevalence of maternal depression means that maternal mental health could have a substantial influence on growth during childhood (Surkan, Kennedy, Hurley, \& Black, 2011; Wach, 2009). A study to assess the long term effects of maternal depression and child growth at four years found that depression was positively associated with wasting and stunting in children (Santos et al., 2010). Another study conducted in Uganda reinforced the relationship between maternal depression and malnutrition in children (Ashaba, Rukundo, Beinempaka, Ntaro, \& LeBlanc, 2015)

\section{Depression and impact on child}

In a review of evidence to examine the association between maternal depression and infant growth, three ways in which maternal depression and child growth impairment may be associated were identified (Stewart, 2007). First confounding factors such as 
poverty, marital status, and education status may play a role in maternal depression and infant undernutrition (Patel, DeSouza, \& Rodrigues, 2003; A. Rahman, Lovel, Bunn, Iqbal, \& Harrington, 2004). Second maternal depression may affect the mother's ability to provide adequate nutritional care to infant that includes early cessation of breastfeeding. A depressed mother may also be less successful in accessing general health care for herself and her child. An alternative by which maternal depression may affect nutrition is through its impact on mother-child interaction. Depressed mothers may be less emotionally sensitive and attuned, which in turn leads to apathy and withdrawal from the infant (Stewart, 2007). Lastly caring for a child who may be failing to grow may cause maternal depression. This depression could arise from maternal fears and worries for her sickly child. Mother's sense of self worth may also be threatened by the stigma of having a child who is not doing well (Stewart, 2007).

Providing continuous care and attention to children is a demanding task and poor mental health in the mother may be expected to have adverse consequences on their children's growth and development. Several studies have robust evidence that postnatal depression is a risk factor for long-term emotional, cognitive and behavioral problems in children (Hay, Pawlby, Angold, Harold, \& Sharp, 2003; Kurstjens \& Wolke, 2001; Murray \& Cooper, 1997; Murray et al., 1999; Sharp et al., 1995). Its impact on physical development has had less attention. The aim of this study is to determine the relationship maternal IPV exposure, maternal pre and post natal depression and child wasting (low weight-for-height measures) in children less than two years of age. 


\section{Materials and methods}

\section{Data}

Existing data from two prior studies will be used for this analysis: R01NR 05313: Nursing smoking cessation intervention during pregnancy (Baby BEEP) and RO1HD0045542: Nursing support better infant outcomes in violent homes (BBK). Women attending rural Women, Infant, and Children Nutrition Supplement Program (WIC) in 21 counties in a Midwestern state who reported smoking at least one cigarette per day, spoke English and were 18 years or older less than 24 weeks gestation were recruited between January 2002 and October 2005 to participate in the Baby BEEP trial (Bullock et al., 2009b). Mothers and infants in the BBK study were drawn from Baby BEEP study beginning May 2004 when they were due for their sixth month assessment. Research nurses who worked on both the Baby BEEP and BBK studies interviewed all mothers to obtain demographic information and obtained weight and height measurements of the index child at 5-11, 12-18 and 19-26 months.

Maternal depression in this study refers to symptoms indicative of depression, but a clinical diagnosis of depression was not made. This variable was measured with the fiveitem Mental Health Inventory (MHI-5) tool (Ware \& Gandek, 1994).

Difficult child scores were derived from Parental Stress Index-Short Form (PSI-SF). The Difficult Child subscale represents behaviors that children often engage in that may make parenting easier or more difficult (Abidin, 1995).

Prenatal abuse/violence was measured with the Abuse Assessment Screen (AAS). AAS measures past and present instances of physical and sexual abuse, as well as who was the 
perpetrator and location of the physical abuse (McFarlane et al., 1992).

Postnatal abuse/violence was measured with the Severity of Violence Against Women Scales (SVAWS) was used to measure postnatal violence. The SVAWS measures behaviors that threaten physical violence and actual physical and sexual violence Marshall, 1992).

\section{Data analysis}

The periods of interest was 24 months; however, the measurements were actually obtained between 19-24 months thus weight and height were interpolated to 24 months. Measurements taken within 15 days of the designated visit month (i.e., 24) were kept for analysis. Those beyond \pm 15 days were interpolated to align to the designated month.

Univariate and multivariate linear regression was used to assess the association between maternal prenatal abuse status (abused/not abused) and prenatal depression (depressed/not depressed) and WHZ at 24 months. The Statistical Package for Social Sciences (Version 23; SPSS Inc., Chicago, IL) was used to analyze the data. Coefficients and standard error was reported for both univariate and multivariate logistic regression. A p value of less than 0.05 was considered significant.

\section{Ethics}

The Ethics Research Committee of University of Virginia approved the study protocol. 


\section{Results}

\section{Sample size}

A sample size of 207 mother-baby dyads was used for this study.

\section{Characteristics of the mothers}

The majority of women in this sample were white (188/207) and their average age at index pregnancy was 23.84 years. More than half $(118 / 207)$ of the women were depressed during pregnancy. For 46\% (97/207) the index child was the first child. Seventy percent of women were married (145/207). There were no statistically significant differences in rates of depression by any of these variables (See Table 1)

\section{Characteristics of the child}

More than half of the children in this sample were male $(52.2 \%)$. There were no statistically significant differences in birth weight, WHZ, and scores on the difficult child scale by maternal depression status. (See Table 1)

\section{Maternal non-exposure to abuse during pregnancy}

After adjusting for WHZ at baseline and the child's gender there was a significant association between gender $(\mathrm{p}=0.008)$ of the child and WHZ. Female children not exposed to abuse had a lower WHZ compared to male children. There was a significant association $(\mathrm{p}=0.032)$ between prenatal depression and WHZ. Children not exposed to abuse but exposed to prenatal depression had greater WHZ (See Table 2). After adjusting for baseline variables and IPV after birth and replacing follow up variables one at a time with IPV and stratifying by abuse, there was an association $(\mathrm{p}=0.047)$ between postnatal depression and WHZ. Children who were not exposed to abuse but whose mothers had depression after birth had a greater WHZ compared to 
those whose mothers were not depressed and not abused (See table 3).

\section{Maternal exposure to abuse during pregnancy}

There was a significant association between $2^{\text {nd }}$ pregnancy $(p=0.042)$ and WHZ at 24 months. A second born child who was exposed to prenatal abuse had a lower WHZ compared to a firstborn child. Additionally, children who were perceived to be difficult by their parents and exposed to abuse had a lower WHZ ( $\mathrm{p}=0.004)$ compared to those not perceived to be difficult (See table 2). An interaction between prenatal abuse and difficult child scores was significant $(\mathrm{p}=0.012)$; this means that children who were perceived to be difficult by their parents and who were exposed to abuse had a lower WHZ (See table 4).

\section{Maternal non-exposure to prenatal depression}

Children whose mothers were not depressed during pregnancy but depressed after birth had a greater WHZ at 24 months $(\mathrm{p}=0.006)$. Children who were missing difficult child scores and whose mothers were not depressed during pregnancy had a lower WHZ $(\mathrm{p}=0.022)$ compared to those that were not exposed depression during pregnancy with difficult child score and were not perceived to be difficult by their parents (See Table 5).

After adjusting for baseline variables and IPV after birth and replacing follow up variables one at a time with IPV and stratifying by depression, children whose mothers had depression after birth but did not have depression during pregnancy had greater WHZ at 24 months $(p=0.003)$ compared to those that did not have depression after birth. (See Table 6).

\section{Discussion}

A significant proportion of women in this study were depressed. Depression was 
higher among married women, and those who were carrying the first pregnancy. As noted in another analysis of these same data (Kimeto et al, in preparation), all of the women in this study were smokers, and there is a strong relationship between smoking and depression (Place, 2014; Rodriguez et al., 2010). The prevalence of IPV during pregnancy measured in this analysis is in line with those of other population-based samples of pregnant women (Daoud et al., 2012; Deshpande \& Lewis-O'Connor, 2013; Gazmararian et al., 2000; Silva, Ludermir, Araujo, \& Valongueiro, 2011; Van Parys, Deschepper, Michielsen, Temmerman, \& Verstraelen, 2014). Thirty-five percent of women were abused during pregnancy and this increased by about $9 \%$ in the postpartum period. This, too, is in line with a previous study that suggested that abuse may increase in the postpartum period, especially the first 3 months (Silva, Valongueiro, de Araujo, \& Ludermir, 2015). It is difficult to interpret this increase in depression in this sample, however, as the researchers used different measures to assess abuse in the prenatal period [the AAS (McFarlane et al., 1992)[ vs the postnatal period [the SVAWS]. It is possible that the longer, more comprehensive SVAWS led to an increase in the number of women who screened positive for abuse. Prenatal depression has been noted to significantly predict postnatal depression (Edwards, Galletly, Semmler-Booth, \& Dekker, 2008; Lee et al., 2007; Milgrom et al., 2008). This finding was true for this study as well.

\section{Effects of prenatal abuse and depression on the child}

In this study, the mothers' prenatal depression was associated with children's increased weight gain at 24 months. This finding does not agree with a study conducted in Latina children in the US that found lower weight gain up to 24 months in those children who were exposed to prenatal depression compared to those whose mothers 
were not depressed (Wojcicki et al., 2011). Prenatal depression has been associated with excessive activity and growth delays in the fetus as well as prematurity and low birth weight (Field, 2011). Other effects of prenatal depression include higher levels of fussing and crying and more sleep problems, which may persist through 18 and 30 months (Field et al., 2007; O'Connor et al., 2007) and which can negatively affect growth. Given findings from these studies, it was expected that children exposed to prenatal depression in this study would have lower weight gain, but the opposite was true. Further research is needed to understand the specific mechanisms at work.

Postnatal depression in mothers was also associated with greater weight gain at 24 months compared to children whose mothers were not depressed, even when the mothers did not also experience prenatal depression. Previous studies suggests that maternal depression at 12, 24, and 48 months post-partum is not a risk factor for impaired child growth or overweight (Santos et al., 2010). Additionally the Avon Longitudinal Study of Parents and Children (ALSPAC) that followed a large birth cohort for 20 months found no significant association between post natal maternal depression and child underweight (Drewett, Blair, \& Emond, 2004). In another study, children of mothers who were depressed at two to three months post partum were most likely to have faltering weight at four months compared to infants of mothers who were not depressed, however this difference was no longer present at 13 months (Wright, Parkinson, \& Drewett, 2006).

While abuse status was not significantly associated with weight changes in either direction in this cohort, children perceived to be difficult by their parents and exposed to prenatal abuse did have lower weight gain than their counterparts. Previous studies have 
assessed the impact of IPV on child's temperament (Bowen, 2015; Burke, Lee, \& O'Campo, 2008) but not the relationship between maternal IPV and mother's perception of child's difficulty. Findings from a study to assess parent/child stress in families experiencing IPV suggests that parents who have experienced partner violence expressed greater parental distress, negative parent/child interaction, and reported the child as being more difficult than the normative sample (Worthy, Bagwell, \& Hudson, 2013). This is the first study to assess weight gain in children perceived to be difficult by their parents and maternal exposure to abuse and depression.

\section{Limitations}

The present study did not dichotomize WHZ because there were too few participants with Z-scores of -2 or below. Thus low WHZ scores in this study do not necessarily mean that the child was wasted. Because the Z-score were mostly above -2 , it is difficult to determine whether weight was greater or lower within normal weight range or on overweight range for this age group.

\section{Conclusion}

Findings from this study suggest that child exposure to prenatal and postnatal depression without exposure to prenatal abuse is associated with increased weight gain at 24 months. It also suggests that prenatal abuse is associated with low weight gain in children perceived to be difficult by their parents. These findings suggest the need for more research to assess impact of pre- and postnatal depression on child's weight gain and the relationship between child's weight and prenatal abuse exposure and difficult child scores in low-income mothers who are smokers. There is also need to screen for maternal depression in prenatal and well baby clinics to identify women who are 
depressed and manage them adequately. 
Tables

Table 1: Baseline demographic data of the sample stratified by Abuse

\begin{tabular}{|c|c|c|c|c|}
\hline & $\begin{array}{c}\text { Total sample } \\
\qquad \mathbf{N}=\mathbf{2 0 7}\end{array}$ & $\begin{array}{c}\text { Not } \\
\text { Depressed } \\
\text { n=89 }\end{array}$ & $\begin{array}{c}\text { Depressed } \\
\mathrm{n}=118\end{array}$ & $P$ value \\
\hline Baseline variables & $n(\%)$ & $n(\%)$ & $n(\%)$ & \\
\hline \multicolumn{5}{|l|}{ Gender } \\
\hline Male & $108(52.2)$ & $46(51.7)$ & $62(52.5)$ & \multirow[t]{2}{*}{0.903} \\
\hline Female & $99(47.8)$ & $43(48.3)$ & $56(47.5)$ & \\
\hline \multicolumn{5}{|l|}{ Prenatal Abuse } \\
\hline No & $134(64.7)$ & $64(71.9)$ & $70(59.3)$ & \multirow[t]{2}{*}{0.061} \\
\hline Yes & $73(35.3)$ & $25(28.1)$ & $48(40.7)$ & \\
\hline \multicolumn{5}{|l|}{ Pregnancies } \\
\hline 1st pregnancy & $97(46.9)$ & 37 (41.6) & $60(50.8)$ & \multirow{3}{*}{0.416} \\
\hline 2nd pregnancy & $91(44.0)$ & $43(48.30$ & $48(40.7)$ & \\
\hline 3rd or more pregnancies & $19(9.2)$ & $9(10.1)$ & $10(8.5)$ & \\
\hline \multicolumn{5}{|l|}{ Breastfeeding Status } \\
\hline Yes & $111(53.6)$ & $45(50.6)$ & $66(55.9)$ & \multirow[t]{2}{*}{0.443} \\
\hline No & $96(46.4)$ & 44 (49.4) & $52(44.1)$ & \\
\hline
\end{tabular}


Mothers Ethnicity

$\begin{array}{lcccc}\text { White } & 188(90.8) & 84(94.4) & 104(88.1) & 0.123 \\ \text { Other } & 19(9.2) & 5(5.6) & 14(11.9) & \end{array}$

Maternal relationship status

$\begin{array}{lcccc}\text { Married } & 145(70) & 65(73.0) & 80(67.8) & 0.415 \\ \text { Other } & 62(30) & 24(27.0) & 38(32.2) & \\ & \text { Mean (SD) } & \text { Mean (SD) } & \text { Mean (SD) } & \\ \text { Mothers age (years)* } & 23.84(4.90) & 23.66(4.78) & 23.97(5.02) & 0.652 \\ \text { Baby's weight (kg)* } & 3.28(0.46) & 3.28(0.44) & 3.27(0.48) & 0.983 \\ \text { Baby's height (cm)* } & 50.07(0.66) & 49.68(6.47) & 50.36(2.58) & 0.284 \\ \text { Weight-for-height Z-score* } & -0.68(1.65) & -0.72(1.52) & -0.65(1.75) & 0.76 \\ \text { Height- for - age Z-score* } & 0.48(1.39) & 0.53(1.41) & 0.45(1.37) & 0.692\end{array}$

Follow up/post natal Data stratified by Abuse

\begin{tabular}{lcccc}
\hline & $\begin{array}{c}\text { Total sample } \\
\mathbf{N = 2 0 7}\end{array}$ & $\begin{array}{c}\text { Not } \\
\text { Depressed } \\
\mathbf{n = 8 9}\end{array}$ & $\begin{array}{c}\text { Depressed } \\
\mathbf{n = 1 1 8}\end{array}$ & P value* \\
\cline { 2 - 5 } Follow up variables & $\mathbf{n ( \% )}$ & $\boldsymbol{n ( \% )}$ & $\boldsymbol{n ( \% )}$ & \\
Intimate partner violence & & & & \\
$\quad$ None & $78(37.7)$ & $38(42.7)$ & $40(33.9)$ & 0.396 \\
Yes & $96(46.4)$ & $39(43.8)$ & $57(48.3)$ &
\end{tabular}




\begin{tabular}{|c|c|c|c|c|}
\hline Missing & $33(15.9)$ & $12(13.5)$ & $21(17.8)$ & \\
\hline \multicolumn{5}{|l|}{ Maternal Depression } \\
\hline Not Depressed & $88(42.5)$ & $41(46.1)$ & $47(39.8)$ & \multirow{2}{*}{0.369} \\
\hline Depressed & $119(57.5)$ & $48(53.9)$ & $71(60.2)$ & \\
\hline \multicolumn{5}{|l|}{ Difficult child scores } \\
\hline Not difficult & $160(77.3)$ & $69(77.5)$ & $91(77.1)$ & \multirow{3}{*}{0.796} \\
\hline Difficult & $33(15.9)$ & $13(14.6)$ & $20(16.9)$ & \\
\hline Missing & $14(6.8)$ & $7(7.9)$ & $7(5.9)$ & \\
\hline \multicolumn{5}{|l|}{ Severity of violence } \\
\hline None & $78(37.7)$ & $39(43.8)$ & $39(33.1)$ & \multirow{5}{*}{0.353} \\
\hline No severity & $47(22.7)$ & $16(18.0)$ & $33(28.0)$ & \\
\hline Mild to minor & $17(8.2)$ & $5(5.6)$ & $12(10.2)$ & \\
\hline Moderate to severe & $32(15.9)$ & $17(19.1)$ & $15(12.7)$ & \\
\hline Missing & $33(15.9)$ & $12(13.5)$ & $21(17.8)$ & \\
\hline \multicolumn{5}{|l|}{ Type of violence } \\
\hline None & $78(37.7)$ & $39(43.8)$ & $39(33.1)$ & \multirow{4}{*}{0.445} \\
\hline Emotional & $49(23.7)$ & $20(22.5)$ & $29(24.6)$ & \\
\hline Emotional and physical & $47(22.7)$ & $18(20.2)$ & $29(24.6)$ & \\
\hline Missing & 33 (15.9) & $12(13.5)$ & $21(17.8)$ & \\
\hline
\end{tabular}


* Student t test, all other Chi square test.

Table 2: Univariate association between baseline and follow up predictors and weight-for height Z-score stratified by abuse

\begin{tabular}{|c|c|c|c|c|c|c|}
\hline & \multicolumn{3}{|c|}{ Abused } & \multicolumn{3}{|c|}{ Not exposed } \\
\hline & Estimates & SE & $P$ value & Estimates & SE & $P$ value \\
\hline WHZ at baseline & 0.176 & 0.095 & 0.07 & 0.011 & 0.055 & 0.841 \\
\hline Gender (girl vs. boy) & -0.294 & 0.291 & 0.315 & -0.487 & 0.18 & $0.008 *$ \\
\hline \multicolumn{7}{|l|}{ Baseline predictors } \\
\hline Depression prenatal & 0.02 & 0.015 & 0.185 & 0.02 & 0.009 & $0.032 *$ \\
\hline \multicolumn{7}{|l|}{ Pregnancies (1st preg is ref) } \\
\hline 2nd pregnancy & -0.582 & 0.281 & $0.042^{*}$ & -0.211 & 0.182 & 0.248 \\
\hline 3rd or more pregnancies & 0.593 & 0.487 & 0.227 & -0.446 & 0.315 & 0.159 \\
\hline \multicolumn{7}{|l|}{ Follow up predictors } \\
\hline \multicolumn{7}{|c|}{ Difficult child scores (No is the ref) } \\
\hline Yes & -1.047 & 0.351 & $0.004 *$ & 0.036 & 0.259 & 0.891 \\
\hline
\end{tabular}


Missing

$-0.249$

0.868

0.775

$-0.38$

0.316

0.231

Note: Each of the predictors (baseline and follow up) are adjusted for weight-for-height Z-score at baseline and gender

*Significant at 0.05

Table 3: Multivariate association of baseline predictors and weight-for-height Z-score at 24 months stratified by abuse for both male and female

\begin{tabular}{|c|c|c|c|c|c|c|}
\hline & \multicolumn{3}{|c|}{ Abused } & \multicolumn{3}{|c|}{ Not abused } \\
\hline & Estimates & SE & $P$ value & Estimates & SE & $P$ value \\
\hline \multicolumn{7}{|l|}{ Baseline Predictors } \\
\hline WHZ at baseline & 0.196 & 0.099 & 0.052 & 0.02 & 0.057 & 0.728 \\
\hline Gender (girl vs boy) & -0.223 & 0.302 & 0.462 & -0.498 & 0.187 & 0.009 \\
\hline \multicolumn{7}{|l|}{ Follow up predictors } \\
\hline \multicolumn{7}{|c|}{ Intimate partner violence (No is the ref) } \\
\hline Yes & 0.081 & 0.341 & 0.812 & -0.041 & 0.199 & 0.837 \\
\hline Missing & 0.232 & 0.472 & 0.625 & -0.049 & 0.273 & 0.857 \\
\hline Depression postnatal (Yes vs No) & 0.029 & 0.016 & 0.073 & 0.019 & 0.009 & $0.047 *$ \\
\hline
\end{tabular}


Difficult child scores (No is the ref)

$\begin{array}{lcccccc}\text { Yes } & -1.001 & 0.391 & 0.013^{*} & 0.078 & 0.263 & 0.768 \\ \text { Missing } & -0.51 & 0.903 & 0.574 & -0.392 & 0.336 & 0.246\end{array}$

Note: Follow up predictors were included in the model individually with baseline predictors

*Significance at 0.05

Table 4: Interaction of abuse and difficult child scores with baseline predictors

\begin{tabular}{llll}
\hline & Estimates & SE & P value \\
\cline { 2 - 4 } Baseline predictors & & & \\
Interaction of abuse and difficult child scores & & & \\
$\quad$ Abuse and yes DC & -1.099 & 0.436 & $0.012^{*}$ \\
$\quad$ Abuse and DC missing & -0.173 & 0.862 & 0.841 \\
\hline
\end{tabular}

Note: Baseline predictors + abuse (yes, no) + Abuse (yes)* difficult child scores (yes) +

Abuse (No)* difficult child scores (missing) * Significant $\mathrm{p}=0.05$ 
Table 5: Univariate association of baseline and follow up predictors with weight-for -height $Z$-score at 24 months stratified by maternal depression status for male and female

\begin{tabular}{|c|c|c|c|c|c|c|}
\hline & \multicolumn{3}{|c|}{ Depressed } & \multicolumn{3}{|c|}{ Not depressed } \\
\hline & Estimates & $\mathbf{S E}$ & $P$ value & Estimates & SE & $P$ value \\
\hline WHZ at baseline & 0.099 & 0.067 & 0.144 & 0.017 & 0.07 & 0.803 \\
\hline Gender (girl vs. boy) & -0.133 & 0.22 & 0.545 & -0.789 & 0.215 & $<.001 *$ \\
\hline \multicolumn{7}{|l|}{ Baseline predictors } \\
\hline Mother's Abuse (Yes vs. No) & 0.169 & 0.221 & 0.448 & 0.385 & 0.237 & 0.107 \\
\hline \multicolumn{7}{|l|}{ Pregnancies (1st preg is ref) } \\
\hline 2nd pregnancy & -0.639 & 0.216 & $0.004 *$ & -0.071 & 0.223 & 0.75 \\
\hline 3rd or more pregnancies & 0.022 & 0.394 & 0.956 & -0.126 & 0.357 & 0.725 \\
\hline Breastfeeding status (Yes vs. No) & -0.545 & 0.217 & $0.014^{*}$ & 0.17 & 0.219 & 0.438 \\
\hline \multicolumn{7}{|l|}{ Follow up predictors } \\
\hline Depression postnatal (Yes vs. No) & 0.063 & 0.224 & 0.78 & 0.594 & 0.21 & $0.006^{*}$ \\
\hline \multicolumn{7}{|l|}{ Difficult child scores (No is the ref) } \\
\hline Yes & -0.506 & 0.289 & 0.083 & -0.243 & 0.306 & 0.429 \\
\hline Missing & -0.011 & 0.459 & 0.981 & -0.915 & 0.393 & $0.022 *$ \\
\hline
\end{tabular}

Note: Each of the predictors (baseline and follow up) are adjusted for weight-for-height Z-score at baseline and gender 
*Significant at 0.05

Table 6: Multivariate association of baseline predictors and weight-for-height Z-score at 24 months stratified by maternal depression for male and female

\begin{tabular}{|c|c|c|c|c|c|c|}
\hline & \multicolumn{3}{|c|}{ Depressed } & \multicolumn{3}{|c|}{ Not depressed } \\
\hline & Estimates & SE & $P$ value & Estimates & SE & $P$ value \\
\hline WHZ at baseline & 0.074 & 0.065 & 0.259 & 0.022 & 0.075 & 0.766 \\
\hline Gender (boy vs. girl) & 0.02 & 0.218 & 0.928 & -0.808 & 0.223 & $0.001 *$ \\
\hline \multicolumn{7}{|l|}{ Baseline predictors } \\
\hline Mother's Abuse (Yes vs. No) & 0.154 & 0.215 & 0.476 & 0.391 & 0.249 & 0.12 \\
\hline \multicolumn{7}{|l|}{ Pregnancies (1st pregnancy is ref) } \\
\hline 2nd pregnancy & -0.742 & 0.249 & $0.004 *$ & -0.135 & 0.285 & 0.637 \\
\hline 3 rd or more pregnancies & -0.358 & 0.484 & 0.461 & -0.302 & 0.497 & 0.545 \\
\hline Breastfeeding status (Yes vs. No) & -0.608 & 0.214 & $0.005^{*}$ & 0.129 & 0.231 & 0.577 \\
\hline \multicolumn{7}{|l|}{ Follow up predictors } \\
\hline Depression postnatal (Yes vs. No) & 0.011 & 0.011 & 0.341 & 0.034 & 0.011 & $0.003 *$ \\
\hline
\end{tabular}

Note: Follow up predictors were included in the model individually with baseline predictors

*Significance at 0.05 


\section{References}

Abidin, R. R. (Ed.). (1995). Parenting stress index: Professional manual. (3rd ed.). Odessa, FL: Psychological Assessment Resources, Inc.

Ashaba, S., Rukundo, G. Z., Beinempaka, F., Ntaro, M., \& LeBlanc, J. C. (2015). Maternal depression and malnutrition in children in southwest Uganda: A case control study. BMC Public Health, 15(1), 1303.

Beydoun, H. A., Beydoun, M. A., Kaufman, J. S., Lo, B., \& Zonderman, A. B. (2012). Intimate partner violence against adult women and its association with major depressive disorder, depressive symptoms and postpartum depression: A systematic review and meta-analysis. Social Science \& Medicine, 75(6), 959-975.

Bifulco, A., Kwon, J., Jacobs, C., Moran, P. M., Bunn, A., \& Beer, N. (2006). Adult attachment style as mediator between childhood neglect/abuse and adult depression and anxiety. Social Psychiatry \& Psychiatric Epidemiology, 41(10), 796-805.

Bonomi, A. E., Thompson, R. S., Anderson, M., Reid, R. J., Carrell, D., Dimer, J. A., \& Rivara, F. P. (2006). Intimate partner violence and women's physical, mental, and social functioning. American Journal of Preventive Medicine, 30(6), 458-466.

Bowen, E. (2015). The impact of intimate partner violence on preschool children's peer problems: An analysis of risk and protective factors. Child Abuse \& Neglect, 50, 141-150. doi:http://doi.org/10.1016/j.chiabu.2015.09.005

Bullock, L., Everett, K. D., Mullen, P. D., Geden, E., Longo, D. R., \& Madsen, R. (2009). Baby BEEP: A randomized controlled trial of nurses' individualized social 
support for poor rural pregnant smokers. Maternal \& Child Health Journal, 13(3), 395-406.

Burke, J. G., Lee, L. C., \& O'Campo, P. (2008). An exploration of maternal intimate partner violence experiences and infant general health and temperament. Maternal \& Child Health Journal, 12(2), 172-179.

Daoud, N., Urquia, M. L., O'Campo, P., Heaman, M., Janssen, P. A., Smylie, J., \& Thiessen, K. (2012). Prevalence of abuse and violence before, during, and after pregnancy in a national sample of Canadian women. American Journal of Public Health, 102(10), 1893-1901.

Deshpande, N. A., \& Lewis-O'Connor, A. (2013). Screening for intimate partner violence during pregnancy. Revue Obstetricale Et Gynecologique, 6(3-4), 141-148.

Devries, K. M., Mak, J. Y., Bacchus, L. J., Child, J. C., Falder, G., Petzold, M., . . . Watts, C. H. (2013). Intimate partner violence and incident depressive symptoms and suicide attempts: A systematic review of longitudinal studies. PLoS Medicine / Public Library of Science, 10(5), e1001439.

Devries, K. M., Watts, C., Yoshihama, M., Kiss, L., Schraiber, L. B., Deyessa, N., . . WHO Multi-Country Study Team. (2011). Violence against women is strongly associated with suicide attempts: Evidence from the WHO multi-country study on women's health and domestic violence against women. Social Science \& Medicine, 73(1), 79-86. 
Deyessa, N., Berhane, Y., Emmelin, M., Ellsberg, M. C., Kullgren, G., \& Hogberg, U. (2010). Joint effect of maternal depression and intimate partner violence on increased risk of child death in rural Ethiopia. Archives of Disease in Childhood, 95(10), 771-775.

Doumas, D. M., Pearson, C. L., Elgin, J. E., \& McKinley, L. L. (2008). Adult attachment as a risk factor for intimate partner violence: The "mispairing" of partners' attachment styles. Journal of Interpersonal Violence, 23(5), 616-634.

Drewett, R., Blair, P., \& Emond, A. (2004). Failure to thrive in the term and preterm infants of mothers depressed in the postnatal period a population based birth cohort study. Journal of Child Psychology \& Psychiatry \& Allied Disciplines, 45, 359-366.

Edwards, B., Galletly, C., Semmler-Booth, T., \& Dekker, G. (2008). Does antenatal screening for psychosocial risk factors predict postnatal depression? A follow-up study of 154 women in Adelaide, south Australia. Australian \& New Zealand Journal of Psychiatry, 42(1), 51-55.

Ellsberg, M., Jansen, H. A. F. M., Heise, L., Watts, C. H., Garcia-Moreno, C., \& WHO Multi-country Study on Women's Health and Domestic Violence against Women Study Team. (2008). Intimate partner violence and women's physical and mental health in the WHO multi-country study on women's health and domestic violence: An observational study. Lancet, 371(9619), 1165-1172.

Field, T. (2011). Prenatal depression effects on early development: A review. Infant Behavior \& Development, 34(1), 1-14. 
Field, T., Diego, M., Hernandez-Reif, M., Figueiredo, B., Schanberg, S., \& Kuhn, C. (2007). Sleep disturbances in depressed pregnant women and their newborns. Infant Behavior \& Development, 30(1), 127-133.

Gale, S., \& Harlow, B. L. (2003). Postpartum mood disorders: A review of clinical and epidemiological factors. J Psychosom Obstet Gynaecol, 24, 257-66. doi:10.3109/01674820309074690

Garcia-Moreno, C., Jansen, H. A., Ellsberg, M., Heise, L., Watts, C. H., \& WHO Multicountry Study on Women's Health and Domestic Violence against Women Study,Team. (2006). Prevalence of intimate partner violence: Findings from the WHO multi-country study on women's health and domestic violence. Lancet, $368(9543), 1260-1269$.

Gazmararian, J. A., Petersen, R., Spitz, A. M., Goodwin, M. M., Saltzman, L. E., \& Marks, J. S. (2000). Violence and reproductive health: Current knowledge and future research directions. Maternal \& Child Health Journal, 4(2), 79-84.

Hay, D. F., Pawlby, S., Angold, A., Harold, G. T., \& Sharp, D. (2003). Pathways to violence in the children of mothers who were depressed postpartum. Developmental Psychology, 39(6), 1083-1094.

Hyde, J. S., Mezulis, A. H., \& Abramson, L. Y. (2008). The ABCs of depression: Integrating affective, biological, and cognitive models to explain the emergence of the gender difference in depression. Psychological Review, 115(2), 291-313. 
Khalifeh, H., \& Dean, K. (2010). Gender and violence against people with severe mental illness. International Review of Psychiatry, 22(5), 535-546.

Kurstjens, S., \& Wolke, D. (2001). Effects of maternal depression on cognitive development of children over the first 7 years of life. Journal of Child Psychology \& Psychiatry \& Allied Disciplines, 42(5), 623-636.

Lee, A. M., Lam, S. K., Sze Mun Lau, S. M., Chong, C. S. Y., Chui, H. W., \& Fong, D. Y. T. (2007). Prevalence, course, and risk factors for antenatal anxiety and depression. Obstetrics \& Gynecology, 110(5), 1102-1112.

Lehrer, J. A., Buka, S., Gortmaker, S., \& Shrier, L. A. (2006). Depressive symptomatology as a predictor of exposure to intimate partner violence among US female adolescents and young adults. Archives of Pediatrics \& Adolescent Medicine, 160(3), 270-276.

Marshall, L. L. (1992). Development of the severity of violence against women scales. Journal of Family Violence, 7, 103-121.

McFarlane, J., Parker, B., Soeken, K., \& Bullock, L. (1992). Assessing for abuse during pregnancy. severity and frequency of injuries and associated entry into prenatal care. JAMA, 267(23), 3176-3178.

McPherson, M. D., Delva, J., \& Cranford, J. A. (2007). A longitudinal investigation of intimate partner violence among mothers with mental illness. Psychiatric Services, 58(5), 675-680. 
Milgrom, J., Gemmill, A. W., Bilszta, J. L., Hayes, B., Barnett, B., Brooks, J., . . Buist, A. (2008). Antenatal risk factors for postnatal depression: A large prospective study. Journal of Affective Disorders, 108(1-2), 147-157.

Murray, L., \& Cooper, P. J. (1997). Postpartum depression and child development. Psychological Medicine, 27(2), 253-260.

Murray, L., Sinclair, D., Cooper, P., Ducournau, P., Turner, P., \& Stein, A. (1999). The socioemotional development of 5-year-old children of postnatally depressed mothers. Journal of Child Psychology \& Psychiatry \& Allied Disciplines, 40(8), 1259-1271.

Nicolson, P. (1990). Understanding postnatal depression: A mother-centred approach. Journal of Advanced Nursing, 15, 689-95. doi:10.1111/j.1365-2648.1990.tb01892.x.

O'Connor, T. G., Caprariello, P., Blackmore, E. R., Gregory, A. M., Glover, V., Fleming, P., \& ALSPAC Study Team. (2007). Prenatal mood disturbance predicts sleep problems in infancy and toddlerhood. Early Human Development, 83(7), 451-458.

Patel, V., DeSouza, N., \& Rodrigues, M. (2003). Postnatal depression and infant growth and development in low-income countries: A cohort study from goa, India. Arch.Dis.Child., 88(1), 34-37. doi:org/10.1136/adc.88.1.34

Place, J. m. (2014). Detecting intimate partner violence and post partum depression. Journal of Global Health, 
Rahman, A., Lovel, H., Bunn, J., Iqbal, Z., \& Harrington, R. (2004). Mothers' mental health and infant growth: A case-control study from Rawalpindi, Pakistan. Child: Care, Health \& Development, 30(1), 21-27.

Riolo, S. A., Nguyen, T. A., Greden, J. F., \& King, C. A. (2005). Prevalence of depression by race/ethnicity: Findings from the national health and nutrition examination survey III. . American Journal of Public Health, 95, 998-1000. doi:10.2105/AJPH.2004.047225

Rodriguez, M. A., Valentine, J., Ahmed, S. R., Eisenman, D. P., Sumner, L. A., Heilemann, M. V., \& Liu, H. (2010). Intimate partner violence and maternal depression during the perinatal period: A longitudinal investigation of Latinas. Violence Against Women, 16(5), 543-559.

Santos, I. S., Matijasevich, A., Domingues, M. R., Barros, A. J. D., \& Barros, F. C. F. (2010). Long-lasting maternal depression and child growth at 4 years of age: A cohort study. Journal of Pediatrics, 157(3), 401-406.

Sharp, D., Hay, D. F., Pawlby, S., Schmucker, G., Allen, H., \& Kumar, R. (1995). The impact of postnatal depression on boys' intellectual development. Journal of Child Psychology \& Psychiatry \& Allied Disciplines, 36(8), 1315-1336.

Silva, E. P., Ludermir, A. B., Araujo, T. V. B. d., \& Valongueiro, S. A. (2011). Frequency and pattern of intimate partner violence before, during and after pregnancy. Revista De Saude Publica, 45(6), 1044-1053. 
Silva, E. P., Valongueiro, S., de Araujo, T. V. B., \& Ludermir, A. B. (2015). Incidence and risk factors for intimate partner violence during the postpartum period. Revista De Saude Publica, 49, 46.

Stewart, R. C. (2007). Maternal depression and infant growth: A review of recent evidence. Maternal \& Child Nutrition, 3(2), 94-107.

Surkan, P. J., Kennedy, C. E., Hurley, K. M., \& Black, M. M. (2011). Maternal depression and early childhood growth in developing countries: Systematic review and meta-analysis. Bulletin of the World Health Organization, 89, 608-615. doi:10.2471/BLT.11.088187

Van Parys, A., Deschepper, E., Michielsen, K., Temmerman, M., \& Verstraelen, H. (2014). Prevalence and evolution of intimate partner violence before and during pregnancy: A cross-sectional study. BMC Pregnancy \& Childbirth, 14, 294.

Wach, T. D. (2009). Models linking nutritional deficiencies to maternal and child mental health. American Journal of Clinical Nutrition, 89, 935-9. doi:10.3945/ajen.2008.26692B

Worthy, S., Bagwell, B., \& Hudson, T. (2013, February 26). Parent/child stress in families experiencing domestic violence.

Wright, C. M., Parkinson, K. N., \& Drewett, R. F. (2006). The influence of maternal socioeconomic and emotional factors on infant weight gain and weight faltering (failure to thrive): Data from a prospective birth cohort. A. Adv.Skin Wound Care, 91(4), 312-317. doi:http://doi.org/10.1136/adc.2005.077750 


\section{CHAPTER SIX: DISCUSSION AND CONCLUSION}

This study set out to look at the difference in growth of children exposed to abuse and those not exposed. No significant difference was seen in weight and height of children exposed to abuse and those not exposed. There was also no difference in maternal characteristics such as age, parity, relationship status, ethnicity, prenatal depression status, postnatal violence and depression in those exposed to abuse and those not exposed. A review of literature to assess impact of intimate partner violence (IPV) and child physical growth showed significant relationship between exposure to IPV and wasting, stunting and undernutrition (Ackerson \& Subramanian, 2008; Asling-Monemi et al., 2009; Boynton-Jarrett et al., 2010; Hasselmann \& Reichenheim, 2006). Th4 review also found a difference in maternal characteristics such as low education, low socioeconomic status, parity and place of residence (urban versus rural) in those exposed to IPV and those not exposed. Additionally, different types of growth failures were found to be associated with different types/severity of IPV as well as controlling behaviors of the perpetrator.

Depression in the mother whether during the pregnancy, after the birth or both was associated with greater weight gain in infants, regardless of abuse status. This finding was surprising in several ways. Previous studies have shown that children exposed to prenatal depression have lower weight gain compared to those not exposed (Wojcicki et al., 2011). Additionally smoking during pregnancy is estimated to account for about a quarter of low birth weight babies (Meyer, 1978; Vogazianos et al., 2005) all women in this study were smokers during pregnancy. Previous studies suggests that maternal depression in the postpartum period was not a risk factor for impaired child growth or overweight (Drewett et al., 2004; Santos et al., 2010). There are several 
possible explanations for the higher weights among infants of depressed women in this study. It may be explained all or in part that women in this study participated in the Women, Infant, and Children Nutrition Supplement Program (WIC). WIC is effective in improving the health of pregnant women, new mothers, and their infants through the provision of supplementary nutritious food and formula to mother and baby (http://www.fns.usda.gov/wic/women-infants-and-children-wic). Additionally, stress influences feeding behaviors including type, quantity and patterns of eating (Dallman, 2010; Gibson, 2006; Torres \& Nowson, 2007). Glucocorticoids produced during depression may drive intake of palatable or "comfort" foods that decrease feelings of stress and reinforce habitual behavior at the expense of homeostatic regulators (Gibson, 2006). Due to stress, the mother may have been overeating and feeding her child every time she ate. This finding merits greater attention in future research. Obesity is a significant problem in the US and substantial research has demonstrated that for many, the overweight begins in childhood or even infancy (Ogden, Carroll, Kit, \& Flegal, 2014). If this finding holds up in future research, it would provide even more reasons for careful screening for prenatal and postpartum depression.

Indeed, a significant proportion of women in this study were depressed, again, regardless of abuse status. Depression was higher amongst married women, and those who were carrying the first pregnancy. Women in this study were all smokers during pregnancy. Although the aim of the Baby BEEP study from which participants for this study were drawn was to help pregnant women quit smoking, eighty-seven percent of women continued to smoke after giving birth (Bullock et al., 2009a). Continued smoking may have been related to depression. Evidence exists to show that smokers, both current 
and former, are more likely to report depressive symptoms than never smokers (Zhu \& Valbo, 2002)

While abuse status was not significantly associated with weight changes in either direction in this cohort, children perceived to be difficult by their parents and exposed to prenatal abuse did have lower weight gain than their counterparts. Previous studies have assessed the impact of IPV on child's temperament (Bowen, 2015; Burke et al., 2008) but not the relationship between maternal IPV and mother's perception of child's difficulty. Findings from a study to assess parent/child stress in families experiencing IPV suggests that parents who have experienced partner violence expressed greater parental distress, negative parent/child interaction, and reported the child as being more difficult than the normative sample (Worthy et al., 2013). This is the first study to assess weight gain in children perceived to be difficult by their parents and maternal exposure to abuse and depression. This is an important finding that warrants further exploration. It is not clear whether the children with high perceived difficulty scores were actually more difficult than their counterparts, or whether factors related to the mother or to her environment, including the nature and severity of the abuse experienced, contributed to the mothers' perception that their children were difficult. A prospective study using careful measures could help untangle the associations. It seems worthwhile, however, to suggest that clinicians pay careful attention to providing appropriate referrals for counseling and/or parenting education to mothers who describe their children as difficult, and to carefully monitor the growth of these children, 


\section{Limitations}

The World Health Organization recommended cut off points for Z-scores are +2 and -2 , which corresponds to the $2.3^{\text {rd }}$ and $97.7^{\text {th }}$ percentiles. These cut off points are chosen to classify problematic growth and /or nutritional status such as malnutrition or obesity (Wang \& Chen, 2012). This study did not dichotomize WHZ because there were too few participants with Z-scores of -2 or below. Thus low WHZ scores in this study do not necessarily mean that the child was wasted or stunted. Because the Zscore were mostly above -2 , it is difficult to determine whether weight was greater or lower within normal weight range or on overweight range for this age group. Direct comparisons between this dissertation study and previous studies need to be undertaken cautiously because of differences in study design. Additionally previous studies were conducted in Brazil, Bangladesh, Nicaragua, Egypt, Honduras, Rwanda, Malawi and Kenya. Mother's and child characteristics assessed in studies from these countries may not be comparable to this study conducted in the United States because of the difference in health care access, availability of food and clean water, level of literacy, Gross Domestic Product (GDP), number of children per woman and women's autonomy.

\section{Conclusion}

Children exposed to depression seem to have normal weight and height that may tend towards overweight. Those children exposed to prenatal abuse and were perceived to be difficult by their parents had lower weight gain. Overall maternal exposure to pre and postnatal depression, breastfeeding status and being a second child affected boys more than it did girls in relation to weight gain. It is not possible to determine whether maternal smoking and WIC participation played a role in children's weight and height 
gain. It is also not possible to infer the findings of this study to the general population because the homogeneous nature of the study participants. Although some of the findings were not statistically significant, there are interesting trends that can guide future studies. Findings from this study make an important contribution to the literature on the impact of IPV on child growth for low-income rural women who are smokers in the United States. In spite of being a worldwide problem due to its pervasive and debilitating nature, the effects of IPV on infants and young children have only received minimal systematic research attention. Research has consistently demonstrated the crucial role that the mother plays in the well-being of her children and family. Studies have highlighted how mothers' parenting, relationship status and stability, and own well-being are correlated with the welfare of their families. It is of interest that in a country as large as the United States, only one study has examined IPV and growth failure in children (Boynton-Jarrett et al., 2010). There is a need to conduct longitudinal studies in more diverse samples to better understand the true impact of IPV on children's growth in the United States.

\section{Implications}

Intimate partner violence is associated with various growth and developmental problems. Identifying those children that are exposed, and the impact of IPV on their lives and subsequently providing interventions for both mother and child will greatly improve the health of both. The Institute of Medicine (IOM) requires all insurance companies to reimburse for screening and counseling for interpersonal and domestic violence (Clinical preventive services for women: Closing the gaps.2011). Well child clinics should take advantage of this and use existing tools such as Abuses Assessment Screen (AAS) to screen for IPV in the well child clinic. 
Screening for maternal depression should be a required component of prenatal and well-child care. Pregnant women and mothers of young children are seen in physician offices frequently, providing a perfect opportunity for screening to occur. Many women do not realize that they are depressed. Physicians may be focused on the woman's or child's physical health. The stigma associated with depression may also prevent mothers from seeking treatment. Without screening for depression it often goes unrecognized. Because Medicaid covers over one third of all U.S. births to low- income pregnant women, it is an important source of support for maternal depression screening, assessment, and treatment. When children who are on Medicaid receive their well-child exams, their mothers could be screened for maternal depression, with the provider reimbursed under the child's Medicaid number. Treatment for depressed mothers is also necessary under Medicaid. Private insurers should also reimburse health care providers for maternal depression screening. Treatment for depressed mothers should be available and covered under their health insurance plans. 


\section{References}

Ackerson, L. K., \& Subramanian, S. V. (2008). Domestic violence and chronic malnutrition among women and children in India. American Journal of Epidemiology, 167(10), 1188-1196.

Asling-Monemi, K., Naved, R. T., \& Persson, L. A. (2009). Violence against women and the risk of fetal and early childhood growth impairment: A cohort study in rural Bangladesh. Archives of Disease in Childhood, 94(10), 775-779.

Bowen, E. (2015). The impact of intimate partner violence on preschool children's peer problems: An analysis of risk and protective factors. Child Abuse \& Neglect, 50, 141-150. doi:http://doi.org/10.1016/j.chiabu.2015.09.005

Boynton-Jarrett, R., Fargnoli, J., Suglia, S. F., Zuckerman, B., \& Wright, R. J. (2010). Association between maternal intimate partner violence and incident obesity in preschool-aged children: Results from the fragile families and child well-being study. Archives of Pediatrics \& Adolescent Medicine, 164(6), 540-546.

Bullock, L., Everet, D. K., Mullen, P. A., Geden, E., Longo, R. D., \& Madsen, R. (2009). Baby BEEP: A randomized control trial of nurses' individualized social support for rural pregnant smokers. Matern.Child Health J., 13(3), 395-406.

Burke, J. G., Lee, L. C., \& O'Campo, P. (2008). An exploration of maternal intimate partner violence experiences and infant general health and temperament. Maternal \& Child Health Journal, 12(2), 172-179. 
Clinical preventive services for women: Closing the gaps. (2011). Retrieved from https://iom.nationalacademies.org/Reports/2011/Clinical-Preventive-Services-forWomen-Closing-the-Gaps.aspx

Dallman, M. F. (2010). Stress-induced obesity and the emotional nervous system. Trends in Endocrinology and Metabolism: TEM, 21(3), 159-165.

doi:10.1016/j.tem.2009.10.004 [doi]

Drewett, R., Blair, P., \& Emond, A. (2004). Failure to thrive in the term and preterm infants of mothers depressed in the postnatal period a population based birth cohort study. Journal of Child Psychology \& Psychiatry \& Allied Disciplines, 45, 359-366.

Gibson, E. L. (2006). Emotional influences on food choice: Sensory, physiological and psychological pathways. Physiology \& Behavior, 89(1), 53-61. doi:S00319384(06)00010-2 [pii]

Hasselmann, M. H., \& Reichenheim, M. E. (2006). Parental violence and the occurrence of severe and acute malnutrition in childhood. Pediatric Perinatal Epidemiology, 20(4), 299-311.

Meyer, M. B. (1978). How does maternal smoking affect birth weight and maternal weight gain? evidence from the Ontario perinatal mortality study. American Journal of Obstetrics \& Gynecology, 131(8), 888-893.

Ogden, C. L., Carroll, M. D., Kit, B. K., \& Flegal, K. M. (2014). Prevalence of childhood and adult obesity in the United States, 2011-2012. JAMA, 311(8), 806-814. 
Santos, I. S., Matijasevich, A., Domingues, M. R., Barros, A. J. D., \& Barros, F. C. F. (2010). Long-lasting maternal depression and child growth at 4 years of age: A cohort study. Journal of Pediatrics, 157(3), 401-406.

Torres, S. J., \& Nowson, C. A. (2007). Relationship between stress, eating behavior, and obesity. Nutrition (Burbank, Los Angeles County, Calif.), 23(11-12), 887-894. doi:S0899-9007(07)00249-3 [pii]

Vogazianos, P., Fiala, J., \& Vogazianos, M. (2005). The influence of active maternal smoking during pregnancy on birth weights in Cyprus. Central European Journal of Public Health, 13(2), 78-84.

Wang, Y., \& Chen, H. (2012). Use of percentiles and Z scores in anthropometry. In V. R. Preedy (Ed.), Handbook of anthropometry: Physical measures 29 of human form in health and disease (pp. 29-42) Springer Science+Business Media. doi:DOI 10.1007/978-1-4419-1788-1_2,

Wojcicki, J. M., Holbrook, K., Lustig, R. H., Epel, E., Caughey, A. B., Munoz, R. F., . . . Heyman, M. B. (2011). Chronic maternal depression is associated with reduced weight gain in Latino infants from birth to 2 years of age. PLoS ONE [Electronic Resource], 6(2), e16737.

Worthy, S., Bagwell, B., \& Hudson, T. (2013, February 26). Parent/child stress in families experiencing domestic violence.

Zhu, S., \& Valbo, A. (2002). Depression and smoking during pregnancy. Addictive Behaviors, 27(4), 649-658. 